\title{
Parent-to-Parent Support for Parents of Children who are Deaf or Hard of Hearing: A Conceptual Framework
}

Rebecca Henderson, The University of Western Ontario

Supervisor: Drs. Sheila Moodie, The University of Western Ontario

Joint Supervisor: Andrew Johnson, The University of Western Ontario

A thesis submitted in partial fulfillment of the requirements for the Master of Science degree in Health and Rehabilitation Sciences

(C) Rebecca Henderson 2015

Follow this and additional works at: https://ir.lib.uwo.ca/etd

Part of the Mental and Social Health Commons, Speech Pathology and Audiology Commons, and the Theory and Philosophy Commons

\section{Recommended Citation}

Henderson, Rebecca, "Parent-to-Parent Support for Parents of Children who are Deaf or Hard of Hearing: A Conceptual Framework" (2015). Electronic Thesis and Dissertation Repository. 3116.

https://ir.lib.uwo.ca/etd/3116

This Dissertation/Thesis is brought to you for free and open access by Scholarship@Western. It has been accepted for inclusion in Electronic Thesis and Dissertation Repository by an authorized administrator of Scholarship@Western. For more information, please contact wlswadmin@uwo.ca. 


\title{
PARENT-TO-PARENT SUPPORT FOR PARENTS OF CHILDREN WHO ARE DEAF OR HARD OF HEARING: A CONCEPTUAL FRAMEWORK \\ Thesis format: Integrated Article
}

\author{
by \\ Rebecca Henderson \\ Graduate Program in Health Promotion, Health and Rehabilitation Sciences
}

A thesis submitted in partial fulfillment of the requirements for the degree of

Masters of Science in Health

The School of Graduate and Postdoctoral Studies

The University of Western Ontario

London, Ontario, Canada

(c) Rebecca Henderson, 2015 


\begin{abstract}
The goals of this project were to: (1) identify the constructs and components of a conceptual framework of parent-to-parent support for parents of children who are deaf or hard of hearing (D/HH); and (2) invite a panel of international experts to provide personal judgment on the conceptual framework.

In a dual-stage scoping review methodology, the first project identified, extracted, and organized data into libraries of thematic and descriptive content. A conceptual framework of parent-to-parent support for parents of children who are D/HH was developed and presented in a comprehensive, bidirectional informational graphic.

A modified eDelphi study satisfied the consultation and second stage of the scoping review. Hand-picked experts (from seven countries) with experience in provision, research or experience in the area of parent-to-parent support participated in the revision of the original conceptual framework.
\end{abstract}

\title{
Keywords
}

Scoping review, eDelphi, parent-to-parent support, children with hearing loss, deaf or hard of hearing, conceptual framework 


\section{Co-authorship Statement}

Rebecca Henderson completed the following work under the supervision of Dr. Andrew Johnson and Dr. Sheila Moodie, who are co-authors of the publications resulting from this work. 


\section{Acknowledgements}

With earnest, I'd like to express an enduring gratitude to my supervisors, Dr. Andrew Johnson and Dr. Sheila Moodie, and my thesis committee Dr. Susan Scollie and Dr. Anita Cramp. Thank you to Andrew Johnson for taking a chance on me after a 10-year hiatus from academia. After four years of raising children at home, you were first to recognize that my passion for parent-to-parent support in babywearing may lead me to an alternative expression in Dr. Sheila Moodie's Family Centred Care Lab for children with hearing loss. Thank you for your connecting me with Dr. Moodie so that we could investigate the ideas of parent-to-parent support in our commitment to research in Child and Family Centred Care.

A heartfelt thanks to Sheila Moodie; you are my foremost and most influential supervisor. When we started two years ago, I did not know what the story would be in the end. There was anticipation and curiosity as the research took shape, always guided by the enduring question: What is the peer-reviewed evidence? This question - your question - held the research secure and strong. I am indebted to your guidance.

Thank you to my thesis committee members Drs. Susan Scollie and Anita Cramp who were available and positive through all efforts big and small. Kevin Liu, our graphic designer and infographic decision-maker, transformed unsophisticated hand-drawn sketches into a gorgeous and accessible infographic. Thank you to Susan, Anita and Kevin for offering up a range of suggestions that are reflected in this research thesis.

Without my parents' openness to intergenerational living as I worked toward this masters' degree, I am certain the entire project would have unravelled. My own strong mother first introduced me to ideas. She inspired me to return to academia after the birth of my children because she, too, completed post-undergraduate work as a mature student and mother. Thank you to my dad, our family engineer whose expertise is well-suited to playing Lego and reading with his grandkids. Thank you, dad, for staying up late with me and finishing our own projects side-by-side at the kitchen table. 
Thank you to Gail, my mother-in-law, who reminds us that all big things can be broken down into small things. She helped keep me focused on the wonder in research, surely something learned in her own theology PhD. To my father-in-law, Jeff, expert in the art and patience in construction who points out, "it gets done when it gets done. "With perspective, I wonder how this degree helped benefit family relationships and shorten geographical distances.

To my children, Norah and Oscar, you are my first classroom. How would I know you would grow faster than this degree? With more anticipation and curiosity than any academic pursuit, I wonder how this masters' degree experience will shape our evolving story. I wonder if you, too, will one day ask, "What is the peer-reviewed evidence?"

Dear BJ, I am always humbled by your constant belief in me and our family to pursue any endeavour. With gentle encouragement, you have so often freed me from obligation - to our children, to you, to our home - so that I could complete class readings, essays, presentations, TAships, and all of the collective pieces that form this degree. With the greatest affection, dear husband, and for all the acts of love you have given, the least I could do is write your name here.

To all of my friends for their encouragement, I'd especially like to thank Leila who strong-armed me to continue my studies. Without your influence I wonder whether I would have returned.

Thank you to the Ontario Infant Hearing Program for the foresight to help fund this important work. I greatly appreciate the researchers, parents, advocates, individuals who identity as Deaf, and leaders at various governing organizations who contributed to the literature to the literature scoping review and eDelphi study.

\section{I am forever indebted to the moms and dads and kids with hearing loss whom I have never met. Your insights, pain, and triumphs are the basis for this degree.}




\section{Table of Contents}

\section{Contents}

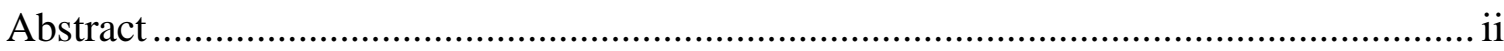

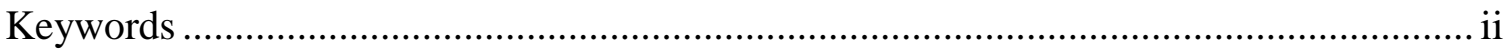

Co-authorship Statement............................................................................................

Acknowledgements ................................................................................................ iv

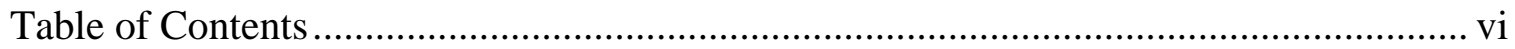

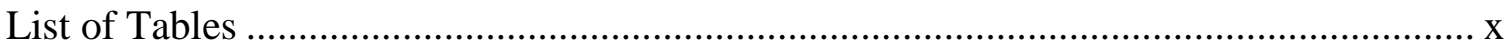

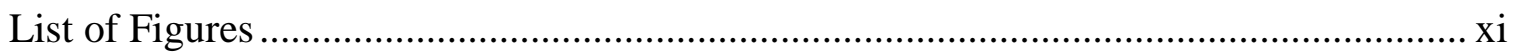

List of Appendices ………....................................................................................

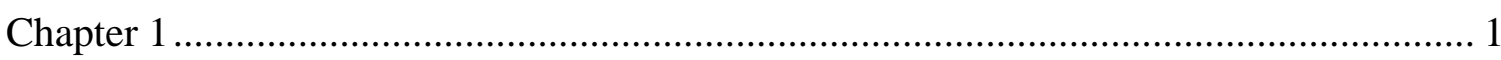

1 Introduction to parent-to-parent support for parents of children who are Deaf or Hard of Hearing (D/HH) ....................................................................................... 1

1.1 Early Hearing Detection and Intervention Programs ............................................. 1

1.2 Child and Family Centred Care (C\&FCC) ……….............................................. 2

1.3 Parent-to-parent support............................................................................ 2

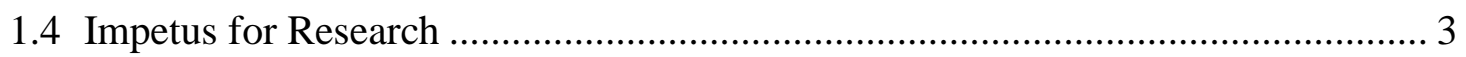

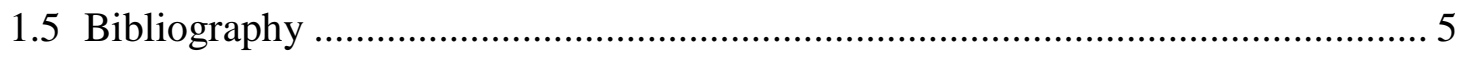

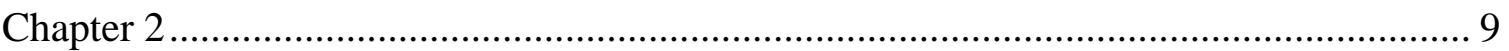

2 Parent-to-parent support for parents with children who are deaf or hard of hearing: A conceptual framework .......................................................................................... 9

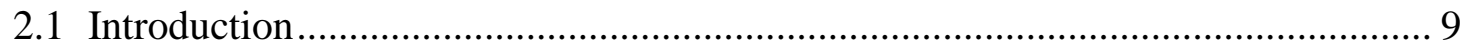

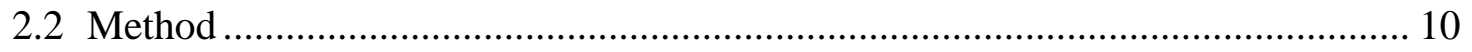

2.2.1 Identifying the Research Question ...................................................... 11

2.2.2 Identifying Relevant Articles ................................................................ 11 
2.2.3 Study Selection (Inclusion / Exclusion Criteria) ............................... 12

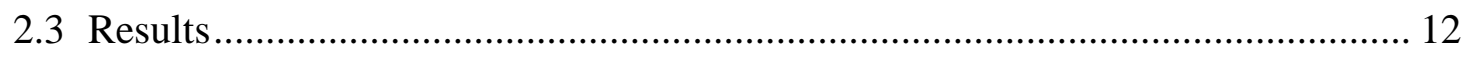

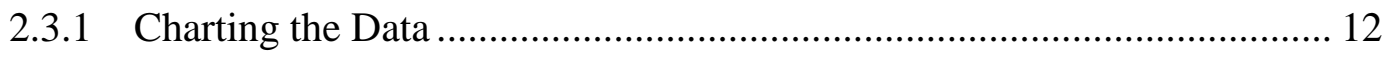

2.3.2 Collating, Summarizing, and Reporting Results................................ 13

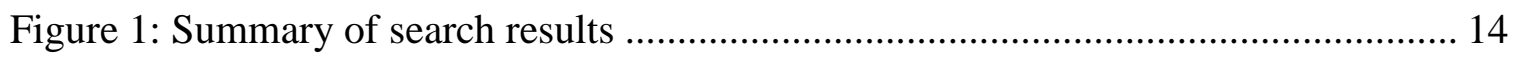

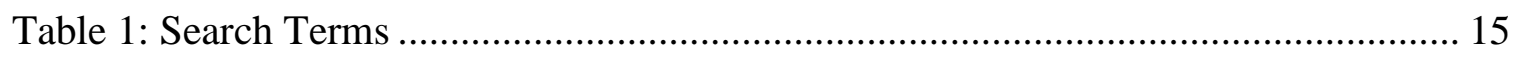

Table 2: Numbers of papers pertaining to each component and construct ..................... 16

2.3.3 Mutuality and Connectedness ....................................................... 18

2.3.4 Evidence related to Well-being .................................................... 20

2.3.5 Evidence related to Knowledge ...................................................... 22

2.3.6 Evidence related to Empowerment .................................................. 25

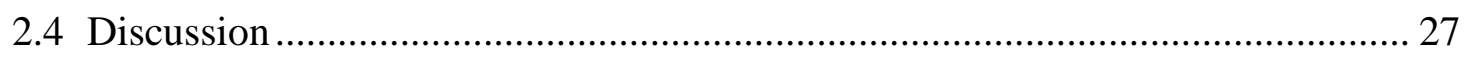

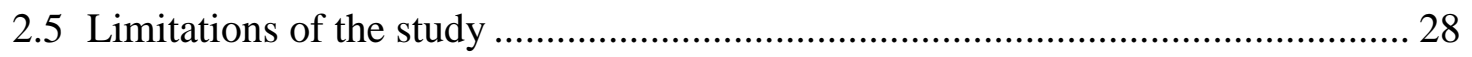

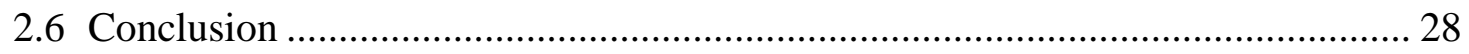

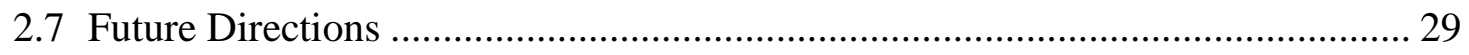

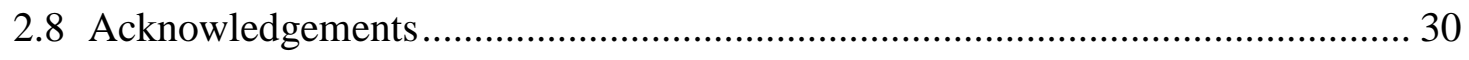

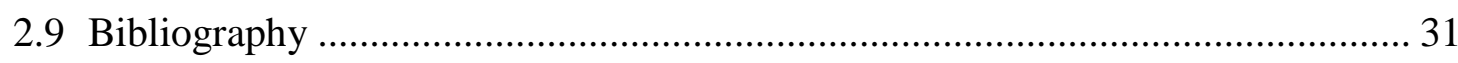

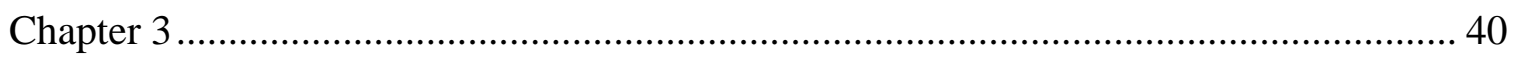

3 Revised Conceptual Framework of Parent-to-Parent Support for Parents of Children who are Deaf or Hard of Hearing: A Modified Delphi Study...................... 40

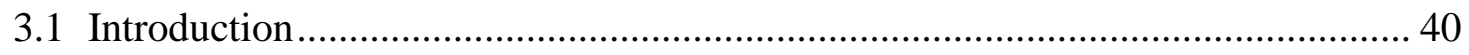

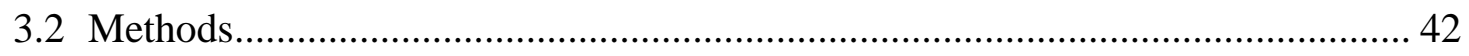

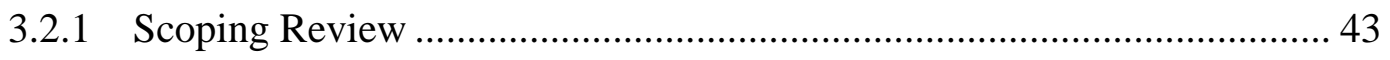

3.2.2 Electronic Delphi (eDelphi) Method .............................................. 43

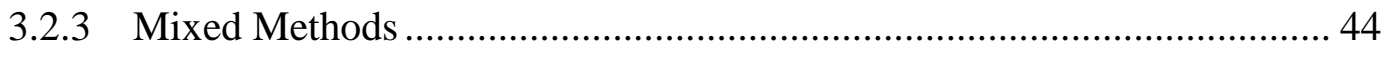




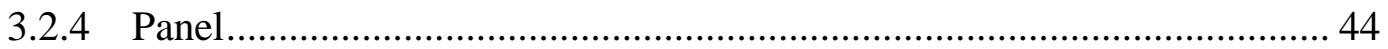

3.2.5 Questionnaire Development................................................................ 45

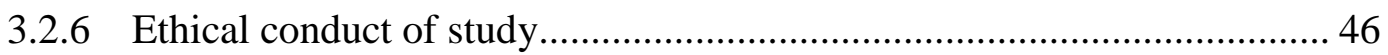

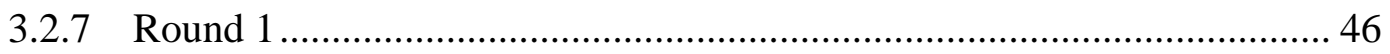

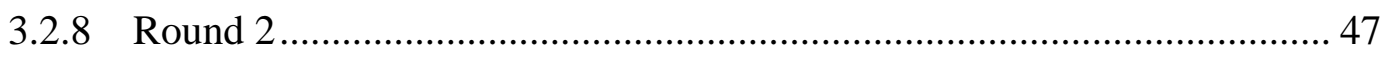

Table 3: Overview of the Research Process ..................................................................... 48

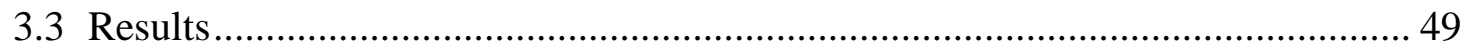

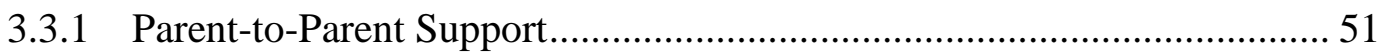

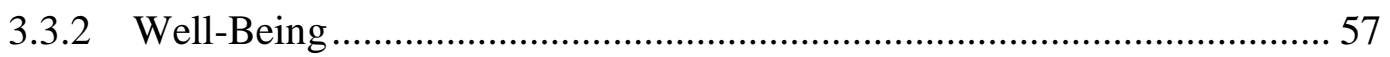

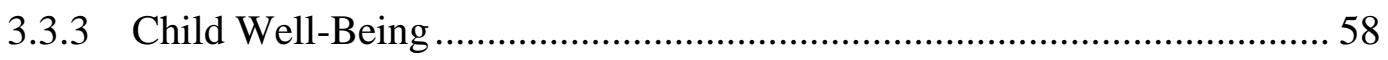

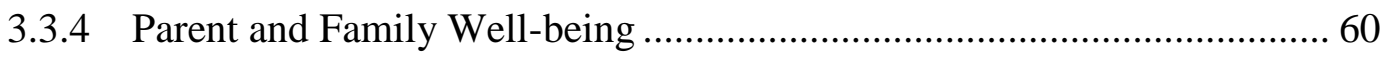

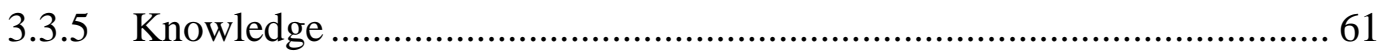

Figure 5: Constructs and Components of Knowledge ………...................................... 62

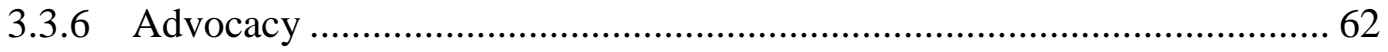

3.3.7 System Navigation and Transition........................................................... 63

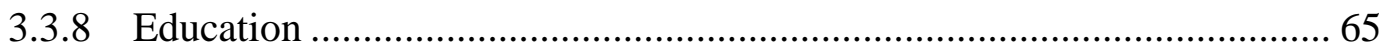

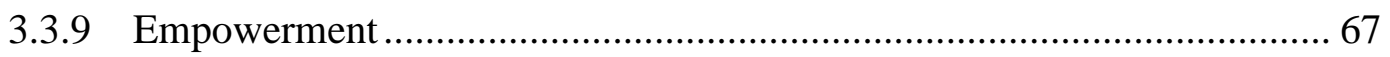

Figure 6: Constructs and Components of Empowerment ................................................. 67

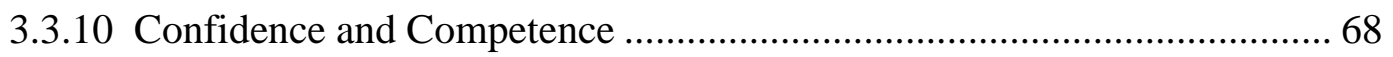

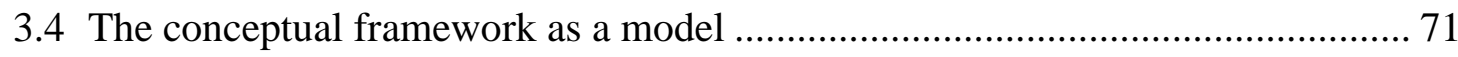

3.5 Other important and relevant information provided by experts............................. 73

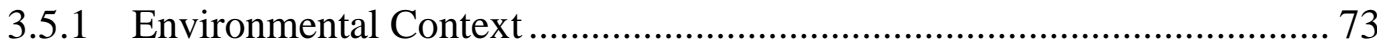

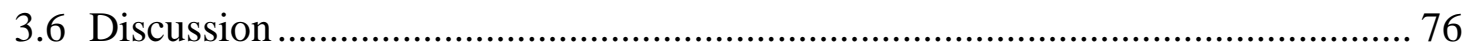

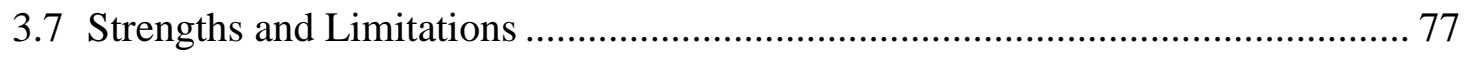

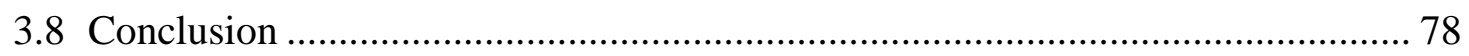




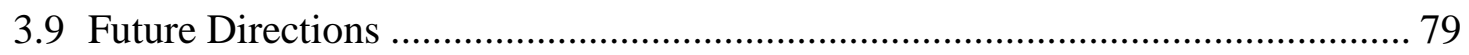

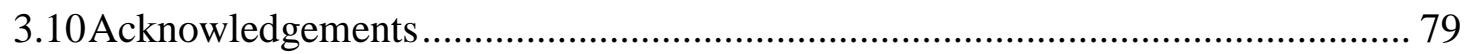

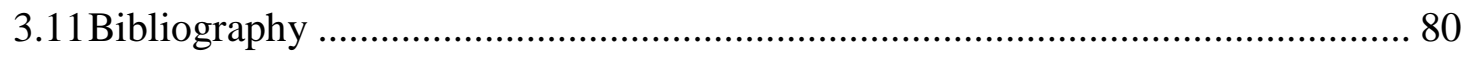

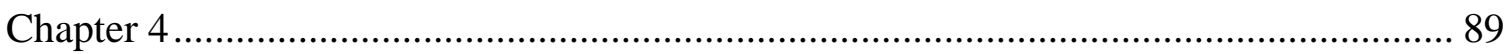

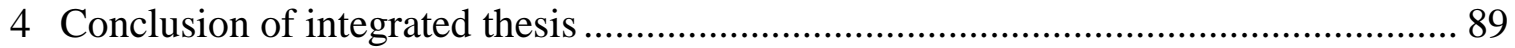

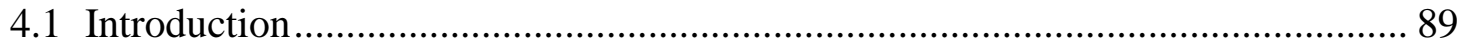

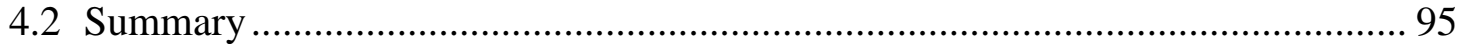

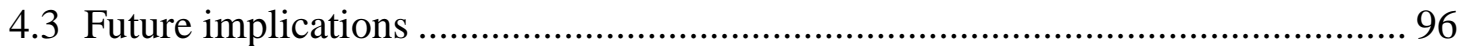

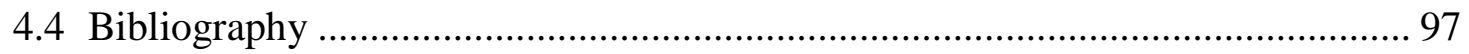

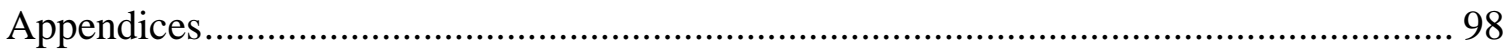

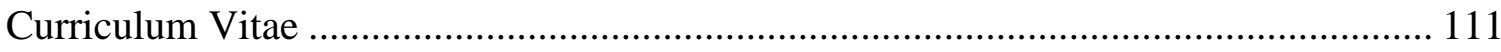




\section{List of Tables}

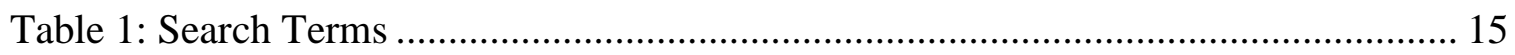

Table 2: Numbers of papers pertaining to each component and construct ...................... 16

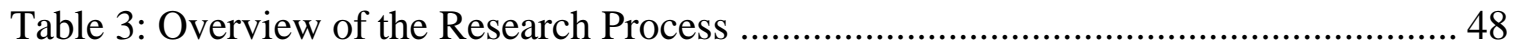

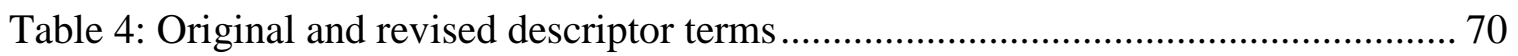

Table 5. Labels and Definitions: A Guide to Understanding the Conceptual Framework for Parent-to-Parent Support for Parents of Children who are Deaf or Hard of Hearing . 91 


\section{List of Figures}

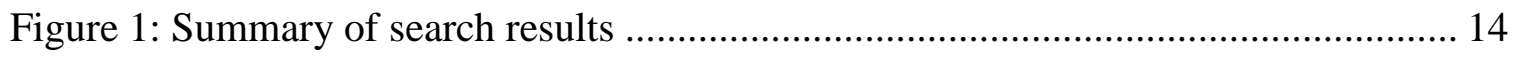

Figure 2: Parent-to-parent support for parents of children who are deaf or hard of hearing:

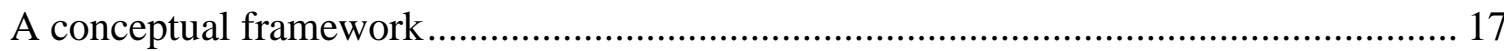

Figure 3: A Revised Conceptual Framework of Parent-to-parent support for parents of children who are deaf or hard of hearing.

Figure 4: Constructs and Components of Well-Being .............................................. 57

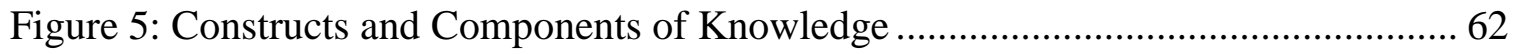

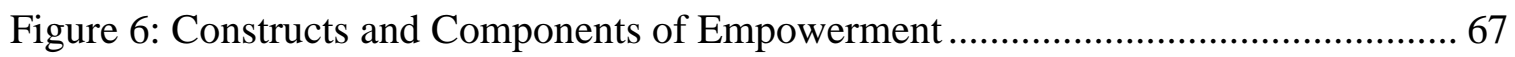




\section{List of Appendices}

Appendix A: Western Research Ethics Approval ........................................... 98

Appendix B: Supplemental Material for Scoping Review Study (Chapter 2)....... 99

Appendix C: Permission for use of Chapter 2 manuscript................................... 102

Appendix D: Round 1 and 2 electronic Delphi study questionnaire .................... 103 


\section{Chapter 1}

\section{Introduction to parent-to-parent support for parents of children who are Deaf or Hard of Hearing $(\mathrm{D} / \mathrm{HH})$}

\subsection{Early Hearing Detection and Intervention Programs}

Early Hearing Detection and Intervention (EHDI) programs are committed to the early identification, intervention, and follow-up care of infants and young children with hearing loss. Many countries have actively implemented EHDI programs, which include universal newborn hearing screening and identify children with, or are at risk, for hearing loss. Hearing loss affects 2-4 per 1000 children in wealthy countries, including Canada, United Kingdom and the United States (American Academy of Pediatrics, 2010; Bagatto, Scollie, Hyde, \& Seewald, 2010; Watkin \& Baldwin, 2011). In Ontario, more than 90 percent of babies are screened, and newborns and children are followed-up with evidence-based approaches to secondary hearing tests when necessary to ensure children are diagnosed in a timely fashion and well-aided. Approximately 400 children yearly are identified with hearing loss (Bagatto et al., 2010). Implemented in 2002, the Ontario Infant Hearing Program (OIHP), provided by Ontario's Ministry of Children and Youth Services (MCYS), is an example of a comprehensive EHDI program. Hearing screening, assessment procedures, hearing aid provision, verification protocols and appropriate follow-up are in place and all paediatric audiological services are conducted exclusively by audiologists trained and monitored by the OIHP (Bagatto et al., 2010). The appropriate interventions are important for families of children identified with hearing loss because the majority of these children will be born to parents with typical hearing who were not expecting the diagnosis. One American study reports 92 percent of children with permanent hearing loss are born to two hearing parents (Mitchell \& Karchmer, 2004). Although there is no international consensus on this statistic, there is agreement that the majority of parents have little knowledge of hearing loss. From a family perspective, the parents' first priority is to learn about the type of their child's hearing loss, and make sure that the selection and fitting of aided equipment is correct. These 
protocols are guided by principles of Child \& Family Centred Care (C\&FCC), "with fully informed family choices based on unbiased information that is grounded in the best available scientific evidence. This means that the family's choices are paramount and that their culture, values, and preferences are respected" (Bagatto, et al., 2010, p.S71).

\subsection{Child and Family Centred Care (C\&FCC)}

In provision of service to families, the OIHP protocol is guided by principles of Child \& Family Centred Care (C\&FCC). At the heart of the C\&FCC model, the medical and professional team work in partnership with the family, and family members are valued partners in the healthcare-team (Arango, 2011; Shaul, 2014). The explicit values and definitions of C\&FCC vary across organizations and subject to diverse interpretation (Kuo et al., 2012). However, Shields et al. (2006, p. 1318) provide the perspective that, "family centred-care is a way of caring for children and their families within health services which ensures that care is planned around the whole family, not just the individual child/person, and in which all the family members are recognized as care recipients" (Shields, Pratt, \& Hunter, 2006). Non-governmental organizations' committed to the well-being of children and families have identified parent-to-parent support in health care principles and policies (American Academy of Pediatrics, 2012; United Nations Children's Fund (UNICEF), 2007). The endorsement of parent-to-parent support as a principle in C\&FCC suggests that this type of support is merit-worthy, as an adjunctive support to professional care, and contributes to whole family health. As a quality of C\&FCC, parent-to-parent support systems are increasingly recognized in position statements and non-governmental organizations' health care principles and policies.

\subsection{Parent-to-parent support}

For parents of children with disabilities, a growing body of evidence documents that parent-to-parent support groups provide positive assistance in managing the needs of parents and families as they seek service for their child (Banach, Iudice, Conway, \& Couse, 2010; Mathiesen, Frost, Dent, \& Feldkamp, 2012; McHugh, Bailey, Shilling, \& Morris, 2013; Olin et al., 2014; Shilling et al., 2013; Wisdom et al., 2013; Wright \& 
Wooden, 2013). Peer parental support for parents with children who are deaf or hard of hearing $(\mathrm{D} / \mathrm{HH})$ is an important component of EHDI programs (Beswick, Driscoll, Kei, Khan, \& Glennon, 2013). For parents of children who are $\mathrm{D} / \mathrm{HH}$, the evidence required to inform parent-to-parent support is emerging in academic literature, and panels of experts have identified family support as an important component of EHDI programs and family access to support as a central tenet in C\&FCC principles (Joint Committee on Infant Hearing, 2013; Moeller, Carr, Seaver, Stredler-Brown, \& Holzinger, 2013).

Currently, parent-to-parent support is provided by the not-for-profit organizations: for example, Alexander Graham Bell Association, Canadian Association of the Deaf, Hands \& Voices, and VOICE for hearing impaired children. Emerging from a grassroots strategy, driven by parents, volunteers and professionals, these organizations provide models of parent-to-parent support, recognizing the importance of family well-being in servicing a child who is $\mathrm{D} / \mathrm{HH}$. These professionals, parents and volunteers who work daily with parents who have a child with hearing loss understand the complexity of peer parental support systems, and are respected in their work of supporting families. Leaders in these organizations have championed the benefits of peer-parental support in that it provides relational well-being, a sense of belonging and adaptational help, which is not provided by clinical or medical providers. Supported parents are better able to care for their children, and parent-to-parent support provides parents with the skills to help their children in goal setting, speech and language development and participation in schools and community (Henderson, Johnson, \& Moodie, 2014).

\subsection{Impetus for Research}

The Joint Committee on Infant Hearing (JCIH) identifies parent-to-parent support as an important component of EHDI programs for children with hearing loss (JCIH, 2007; 2013). The JCIH is a committee comprised of professional representatives from national organizations, and has published position statements on infant hearing since 1973. The JCIH supports the development and implementation of guidelines for family-to-family support (JCIH, 2013). In addition, a recent international consensus statement for children who are D/HH identified family access to parent-to-parent support as a central tenet in 
family-centered principles (Moeller et al., 2013). A synthesis of evidence indicates parent-to-parent support is a necessary part of the whole health care system and ought to be provided or supported by a formalized entity (Eleweke, Gibert, \& Bays, 2008; Fitzpatrick, Angus, Durieux-Smith, Graham, \& Coyle, 2008; Jackson, 2011; Jamieson, Zaidman-Zait, \& Poon, 2011; Joint Committee on Infant Hearning, 2013; Moeller, Carr, Seaver, Stredler-Brown, \& Holzinger, 2013; Poon \& Zaidman-Zait, 2014). The evidence required to inform parent-to-parent support is emerging in academic literature and endorsed by non-governmental organizations as a principle in $\mathrm{C} \& \mathrm{FCC}$.

The OIHP operates within evidence-based protocols and procedures in paediatric audiology; and its system for identifying and aiding hearing loss is well in hand. Currently, there is strong interest to integrate parent-to-parent support as a principle of C\&FCC as a component of the EHDI program. Reviewing the evidence of parent-toparent support aligns with the OIHP's historic and systematic approach to decision making. Therefore, the timing is appropriate to turn to the peer-reviewed literature and seek expert opinion to develop a conceptual framework of parent-to-parent support for parents of children who are $\mathrm{D} / \mathrm{HH}$. Our research addressed the following question:

\section{For parents of children who are $\mathrm{D} / \mathrm{HH}$, what thematic content is central to the constructs and components of a conceptual framework of parent-to-parent support?}

We used two complementary research techniques - a scoping review and eDelphi study to establish rigour in our methodology. Chapter 2 presents a published paper on the conceptual framework of parent-to-parent support for parents who are $\mathrm{D} / \mathrm{HH}$ based on the results from the scoping review. Chapter 3 uses the eDelphi method to invite 21 international experts to provide personal judgment and opinion on the conceptual framework, resulting in a revised model. 


\subsection{Bibliography}

American Academy of Pediatrics. (2010). Evaluation of the universal newborn hearing screening and intervention program. Pediatrics, 126 Suppl, S19-27. doi:10.1542/peds.2010-0354F

American Academy of Pediatrics. (2012). Patient- and family-centered care and the pediatrician's role. Pediatrics, 129(2), 394-404. doi:10.1542/peds.2011-3084

Arango, P. (2011). Family-Centered care. Academic Pediatrics, 11(2), 97-9. doi:10.1016/j.acap.2010.12.004

Bagatto, M., Scollie, S. D., Hyde, M., \& Seewald, R. (2010). Protocol for the provision of amplification within the Ontario infant hearing program. International Journal of Audiology, 49 Suppl 1, S70-9. doi:10.3109/14992020903080751

Banach, M., Iudice, J., Conway, L., \& Couse, L. J. (2010). Family Support and Empowerment: Post Autism Diagnosis Support Group for Parents. Social Work With Groups, 33(1), 69-83. doi:10.1080/01609510903437383

Beswick, R., Driscoll, C., Kei, J., Khan, A., \& Glennon, S. (2013). Which risk factors predict postnatal hearing loss in children? Journal of the American Academy of Audiology, 24(3), 205-13. doi:10.3766/jaaa.24.3.6

Eleweke, C. J., Gilbert, S., \& Bays, D. (2008). Information about Support Services for Families of Young Children with Hearing Loss : A Review of Some Useful Outcomes and

Fitzpatrick, E., Angus, D., Durieux-Smith, A., Graham, I. D., \& Coyle, D. (2008). Parents' needs following identification of childhood hearing loss. American Journal of Audiology, 17(1), 38-49. doi:10.1044/1059-0889(2008/005)

Henderson, R. J., Johnson, A., \& Moodie, S. T. (2014). Parent-to-Parent Support for Parents With Children Who Are Deaf or Hard of Hearing: A Conceptual 
Framework. American Journal of Audiology, 23(4), 437-48.

doi:10.1044/2014_AJA-14-0029

Jackson, C. W. (2011). Family Supports and Resources for Parents of Children Who are Deaf or Hard of Hearing. American Annals of the Deaf, 156(4), 343-362. doi:10.1353/aad.2011.0038

Jamieson, J. R., Zaidman-Zait, A., \& Poon, B. (2011). Family Support Needs as Perceived by Parents of Preadolescents and Adolescents Who are Deaf or Hard of Hearing. Deafness \& Education International, 13(3), 110-130. doi:10.1179/1557069X11Y.0000000005

Joint Committee on Infant Hearing. (2007). Year 2007 position statement: Principles and guidelines for early hearing detection and intervention programs. Pediatrics, 120(4), 898-921. doi:10.1542/peds.2007-2333

Joint Committee on Infant Hearing. (2013). Supplement to the JCIH 2007 position statement: principles and guidelines for early intervention after confirmation that a child is deaf or hard of hearing. Pediatrics, 131(4), e1324-49. doi:10.1542/peds.2013-0008

Kuo, D. Z., Houtrow, A. J., Arango, P., Kuhlthau, K. a, Simmons, J. M., \& Neff, J. M. (2012). Family-centered care: current applications and future directions in pediatric health care. Maternal and Child Health Journal, 16(2), 297-305. doi:10.1007/s10995-011-0751-7

Mathiesen, A. M., Frost, C. J., Dent, K. M., \& Feldkamp, M. L. (2012). Parental needs among children with birth defects: defining a parent-to-parent support network. Journal of Genetic Counseling, 21(6), 862-72. doi:10.1007/s10897-012-9518-6

McHugh, C., Bailey, S., Shilling, V., \& Morris, C. (2013). Meeting the information needs of families of children with chronic health conditions. Physical \& Occupational Therapy in Pediatrics, 33(3), 265-70. doi:10.3109/01942638.2013.799628 
Mitchell, R. E., \& Karchmer, M. A. (2004). Chasing the Mythical Ten Percent: Parental Hearing Status of Deaf and Hard of Hearing Students in the United States. Sign Language Studies, 4(2), 138-163. doi:10.1353/sls.2004.0005

Moeller, M. P., Carr, G., Seaver, L., Stredler-Brown, A., \& Holzinger, D. (2013). Best practices in family-centered early intervention for children who are deaf or hard of hearing: an international consensus statement. Journal of Deaf Studies and Deaf Education, 18(4), 429-45. doi:10.1093/deafed/ent034

Olin, S. S., Williams, N., Pollock, M., Armusewicz, K., Kutash, K., Glisson, C., \& Hoagwood, K. E. (2014). Quality Indicators for Family Support Services and Their Relationship to Organizational Social Context. Administration and Policy in Mental Health, 4(1), 43-54. doi:10.1007/s10488-013-0499-z

Poon, B. T., Jamieson, J. R., Buchanan, M., \& Brown, D. K. (2008). Parent-Screener Discourse in a Newborn Hearing Screening Program. Infants \& Young Children, 21(2), 160-173.

Shaul, R. (2014). Paediatric Patient and Family-Centred Care: Ethical and Legal Issues. International Library of Ethics, Law, and the New Medicine, 57, 1-358. doi:10.1007/978-1-4939-0323-8

Shields, L., Pratt, J., \& Hunter, J. (2006). Family centred care: a review of qualitative studies. Journal of Clinical Nursing, 15(10), 1317-23. doi:10.1111/j.13652702.2006.01433.x

Shilling, V., Morris, C., Thompson-Coon, J., Ukoumunne, O., Rogers, M., \& Logan, S. (2013). Peer support for parents of children with chronic disabling conditions: a systematic review of quantitative and qualitative studies. Developmental Medicine and Child Neurology, 55(7), 602-9. doi:10.1111/dmcn.12091

Watkin, P. M., \& Baldwin, M. (2011). Identifying deafness in early childhood: requirements after the newborn hearing screen. Archives of Disease in Childhood, 96(1), 62-66. doi:10.1136/adc.2010.185819 
Wisdom, J. P., Lewandowski, R. E., Pollock, M., Acri, M., Shorter, P., Olin, S. S., ... Hoagwood, K. E. (2013). What Family Support Specialists Do: Examining Service Delivery. Administration and Policy in Mental Health. doi:10.1007/s10488-0130526-0.

Wright, K. N., \& Wooden, C. (2013). An Evaluation of a Parent-Developed, Parent-Run Parent Education Program. Journal of Family Social Work, 16(2), 164-183. doi:10.1080/10522158.2012.762596 


\section{Chapter 2}

\section{Parent-to-parent support for parents with children who are deaf or hard of hearing: A conceptual framework ${ }^{1}$}

\subsection{Introduction}

Parent-to-parent support, described as parents with lived experiences providing support to each other, is recognized as a distinctive and important type of support system. A growing body of evidence documents that parent-to-parent support groups provide positive assistance in managing the needs of parents with children who have disabilities and their families as they seek service for their child.

Research comprising parental perspectives and experiences of parents with children who are deaf or hard of hearing $(\mathrm{D} / \mathrm{HH})$ documents the pressing need for parent support. Existing evidence indicates that for parents with children who are $\mathrm{D} / \mathrm{HH}$, parent-to-parent support is a vital service not otherwise provided in formal support systems. Organizations such as the Alexander Graham Bell Association, Canadian Association of the Deaf, Hands and Voices, and VOICE for hearing impaired children have provided service models of parent-to-parent support, recognizing the importance of family well-being in servicing a child who is $\mathrm{D} / \mathrm{HH}$.

Many countries have actively implemented early hearing detection and intervention programs (EDHI) where newborn screening identifies children with, or at risk for, hearing loss, and follow this with evidence-based approaches to secondary hearing tests when necessary, appropriate intervention within a timely fashion and information to assist families with decision-making. Relevant and timely support and intervention are important for families of children identified with hearing loss because the majority of

\footnotetext{
1 A version of this manuscript has been published, as follows: Henderson, R. J., Johnson, A., \& Moodie, S. (2014). Parent-to-Parent Support for Parents With Children Who Are Deaf or Hard of Hearing: A Conceptual Framework. American Journal of Audiology, (4), 1-12. doi:10.1044/2014_AJA-14-0029. It is reprinted with permission (see Appendix C).
} 
these children will be born to parents with normal hearing who were not expecting the diagnosis.

Supporting the evidence, the Joint Committee on Infant Hearing identifies parent-toparent support as an important component of early hearing detection and intervention (EHDI) programs for children with hearing loss. The JCIH supports the development and implementation of guidelines of family-to-family support. In addition, a recent international consensus statement for children who are $\mathrm{D} / \mathrm{HH}$, identified family access to parent-to-parent support as a central tenet in family-centred principles. Panels of experts in EHDI draw attention to the unique attributes of peer-parental support as it pertains to social and emotional well-being for families, and calls for provision of ingress; that all families have access to peer parental support systems.

A synthesis of evidence specific to parent-to-parent support from leading researchers indicates parent-to-parent support is a necessary part of the whole health care system and ought to be provided or supported by a formalized entity.

Yet despite the benefits of peer parental support, very few syntheses of studies have been conducted. In fact, to the best of our knowledge, this is the first scoping review study to analyze thematic content centred on ideas central to parent-to-parent support of parents with children who are $\mathrm{D} / \mathrm{HH}$. The purpose of the review was to identify themes and ideas (constructs), and determine the key elements or specific parental needs of peer support (components).

\subsection{Method}

A scoping review of the literature was the appropriate method to meet the objectives of this study. Scoping reviews are defined as "a form of knowledge synthesis that addresses an exploratory research question aimed at mapping key concepts, types of evidence, and gaps in research related to a defined area or field by systematically searching, selecting, and synthesizing existing knowledge" (Colquhoun et al., 2014, p. 2-4 ). A key strength of a scoping review in health-related practice is "its ability to extract the essence of a diverse body of evidence and give meaning and significance to a topic that is both 
developmental and intellectually creative" ). This may explain why health-related research has increasingly adopted scoping reviews as a method of digesting research evidence. This evidence may be neglected through a formal systematic review of the literature. A formal systematic review, on the other hand, aims to answer a particular research question through the critical appraisal of studies with specific methodological characteristics, which may exclude less rigorous research material that may offer valuable evidence. Scoping reviews also vary from literature reviews because scoping reviews require critical interpretation of the research.

Similar to formal systematic reviews, scoping reviews use standardized and replicable procedures. Arksey and O'Malley (2005) developed a six-stage methodological framework for conducting scoping reviews. This framework was clarified and enhanced by Levac et al. (2010), who identify the six stages as 1) identify the research questions; 2) identify relevant studies; 3) study selection; 4) charting the data; 5) collating, summarizing, and reporting the results; and 6) consultation. Unlike Arksey and O'Malley, Levac et al. contend that consultation should be an essential component of scoping study methodology. As such, the present study is the first stage of a two phase scoping review. The present study is intended to report collated results from the literature - the consultation process is currently under way, and will be reported in a future publication.

\subsubsection{Identifying the Research Question}

Our scoping review addressed the question: For parents of children who are deaf or hard of hearing $(D / H H)$, what thematic content is central to the constructs and components of a conceptual framework of parent-to-parent support?

\subsubsection{Identifying Relevant Articles}

The search strategy used CINAHL, Scopus, MEDLINE and EMBASE electronic databases between 2000 and 2014. The initial search revealed 120 articles in CINAHL, 434 articles in Scopus, 397 in EMBASE and 289 articles in Medline. Keywords were broad to capture the components of parents and families, peer parental support systems and children who are $\mathrm{D} / \mathrm{HH}$. Subject headings were defined and adapted for each 
database, to limit to parental support systems. Citation tracking from salient articles was also conducted. See Table 1 for search terms.

\subsubsection{Study Selection (Inclusion / Exclusion Criteria)}

Selection of studies: Peer-reviewed studies, regardless of their design, met the inclusion criteria if they focused on (1) ideas central to parent-to-parent support for parents and families with a child who is deaf or hard of hearing, including children with comorbidities, (2) children aged $0-18$ (although most studies concentrated on children ages 0-6), (3) parental support provided by professionals or peers, (4) limited to the years 2000 - 2014, (5) full articles written in English. Studies were excluded if they focused on adolescents and/or grandparent perspectives.

For this scoping review, the inclusion criteria include articles from professional and parental perspectives of parental support needs. We included articles of professionalparent support and professional perspectives when parental support needs were outside of the scope of professional practice. The year 2000 was chosen as a cut-off point for study inclusion as this represents a point in time where Universal Newborn Hearing Screening (UNHS) was widely implemented in the United States. Furthermore, this provides us with research articles that more accurately reflect the current needs of families in a contemporary, diverse and global society.

The lead author reviewed titles and abstracts of articles identified by the above-described searches and obtained full-text copies of articles believed to meet the inclusion criteria. The research team reviewed the articles and confirmed the final selection of papers through consensus.

\subsection{Results}

\subsubsection{Charting the Data}

Data extracted from the research papers included study design or method, purpose or objective of the study, study outcomes or findings, components of parent-to-parent support, number and sex of participants (parents), country, and future research directions 
outlined in the manuscript. Components of parent-to-parent support were extracted from parental experiences, semi-structured interviews, focus groups, consultancy with clinicians, surveys and questionnaires. The components were organized into tables of data. Provided as supplementary material, Table 3 identifies the articles in this scoping review and charts the constructs and components.

We collectively compared and discussed the tables of charted information. The tables of thematic and descriptive data were derived from quotes, testimonials, themes, recollection and expert opinion. We then interpreted the findings and organized the thematic and descriptive data into components, refining the language chosen to label each component throughout the process. Next we grouped components according to similar themes. Groups of components were organized under constructs and appropriate labels were derived for the constructs. Through consensus, we were able to determine the organization of the constructs and components.

Results of the thematic and descriptive data were organized into a conceptual framework and depicted as an informational graphic. The informational graphic is a visual representation of evidence extracted in the scoping review and is intended to present complex information quickly and clearly.

\subsubsection{Collating, Summarizing, and Reporting Results}

As shown in Figure 1, 1240 articles were located. Of the screened articles, 29 met the inclusion criteria. We further found ten articles through citation tracking. A total of 39 articles are included in this scoping review. Approximately half of the articles were quantitative (18) followed by qualitative (11) and review (7) and finally mixed-method studies (3). Of the 39 articles, 26 articles focused on parental perspectives of family needs in relation to parent-to-parent support or professional-to-parent support. One article addressed parental or family support needs from solely a professional perspective. One study considered parental and family needs from both professional and family perspectives. We have classified the remaining eight articles as review papers. The studies' sample size for families ranged between nine and 456. Excluding review articles, 
18 studies or $60 \%$ had a sample size between nine -50 families. The two studies researching professionals had 27 and 35 participants.

\section{Figure 1: Summary of search results}

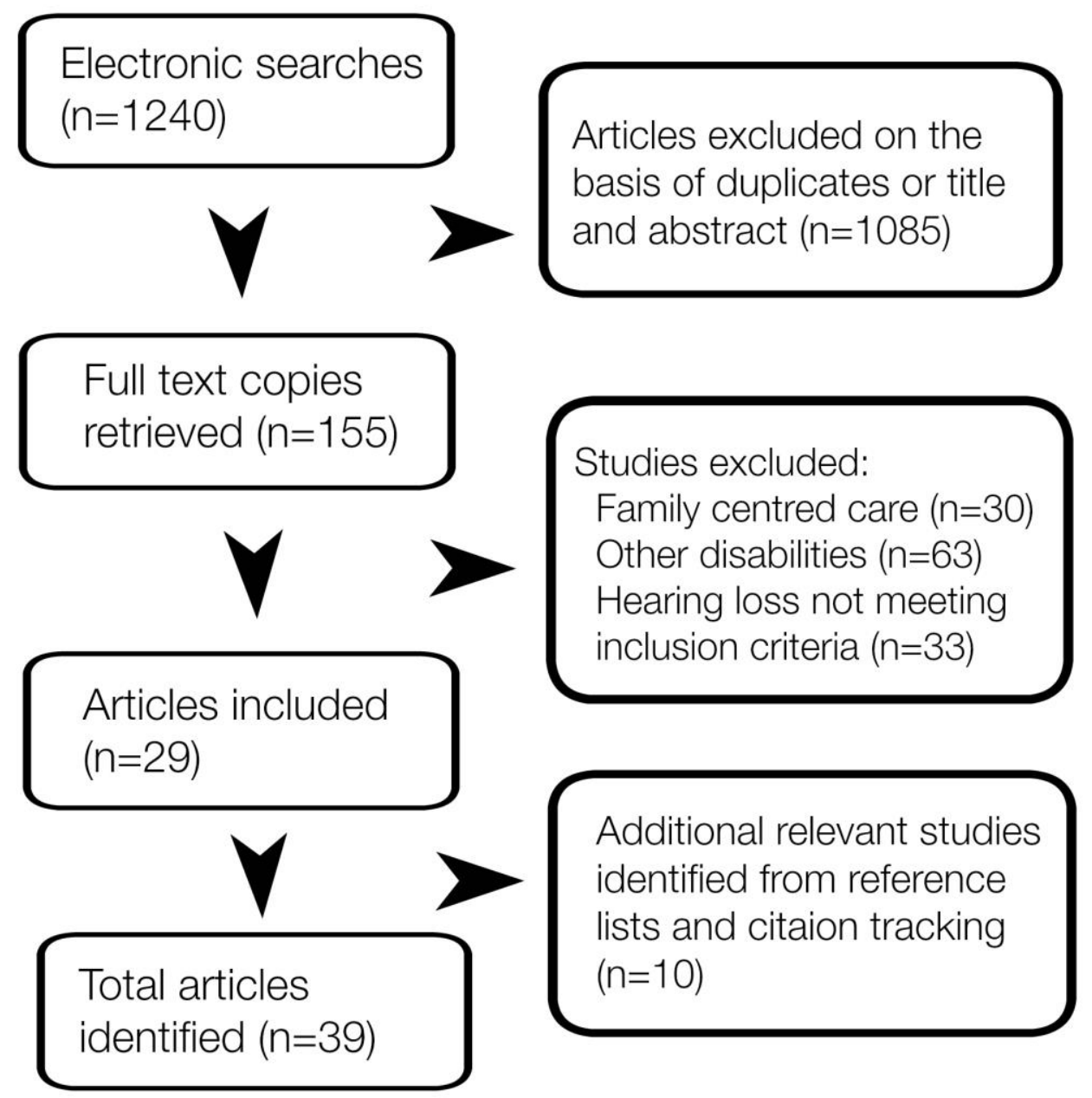




\section{Table 1: Search Terms}

\begin{tabular}{|c|c|}
\hline Category & Search term \\
\hline \multirow[t]{5}{*}{ Parents of disabled children } & Parent \\
\hline & Family \\
\hline & Extended family \\
\hline & Mother \\
\hline & Father \\
\hline \multirow[t]{18}{*}{ Support } & Program development \\
\hline & Program \\
\hline & Patient centered/centered care \\
\hline & Family centered/centered care \\
\hline & Professional family relations \\
\hline & Caregiver support \\
\hline & Support groups \\
\hline & Peer counseling \\
\hline & Early childhood intervention \\
\hline & Early intervention \\
\hline & Parent-to-parent support \\
\hline & Social support \\
\hline & Peer support \\
\hline & Education \\
\hline & Neonatal screening Universal neonatal hearing Screening \\
\hline & Early diagnosis \\
\hline & Health services needs and demands \\
\hline & Early hearing detection and intervention programs \\
\hline \multirow{13}{*}{$\begin{array}{r}\text { Child who is deaf or hard of } \\
\text { hearing }(\mathrm{D} / \mathrm{HH})\end{array}$} & Infant \\
\hline & Newborn \\
\hline & Child, children \\
\hline & Preschool \\
\hline & Adolescent \\
\hline & Hearing loss, conductive \\
\hline & Hearing loss, sensorineural \\
\hline & Hearing loss, functional \\
\hline & Hard of hearing Deaf \\
\hline & Hearing loss \\
\hline & Hearing impairment \\
\hline & Hearing disorder \\
\hline & Hearing aid \\
\hline
\end{tabular}


The purpose of this review was to identify thematic concepts (constructs) through key elements (components) of parent-to-parent support for parents of children who are $\mathrm{D} / \mathrm{HH}$, and design an evidence-based conceptual framework. Table 2 provides an overview of the number of studies identified through the literature review for each construct/component of the framework.

\section{Table 2: Numbers of papers pertaining to each component and construct}

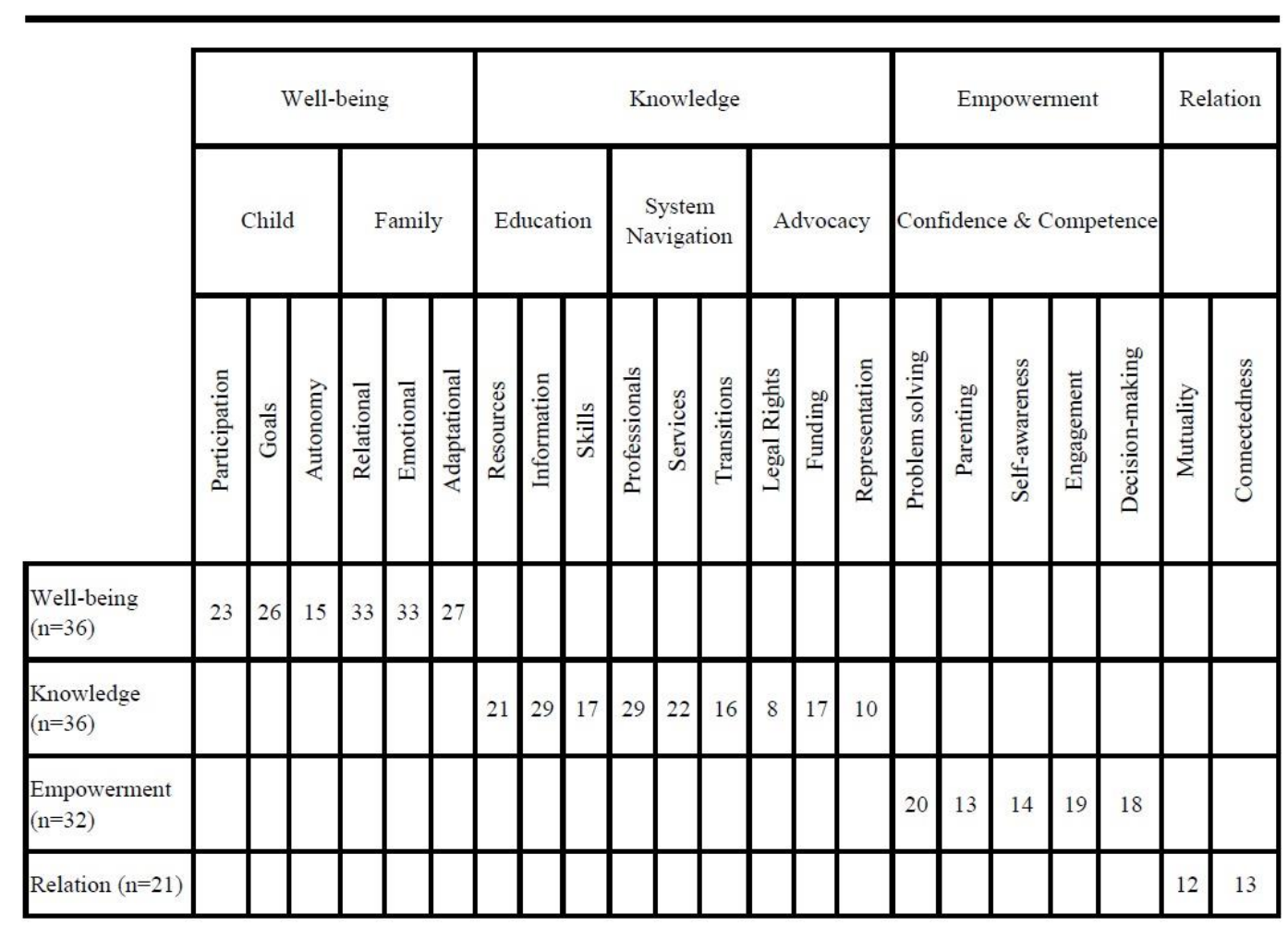

A table of 39 articles included in the scoping review identifies the constructs and components extracted from the articles in available as Appendix B.

The conceptual framework is illustrated in Figure 2. 
Figure 2: Parent-to-parent support for parents of children who are deaf or hard of hearing: A conceptual framework

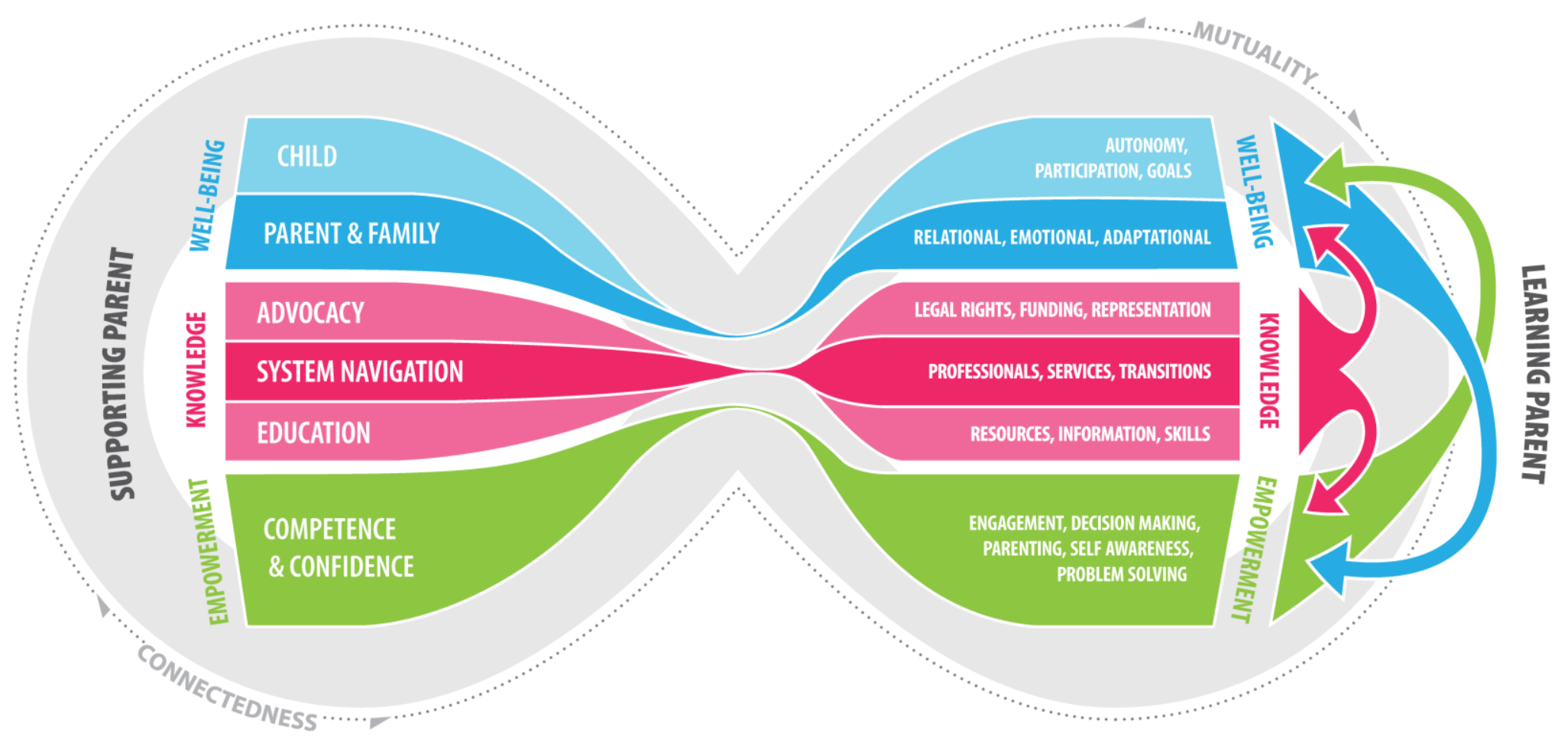


The constructs and components are presented in a closed helix visual design with the supporting and learning parents at opposite curves. The learning parent is characterized as having a child recently identified as $\mathrm{D} / \mathrm{HH}$. The supporting parent has the lived experience of a child with hearing loss. The helix represents the exchange of information between the parents. Two descriptive words - connectedness and mutuality - describe the underpinnings of the relationship. There are several layers of data available. Three overarching themes (constructs) - knowledge, well-being and empowerment - are mirrored in the roles of the supporting and learning parents. In the flexure of the learning parent, arrows indicate relationships exist between the defining constructs, namely that knowledge and well-being promote empowerment and empowerment and knowledge increase well-being. Under each construct, broad descriptive elements (components) are found on the supporting parent's spiral. Finally, specific key elements (components) itemize specific parental needs by the learning parent.

The remainder of this paper provides detail about each component / construct illustrated in the diagram and included in the framework.

\subsubsection{Mutuality and Connectedness}

The relationship between the supporting parent - as defined as a parent with lived experience - and learning parent in the parent-to-parent support dynamic requires mutuality and connectedness. Parent-to-parent support can be cyclical in nature when the learning parent transitions into the supporting parent role. Building a community of mentors and role models of thoughtful and supportive parents of children who are D/HH is becoming increasingly important for sustainable parent-to-parent support.

Mutuality. Mutuality is an important component of parent-to-parent support. Parents have expressed that a mutual exchange of information, thoughts and resources benefits both the supporting and learning parent. In this model, parents require access and meaningful interaction with role models and mentors. In addition, studies report that 
supporting parents indicate giving support was as important as receiving it, and that the learning parent may feel motivated to help other parents who have a similar social identity.

Connectedness. A parent-to-parent support system creates a sense of social identity, social connectedness, affirmation and belonging, which contributes greatly to parental well-being.

The common experience of raising a child who is $\mathrm{D} / \mathrm{HH}$ is an intangible, vital quality, and a shared social identity fosters a sense of belonging, acceptance and support from others. Awareness of a social identity may act as a buffering effect against stress and safeguard parents from negative psychological and physical health impacts. Evidence of shared social identity as a buffer for parents of children with disabilities outside of children who are $\mathrm{D} / \mathrm{HH}$ is well-documented.

Connectedness refers to a welcoming and cordial atmosphere and experiencing social kinship with other families. Connectedness may involve building parental and family relationships, participating in community partnerships, engaging in political initiatives, reaching out to families who have children who are $\mathrm{D} / \mathrm{HH}$, and volunteering together. Sharing experiences reassures parents about their family and child's future, and parents of children who are $\mathrm{D} / \mathrm{HH}$ attribute a sense of belonging to better well-being, especially during stressful events. Parents describe deeper connections over a shared experience. Matching parents whose child has a similar diagnosis on the spectrum of hearing loss may also help. For example, parents considering cochlear implantation are likely to have different peer parental support needs than the parents of a child with a mild hearing loss.

Affirmational support is being able to share their experience and have their feelings and experiences validated. Parents describe affirmational support as being understood and appreciated. Parents with similar experiences, such as a shared child's diagnosis, care requirements or life circumstances (e.g. living in a rural community) was important to feeling understood. Benefits of relational support are described as sense of belonging in 
the group, understanding, learning from the experience of others and safe environment for support.

\subsubsection{Evidence related to Well-being}

For parents and families of children who are $\mathrm{D} / \mathrm{HH}$, the evidence indicates that the key predictors to well-being for parents and families are (1) emotional, (2) relational, and (3) adaptational support. For the child who is $\mathrm{D} / \mathrm{HH}$, key predictors to well-being are (1) participation, (2) goals, and (3) autonomy.

\subsubsection{Well-being for Parents and Families}

Emotional support. Parents require emotional support, and many articles indicate parentto-parent support positively influences emotional well-being. Emotional priorities (and concerns) are key attributes of wellness and affect a parent's ability to cope with their own needs to support their child. The most common emotional concerns researchers have ascribed to parents include emotional distress, low self-esteem, grief, unpredictability, loneliness, incompetence, vulnerability, lack of fulfillment and perceived stigma. Many of these negative emotions arose after the child's diagnosis with hearing loss and/or at periods of transition. Parent support groups offered psychological benefits, including selfreliance, less-isolated, autonomous, positive identity, self-worth, confidence, readiness to engage and bravery. Leading researchers have documented evidence that parent-to-parent support may increase parental emotional well-being.

Adaptational support. Studies link well-being to adaptation, adjustment and acceptance. Examples of important components of how parent-to-parent support assists with adaptation to the child's hearing loss includes developing personal strategies, assisting in resolving grief, helping to accept a child's hearing loss, understanding around the unpredictability associated with a diagnosis and coping with change. Positive emotions associated with adaptation include motivation, relief, increased sense of power, resilience, gratitude, learning, persistence, hopefulness, peacefulness, sense of safety and optimism. Adaptational support assists the parent to develop an awareness of and the 
skills necessary to create an optimal environment for language and literacy development, such as changing routines or learning sign language.

Relational support. Overall, 30 studies indicate relational support as a key attribute of parent-to-parent support. Relational support refers to relationships and well-being between the members of the immediate and extended family. Relational support in this framework is identified as bonding with the child, family functioning, family and marital cohesiveness, interaction and communication between family members. Parent-to-parent support systems recognize family members cope better when they have a sense of togetherness. For children who are D/HH, the impairment may affect language development, which can affect the family members' ability to communicate with the child and the child with his / her family. Parent support groups can help all members understand hearing loss, and boost positive interactions between parent-child, grandparent-child, extended family-child and sibling relationships.

\subsubsection{Well-being for child}

Participation. Twenty-three studies indicate that parents of children who are $\mathrm{D} / \mathrm{HH}$ identify child participation in hearing and Deaf communities as a priority. Parents want their children to fully experience leisure / extracurricular activities, daycare/ school, and ventures with their siblings and friends. Parent support groups may identify solutions to full participation barriers, such as recommendations for community-based accommodations. Sometimes a child who is D/HH may have language or socialemotional delay, which may complicate peer acceptance and relationships, and parent support groups can support parents to improve their child's well-being.

Autonomy. Parents who have children with disabilities have indicated that their overprotectiveness may limit their child's autonomy. Peer parental support provides an opportunity for parents to encourage and provide strategies for other parents who may feel unsure or uncertain about when and how to support autonomous behaviour in their children. Autonomous motivated children perceive greater control over decision-making, 
exhibit persistence, curiosity, and stress-related coping strategies. All of these skills are important for parents to assist children with developing so that they become active participants in their hearing health-care, education and social environments as early as possible in life.

Goals. Twenty-eight studies report the positive influence of parent-to-parent support on reassuring parents about their child's short and long term goals. Parents are concerned about language achievement, communication outcomes, and have expressed hopes and fears regarding their child's educational success and employment opportunities. Peer parental support systems boost parental morale and confidence when looking towards the future, and at points of transition. Parents are better positioned to support the goals chosen by the child through meaningful collaboration.

\subsubsection{Evidence related to Knowledge}

Thirty-six studies highlighted the need for parental access to accurate and unbiased knowledge. Given the magnitude of information on hearing loss, parents may find it difficult to ascertain quality information. Our informational graphic of parent-to-parent support for hearing parents of children who are $\mathrm{D} / \mathrm{HH}$ depicts how knowledge leads to parental empowerment and well-being. Defining components of knowledge are: (1) advocacy, (2) system navigation, and (3) education. Adolescents and adults who are D/HH may provide enhanced cultural and linguistic experiences and help build family networks, if through no other means than giving a reassuring example of successful aging with a hearing loss.

\subsubsection{Advocacy}

Legal Rights. In many countries, positive attitudes toward disability and inclusion are reflected in policy and legislation. Yet, stigma and barriers continue for children who are D/HH. In eight studies, parents wanted clear and accurate information about laws, entitlements and rights for their child, especially regarding special education laws. 
Parent-to-parent support may provide parents with information on federal legislation and regulation, and keep families apprised of changes to laws.

Representation. Parent-to-parent support can guide parents on how to advocate on behalf of their child who is $\mathrm{D} / \mathrm{HH}$ at the local, provincial and federal levels. Parental consultants may provide strength and advice at medical, professional and educational appointments. Learning parents indicate feeling inadequate and lacking confidence at difficult, decisionmaking meetings, and would benefit from a peer advocate. Peer consultants may represent families and collaborate with governments, organizations and initiatives.

Funding. Parents with children who are D/HH may have increased financial strain.

Developing knowledge and skills around accessing financial assistance and entitlements through private insurance, government funding and not-for-profit supplements may reduce stress. Supporting parents can assist learning parents with developing strategies to obtain assistance with expenses related to private speech therapy, time off work for medical appointments and travel, and expenses related to technological equipment (e.g. hearing aids, earmolds and batteries).

\subsubsection{System Navigation}

Services. Children who are $\mathrm{D} / \mathrm{HH}$ require services to meet their needs, and their parents require assistance manoeuvring through health care, school, legal and community systems. Parent-to-parent support can assist parents with children who are D/HH by (a) identifying services (b) accessing services, and (c) navigating services. Parents require assistance in identifying programmes available in the community for today or in anticipation of a future or potential need. Peer parental support can assist parents with locating programs, determining eligibility criteria, navigation of the application process and accessing appropriate programmes. To illustrate, parents need to know about available community services, such as supports beyond the preschool years. If parents are unaware of a service; it cannot be accessed. Further, parent-to-parent support may help families create a program if one does not meet a child's needs. 
Professionals. Parents require a roadmap and care coordination in order to best work with their child's professionals. Twenty-nine studies refer to parents receiving inadequate support navigating the process from referral to hearing aids / cochlear implant provision and understanding roles of the professionals they may encounter. Within our framework, parents seen as supporting parents can help explain to the learning parents how to coordinate efforts, book appointments, and determine timely service. Further, parents may not know the jobs and roles of their child's specialists. Parent-to-parent support can inform parents how speech-language pathologists, audiologists and otolaryngologist work together and perform different tasks in their child's habilitation. Parent-to-parent support can also connect parents with skilled professionals, such as optometrists, dentists or child care workers, who understand hearing loss.

Transitions. Sixteen articles indicate that manoeuvring through these complex systems, processes and stages can be frustrating periods, especially when unexpected barriers are presented. Support and informational needs increase at periods often referred to as transitional, such as when a child enters daycare or school, becomes an adolescent or begins to explore careers. Parents have suggested that educational components to prepare for transitional stages be part of paediatric habilitation for children who are $\mathrm{D} / \mathrm{HH}$ to better support parents and children. Further, parents need ongoing support, not just when entering the school system. Parents express stress around educational concerns, such as learning supports, technological needs, policies and specialized educational programs.

\subsubsection{Education}

Resources. Parent-to-parent support can provide parents with resources in the community. Recognized affiliations with national and local agencies, and referrals to those organizations, are an important component of peer parental support. Peer parental support can suggest volunteer networks, not-for-profit organizations, community partners and support programs to parents at the point of diagnosis. The literature indicates that parents who have the lived experience of raising a child who is $\mathrm{D} / \mathrm{HH}$ are more 
knowledgeable than many professionals about resources available for families in the communities in which they live.

Skills. Mastering new skills can be both rewarding and challenging for parents of children who are D/HH. Endeavouring to best support their child's language and educational needs, many parents receive instruction in sign language, speech training and technological skills from experts in these fields. As a supplement to professional support, parents indicate they want skills-based instruction in peer parental support groups. Skillsbased instruction pertaining to sign-language may include workshops and opportunities to practice. Peer parental support recognizes the parent's effort and dedication to acquiring new skills.

Information. Parents require "information that is accurate, well-balanced, comprehensive, and conveyed in an unbiased manner". For parents, quality information is critical and informs decisions at diagnosis and during their child's early development. Parents indicate they have received inadequate, out-dated, biased and incomplete information from their child's specialists. Parent-to-parent support creates an environment of shared information where parents can learn about best practice, industry protocols, technological advancements, latest research, amplification options and communication choices. Twenty-nine research studies indicate parents would benefit from improved information.

\subsubsection{Evidence related to Empowerment}

Thirty-two research articles provide evidence for the positive influence of parent-toparent support on parental empowerment. Empowerment is a construct that is a social process, influenced by well-being and knowledge, which fosters power through confidence and competence in people's lives. We define the components of competence and confidence as: (1) problem solving (2) parenting (3) self-awareness (4) engagement, and (5) decision-making. 


\subsubsection{Confidence and Competence}

Parenting. The exchange of parenting knowledge learned through the experience of raising a child who is $\mathrm{D} / \mathrm{HH}$ is a vital component of peer parental support in 13 studies. Parents are eager to learn practical parenting skills, such as teaching their child to safely cross the street and how to anticipate their child's needs at a birthday party. Beyond the early years, peer parental support may offer parenting advice to improve child-parent interactions, and guidance when parenting a child who may require behavioural or social supports.

Decision-making. Peer parental support offers parents the opportunity to access knowledge, information and resources, and to cultivate ideas and opinions for informed decision-making. Further, emotional support provided in parent-to-parent structures helps parents develop the capacity and confidence to make decisions. Families fully engaged in decisions about their child's options and care with specialists, can find validation in their peer support group.

Self-awareness. Several studies indicate peer to peer support may provide a sense of selfawareness by helping hearing parents respond with intention to their child's diagnosis. Supporting parents' emotional and educational needs empowers parents to be more selfefficacious in orienting to the present and set goals for the future. Self-awareness is a process; parents build on areas of strength, acknowledge areas to learn and become confident to act in-line with personal and family values. Finding clarity with parent-toparent support empowers parents to rediscover their personal strength and resilience to support their child who is $\mathrm{D} / \mathrm{HH}$.

Problem solving. Parent-to-parent support may empower parents to trust their innate problem-solving and coping abilities. Unable to rely on specialists in daily living, parents must acquire skills and confidence to improve problem-solving abilities. Parent-to-parent support can help parents acquire problem-solving skills specific to raising a child who is $\mathrm{D} / \mathrm{HH}$ and enhance the process together. 
Engagement. Confidence and competence equip parents to play an active and engaged role in the management of their child's daily life. A parent's ability and readiness to assume their expert parental role with their child's specialist team to foster their child's development is related to the parent's willingness and ability to fully engage. Peer parental support can provide positive support and help parents actively engage in their child's habilitation process.

\subsection{Discussion}

The specific objective of this scoping review was to provide a synthesis of the existing peer-reviewed knowledge regarding clinical and parental experiences relating to parentto-parent support for parents of children who are $\mathrm{D} / \mathrm{HH}$. The key finding to emerge is the development a conceptual framework of parent-to-parent support for parents of children who are $\mathrm{D} / \mathrm{HH}$.

The 2013 Supplement to the Joint Committee on Infant Hearing (JCIH) and Moeller et al.’s International Consensus Statement indicate parent-to-parent support has an appreciable quality that cannot be reproduced by clinicians, and that this specific support is recommended for the social and emotional well-being of families. In order for parents to function effectively on behalf of their child who is $\mathrm{D} / \mathrm{HH}$, the panels of experts recommend the development and implementation of guidelines for best practice parentto-parent support. The JCIH and International Consensus Statement served as the catalyst for this scoping review. Prompted by these recommendations, this scoping review sought to determine the constructs and components of this specific type of support. The conceptual framework, developed through this scoping review, may serve as a foundational tool in the development of these guidelines.

The assessment and assimilation of a diverse body of evidence across developed nations in Africa, Australia, Europe and North America has identified central themes and ideas relating to peer parental support needs, and has the potential to standardize content of parent-to-parent support for parents of children who are $\mathrm{D} / \mathrm{HH}$. 
In addition to establishing parent-to-parent guidelines, leading researchers suggest that strengthened peer parent support programs may complement existing services and have a sequential effect, such as augmenting EHDI programs.

\subsection{Limitations of the study}

We did not complete a quality appraisal of the studies, which is not required in the methodological process of a scoping review of the literature. In addition, although grey material, such as what is produced on all levels of government, business and industry, is permissible in scoping reviews, we chose to limit our search to academic literature. Therefore, we did not use parent-to-parent support material from not-for-profit organizations who may work daily with parents of children who are D/HH. Further, the interpretive nature of developing the conceptual framework may be a limitation. Although the scoping review adhered to the methodological standards of a scoping review, the development of the conceptual framework may not be replicable due to authors' interpretations, creative allowances and subjectivity of assigning significance.

\subsection{Conclusion}

There is increasing evidence regarding the vital and beneficial role of parent-to-parent support. To the best of our knowledge, this is the first conceptual framework of parent-toparent support for parents of children who are D/HH. This conceptual framework provides a comprehensive overview of the literature and in doing so addresses recommendations from the $\mathrm{JCIH}$ and the international consensus statement on best practices in family-centered early intervention for children who are $\mathrm{D} / \mathrm{HH}$.

The conceptual framework was developed with the intent to be of service to parents, policy makers, clinical practitioners and researchers. It has the potential to influence the development and implementation of family support guidelines, policy, legislation and practice. 
This review concludes that parent-to-parent support is a central tenet in family-centred care for families with children who are $\mathrm{D} / \mathrm{HH}$, that it must be provided by experienced parents and that it cannot be replicated by healthcare professionals. Evidence indicates parent-to-parent support is necessary and adjunctive to professional services. High priority must be given to ensure parent-to-parent support is incorporated within but complementary to EHDI programs, and that professionals serving parents are informed of peer parental programs.

This research has the capacity to refine the content and type of support offered by institutions and organizations. Parents have already emerged in this health care role but they must be widely recognized as integral providers of this service.

Most importantly, this new information may improve health outcomes for children who are $\mathrm{D} / \mathrm{HH}$ by fully supporting their parents and families.

\subsection{Future Directions}

This is a dual-phase scoping review. The initial conceptual framework was developed based on diverse peer-reviewed literature in the field. However, as per scoping review methodology, we recognize leaders in this field may be able to provide additional insights beyond the literature and we will seek stakeholder involvement. Therefore, the next stage for this program of research will be to present the framework to professionals and parents with expertise in the area of parent-to-parent support to gather additional evidence to support and or direct revisions for the framework.

Additionally, we appreciate how context and environment influences and impacts best practice parent-to-parent support. Conditions affected by 'who', 'where' and 'how' will impact potential implementation of the conceptual framework. Future research directions may consider strategies for best environmental context to complement this conceptual framework. The findings from the parent-to-parent support conceptual framework contextualized in an evidence-based peer parental support environment would be 
depicted in an interactive 3D model. A 3D model would best represent the interaction and merging of the conceptual framework and the environment to support it.

\subsection{Acknowledgements}

Funding for this work was provided by the Ontario Ministry of Children and Youth

Services. We acknowledge and appreciate the comments and suggestions provided by

Dr. Anita Cramp and Dr. Susan Scollie on earlier versions of this manuscript. 


\subsection{Bibliography}

Anaby, D., Hand, C., Bradley, L., Direzze, B., Forhan, M. Digiacomo, A., \& Law, M. (2013). The effect of the environment on participation of children and youth with disabilities: A scoping review. Disability and Rehabilitation, 35, 1589-1598. doi:10.3109/09638288.2012.748840

Arksey, H., \& O’Malley, L. (2005). Scoping studies: Towards a methodological framework. International Journal of Social Research Methodology, 8, 19-32. doi:10.1080/1364557032000119616

Åsberg, K. K., Vogel, J. J., \& Bowers, C. A. (2007). Exploring correlates and predictors of stress in parents of children who are deaf: Implications of perceived social support and mode of communication. Journal of Child and Family Studies, 17, 486-499. doi:10.1007/s10826-007-9169-7

Banach, M., Iudice, J., Conway, L., \& Couse, L. J. (2010). Family support and empowerment: Post autism diagnosis support group for parents. Social Work With Groups, 33, 69-83.doi:10.1080/01609510903437383

Barlow, J. H., \& Ellard, D. R. (2006). The psychosocial well-being of children with chronic disease, their parents and siblings: An overview of the research evidence base. Child Care, Health and Development, 32, 19-31. doi:10.1111/j.13652214.2006.00591.x

Bradham, T. S. (2011). Strategic analysis of family support in EHDI systems. The Volta Review, 111, 181-194.

Brown, P. M., Abu Bakar, Z., Rickards, F. W., \& Griffin, P. (2006). Family functioning, early intervention support, and spoken language and placement outcomes for children with profound hearing loss. Deafness \& Education International, 8, 207226. doi:10.1002/dei 
Brown, P. M., \& Remine, M. D. (2008). Flexibility of programme delivery in providing effective family-centred intervention for remote families. Deafness \& Education International, 10, 213-225. doi:10.1002/dei

Colquhoun, H. L., Levac, D., O’Brien, K. K., Straus, S., Tricco, A., Perrier, L., . . Moher, D. (2014). Scoping reviews: Time for clarity in definition, methods and reporting. Journal of Clinical Epidemiology. Advance Online Publication. doi:10.1016/j.jclinepi.2014.03.013

Dalzell, J., Nelson, H., Haigh, C., Williams, A., \& Monti, P. (2007). Involving families who have deaf children using a family needs survey: A multi-agency perspective. Child Care Health and Development, 33, 576-585. doi:10.1111/j.13652214.2007.00761.x

Davis, K., Drey, N., \& Gould, D. (2009). What are scoping studies? A review of the nursing literature. International Journal of Nursing Studies, 46, 1386-1400. doi:10.1016/j.ijnurstu.2009.02.010

DesGeorges, J. (2003). Family perceptions of early hearing, detection, and intervention systems: Listening to and learning from families. Mental Retardation and Developmental Disabilities Research Reviews, 9, 89-93. doi:10.1002/mrdd.10064

Dunst, C. J. (2011). Parapatric speciation in the evolution of early intervention for infants and toddlers with disabilities and their families. Topics in Early Childhood Special Education, 31, 208-215. doi:10.1177/0271121411426904

Eleweke, C. J., Gilbert, S., \& Bays, D. (2008). Information about support services for families of young children with hearin loss: A review of some useful outcomes and challenges. Deafness \& Education International, 10, 190-212. doi:10.1002/dei

Fitzpatrick, E. (2010). A framework for research and practice in infant hearing. Canadian Journal of Speech-Language Pathology and Audiology, 34, 25-32. 
Fitzpatrick, E., Angus, D., Durieux-Smith, A., Graham, I. D., \& Coyle, D. (2008). Parents' needs following identification of childhood hearing loss. American Journal of Audiology, 17,38-49. doi:10.1044/1059-0889(2008/005)

Fitzpatrick, E., Graham, I. D., Durieux-Smith, A., Angus, D., \& Coyle, D. (2007). Parents' perspectives on the impact of the early diagnosis of childhood hearing loss. International Journal of Audiology, 46, 97-106. doi:10.1080/14992020600977770

Fitzpatrick, E. M., \& Durieux-Smith, A. (2011). Universal newborn hearing screening improves quality of life in children aged 3-5 years but does not show a clear relationship with spoken language skills. Evidence-Based Medicine, 16, 57-58. doi:10.1136/ebm1178

Glanemann, R., Reichmuth, K., Matulat, P., \& Zehnhoff-Dinnesen, A. A. (2013). Muenster Parental Programme empowers parents in communicating with their infant with hearing loss. International Journal of Pediatric Otorhinolaryngology, 77, 2023-2029. doi:10.1016/j.ijporl.2013.10.001

Grant, M. J., \& Booth, A. (2009). A typology of reviews: An analysis of 14 review types and associated methodologies. Health Information and Libraries Journal, 26, 91108. doi:10.1111/ j.1471-1842.2009.00848.x

Hardonk, S., Desnerck, G., Loots, G., Matthijs, L., Van Hove, G., Van Kerschaver, E., . . . Louckx, F. (2011). From screening to care: A qualitative analysis of the parental experiences related to screening and (re)habilitation care for children with congenital deafness in Flanders, Belgium. The Volta Review, 111, 299-324.

Hardonk, S., Desnerck, G., Matthijs, L., Loots, G., Van Hove, G., Van Kerschaver, E., . . . Louckx, F. (2013). Analysing care-related decisions in parents of congenitally deaf children: Introduction of an explanatory model. Scandinavian Journal of Disability Research, 15, 264-281. doi:10.1080/15017419.2012.703966 
Hintermair, M. (2006). Parental resources, parental stress, and socioemotional development of deaf and hard of hearing children. Journal of Deaf Studies and Deaf Education, 11,493-513. doi:10.1093/deafed/enl005

Hoagwood, K. E. (2013). Don’t mourn: Organize. Reviving mental health services research for healthcare quality improvement. Clinical Psychology: Science and Practice, 20, 120-126. doi:10.1111/cpsp.12028

Hoagwood, K. E., Cavaleri, M., Olin, S., Burns, B., Slaton, E., Gruttadaro, D., \& Hughes, R. (2010). Family support in children's mental health: A review and synthesis. Clinical Child and Family Psychology Review, 13, 1-45. doi:10.1007/s10567009-0060-5

Holzinger, D., Fellinger, J., \& Beitel, C. (2011). Early onset of family centred intervention predicts language outcomes in children with hearing loss. International Journal of Pediatric Otorhinolaryngology, 75, 256-260. doi:10.1016/j.ijporl.2010.11.011

Ingber, S. (2009). Demographics affecting parental expectations from early deaf intervention. Deafness \& Education International,11, 83-111. doi:10.1002/dei

Ingber, S., \& Dromi, E. (2010). Actual versus desired family centered practice in early intervention for children with hearing loss. Journal of Deaf Studies and Deaf Education, 15,59-71. doi:10.1093/deafed/enp025

Ireys, H., Chernoff, R., Stein, R., DeVet, K., \& Silver, E. (2001).Outcomes of community-based family-to-family support:Lessons learned from a decade of randomized trials. Children's Services, Social Policy, Research, and Practice, 4, 203-216. doi:10.1207/S15326918CS0404_04 
Jackson, C. W. (2011). Family supports and resources for parents of children who are deaf or hard of hearing. American Annals of the Deaf, 156, 343-362. doi:10.1353/aad.2011.0038

Jackson, C. W., Wegner, J. R., \& Turnbull, A. P. (2010). Family quality of life following early identification of deafness. Language, Speech, and Hearing Services in Schools, 41, 194-206.

Jamieson, J. R., Zaidman-Zait, A., \& Poon, B. (2011). Family support needs as perceived by parents of preadolescents and adolescents who are deaf or hard of hearing. Deafness \& Education International, 13, 110-130. doi:10.1179/1557069X11Y.0000000005

Joint Committee on Infant Hearing. (2007). Year 2007 position statement: Principles and guidelines for early hearing detection and intervention in programs. Pediatrics, 120, 898-921. doi:10.1542/peds.2007-2333

Joint Committee on Infant Hearing. (2013). Supplement to the JCIH 2007 position statement: Principles and guidelines for early intervention after confirmation that a child is deaf or hard of hearing. Pediatrics, 131, e1324-1349. doi:10.1542/ peds.2013-0008

Kerr, S. M., \& McIntosh, J. B. (2000). Coping when a child has a disability: Exploring the impact of parent-to-parent support. Child: Care, Health and Development, 26, 309-322. Retrieved from http://www.ncbi.nlm.nih.gov/pubmed/10931070

Larsen, R., Muñoz, K., DesGeorges, J., Nelson, L., \& Kennedy, S. (2012). Early hearing detection and intervention: Parent experiences with the diagnostic hearing assessment. American Journal of Audiology, 21, 91-99. 
Law, M., King, S., Stewart, D., \& King, G. (2001). The perceived effects of parent-led support groups for parents of children with disabilities. Physical \& Occupational Therapy in Pediatrics, 21,29-48. Retrieved from http://www.ncbi.nlm.nih.gov/pubmed/12029852

Lederberg, A. R., \& Golbach, T. (2002). Parenting stress and social support in hearing mothers of deaf and hearing children: A longitudinal study. Journal of Deaf Studies and Deaf Education,7, 330-345. doi:10.1093/deafed/7.4.330

Levac, D., Colquhoun, H., \& O’Brien, K. K. (2010). Scoping studies: Advancing the methodology. Implementation Science, 5, 69. doi:10.1186/1748-5908-5-69

Luterman, D. (2004). Counseling families of children with hearing loss and special needs. The Volta Review, 104, 215-220.

Marriage, J. (2013). Integrating parents into the diagnostic and habilitation process. Seminars in Hearing, 34, 3-10.

Mathiesen, A. M., Frost, C. J., Dent, K. M., \& Feldkamp, M. L. (2012). Parental needs among children with birth defects: Defining a parent-to-parent support network. Journal of Genetic Counseling, 21, 862-872. doi:10.1007/s10897-012-9518-6

McHugh, C., Bailey, S., Shilling, V., \& Morris, C. (2013). Meeting the information needs of families of children with chronic health conditions. Physical \& Occupational Therapy in Pediatrics, 33, 265-270. doi:10.3109/01942638.2013.799628

Meinzen-Derr, J., Lim, L. H. Y., Choo, D. I., Buyniski, S., \&Wiley, S. (2008). Pediatric hearing impairment caregiver experience: Impact of duration of hearing loss on parental stress. International Journal of Pediatric Otorhinolaryngology, 72, 1693-1703. doi:10.1016/j.ijporl.2008.08.005 
Moeller, M. P., Carr, G., Seaver, L., Stredler-Brown, A., \& Holzinger, D. (2013). Best practices in family-centered early intervention for children who are deaf or hard of hearing: An international consensus statement. Journal of Deaf Studies and Deaf Education, 18, 429-445. doi:10.1093/deafed/ent034

Morrison, S. A., Dashiff, C. J., \& Vance, D. E. (2013). Role of parental autonomy support on self-determination in influencing diet and exercise motivation in older adolescents. Nursing Research and Reviews, 3, 77-85.

Muñoz, K., Blaiser, K., \& Barwick, K. (2013). Parent hearing aid experiences in the United States. Journal of the American Academy of Audiology, 24, 5-16. doi:10.3766/jaaa.24.1.2

Olin, S. S., Williams, N., Pollock, M., Armusewicz, K., Kutash, K., Glisson, C., \& Hoagwood, K. E. (2014). Quality indicators for family support services and their relationship to organizational social context. Administration and Policy in Mental Health, 4, 43-54. doi:10.1007/s10488-013-0499-z

Poon, B. T., Jamieson, J. R., Buchanan, M., \& Brown, D. K. (2008). Parent-screener discourse in a newborn hearing screening program. Infants \& Young Children, 21, $160-173$.

Poon, B. T., \& Zaidman-Zait, A. (2014). Social support for parents of deaf children: Moving toward contextualized understanding. Journal of Deaf Studies and Deaf Education, 19,176-188. doi:10.1093/deafed/ent041

Porter, A., \& Edirippulige, S. (2007). Parents of deaf children seeking hearing lossrelated information on the Internet: The Australian experience. Journal of Deaf Studies and Deaf Education, 12, 518-529. doi:10.1093/deafed/enm009 
Poulsen, A. A., Rodger, S., \& Ziviani, J. M. (2006). Understanding children's motivation from a self-determination theoretical perspective: Implications for practice. Australian Occupational Therapy Journal, 53, 78-86. doi:10.1111/j.14401630.2006.00569.x

Quittner, A. L., Barker, D. H., Cruz, I., Snell, C., Grimley, M. E., \& Botteri, M. (2010). Parenting stress among parents of deaf and hearing children: Associations with language delays and behavior problems. Parenting, Science and Practice, 10,136-155. doi:10.1080/15295190903212851

Resch, J. A., Mireles, G., Benz, M. R., Grenwelge, C., Peterson, R., \& Zhang, D. (2010). Giving parents a voice: A qualitative study of the challenges experienced by parents of children with disabilities. Rehabilitation Psychology, 55, 139-150. doi:10.1037/a0019473

Sartore, G., Lagioia, V., \& Mildon, R. (2013). Peer support interventions for parents and carers of children with complex needs (protocol). The Cochrane Library. Retrieved from http://onlinelibrary.wiley.com/doi/10.1002/14651858.CD010618/abstract

Shilling, V., Morris, C., Thompson-Coon, J., Ukoumunne, O., Rogers, M., \& Logan, S. (2013). Peer support for parents of children with chronic disabling conditions: A systematic review of quantitative and qualitative studies. Developmental Medicine and Child Neurology, 55, 602-609. doi:10.1111/dmcn.12091

Sipal, R. F., \& Sayin, U. (2012). Impact of perceived social support and depression on the parental attitudes of mothers of children who are deaf. Journal of Child and Family Studies, 22, 1103-1111. doi:10.1007/s10826-012-9672-3 
Sorkin, D. L., \& Zwolan, T. A. (2008). Parental perspectives regarding early intervention and its role in cochlear implantation in children. Otology \& Neurotology, 29, 137142. doi:10.1097/mao.0b013e3181616c88

Uus, K., Young, A., \& Day, M. (2012). Auditory neuropathy spectrum disorder in the wider health context: Experiences of parents whose infants have been identified through newborn hearing screening programme. International Journal of Audiology, 51, 186-193. doi:10.3109/14992027.2011.625986

van der Spuy, T., \& Pottas, L. (2008). Infant hearing loss in South Africa: Age of intervention and parental needs for support. International Journal of Audiology, 47(Suppl. 1), S30-S35. doi:10.1080/14992020802286210

Wright, K. N., \& Wooden, C. (2013). An evaluation of a parent developed, parent-run parent education program. Journal of Family Social Work, 16, 164-183. doi:10.1080/10522158.2012.762596

Yucel, E., Derim, D., \& Celik, D. (2008). The needs of hearing impaired children's parents who attend to auditory verbal therapy-counseling program. International Journal of Pediatric Otorhinolaryngology, 72, 1097-1111. doi:10.1016/j.ijporl.2008.03.020

Zaidman-Zait, A. (2007). Parenting a child with a cochlear implant: A critical incident study. Journal of Deaf Studies and Deaf Education, 12, 221-241. doi:10.1093/deafed/en1032

Zaidman-Zait, A., \& Jamieson, J. R. (2007). Providing web-based support for families of infants and young children with established disabilities. Infants \& Young Children, 20, 11-25 


\section{Chapter 3}

\section{Revised Conceptual Framework of Parent-to-Parent Support for Parents of Children who are Deaf or Hard of Hearing: A Modified Delphi Study}

\subsection{Introduction}

Parent-to-parent support is a mutual process of parents with lived experiences supporting each other. For parents raising children with disabilities, parent-to-parent support yields many positive benefits and rewards, and leverages peer-partnership so that parents are encouraged and supported in ways that are meaningful to them. Evidence of the benefits of parent-to-parent support is recognized in the literature for children with autism spectrum disorder, birth defects, chronic disease, cognitive disabilities, cystic fibrosis, developmental disabilities, limb deformities, and mental health disorders (Banach \& Couse, 2012; Barlow \& Ellard, 2006; Baum, 2004; Hoagwood et al., 2010; Ireys, Chernoff, Stein, DeVet, \& Silver, 2001; Kerr \& McIntosh, 2000; Law, King, Stewart, \& King, 2001; Mathiesen, Frost, Dent, \& Feldkamp, 2012; Olin et al., 2014; Resch et al., 2010). Parents recognize that interacting and co-learning with parents in similar situations contributes to parental and family well-being.

For parents of children who are deaf or hard of hearing (D/HH), parent-to-parent support has an important role in helping parents provide assistance to their children (Åsberg, Vogel, \& Bowers, 2007; Bradham, Houston, Guignard, \& Hoffman, 2011; Brown \& Remine, 2008; Dalzell, Nelson, Haigh, Williams, \& Monti, 2007; Eleweke, Gilbert, \& Bays, 2008; Fitzpatrick, Graham, Durieux-Smith, Angus, \& Coyle, 2007; Fitzpatrick, 2010; Hardonk et al., 2013; Jackson, Wegner, \& Turnbull, 2010; Jackson, 2011; Jamieson, Zaidman-Zait, \& Poon, 2011; Larson, Munoz, DesGeorges, Nelson, \& Kennedy, 2012; Lederberg \& Golbach, 2002; Muñoz, Blaiser, \& Barwick, 2013; Poon \& Zaidman-Zait, 2014; Sipal \& Sayin, 2012). When a child is diagnosed with a hearing 
loss, the majority of these children will be born to parents with typical hearing who were not expecting the diagnosis (Bagatto, Scollie, Hyde, \& Seewald, 2010; Mitchell \& Karchmer, 2004). Parents and volunteers who work daily with parents who have a child who is $\mathrm{D} / \mathrm{HH}$ can provide empathetic support, knowledge and skills to facilitate navigation of this new experience.

This important type of support system may be referred to as family-to-family support, peer-to-peer support, peer-mentor support, parent coach or guide, and one-on-one parent support, but the term parent-to-parent best characterizes the system of support described by parental narratives in the peer-reviewed literature. For parents of children who are $\mathrm{D} / \mathrm{HH}$ in this study, the word parent is used broadly to refer not just to parents, but to primary guardians and caregivers.

An international consensus document, Best Practices in Family-Centered Early Intervention for Children Who Are Deaf or Hard of Hearing (Moeller, Carr, Seaver, Stredler-Brown, \& Holzinger, 2013), provides 10 guiding principles to family-centred care intervention. Principle 4 identifies family social and emotional support as a priority stating, "Families are connected to support systems so they can accrue the necessary knowledge and experiences that can enable them to function effectively on behalf of their D/HH children" (Moeller et al., 2013, p. 435). Providers and organizational decisionmakers are given objectives to achieve Principle 4, and are encouraged to:

Ensure that all families have access to parent-to-parent support from other families of children who are D/HH. Recognize the key role of parent-to-parent support in promoting social and emotional well-being for families. Recognize and actively support parent organizations and networks for direct parent-peer support opportunities. Support connections between families and adult role models who are $\mathrm{D} / \mathrm{HH}$ (p. 435).

Moeller et al. (2013) asked providers to re-consider their responsibilities to parents. This document provided internationally agreed-upon principles to sustain and remove barriers, 
review and expand outreach strategies, and provide parents with the knowledge and tools to access parent-to-parent support.

The international consensus document provided the impetus for this research study. Using evidence from studies that examine parent-to-parent support facilitates awareness of the components of successful support, identifies needs and challenges of families and enables differentiation of this support from professional or other provider-related supports. It also provides an opportunity to develop ways to evaluate successful parentto-parent support systems and/or provide evidence that can be used to improve them.

Development of a conceptual framework of parent-to-parent support for parents of children who are $\mathrm{D} / \mathrm{HH}$ is required to determine the design and integral elements in a comprehensive, relevant and authentic parent-to-parent support structure. This is the second of a dual-stage study that responds to the same question, "What are the constructs and components of a conceptual framework of parent-to-parent support for parents of children who are D/HH?" Henderson et al. (2014) used a scoping review methodology within the peer-reviewed literature to determine the constructs and components of a conceptual framework (Henderson, et al, 2014). The second stage of the study provides an opportunity to engage with experts, transfer knowledge between experts, and work towards a satisfactory consensus (Colquhoun et al., 2014). Experts are leaders and stakeholders in the field who have comprehensive and authoritative knowledge. Individual contributions and the tacit knowledge of experts who have learned from parents, or are parents themselves, engaged in parent-to-parent support are important factors in addition to theory, literature and research to develop a comprehensive conceptual framework (Colquhoun et al., 2014).

\subsection{Methods}

The findings from the scoping review of the literature led to the development of a structured conceptual framework of parent-to-parent support for parents of children who are D/HH (Henderson, et al., 2014). The scoping review identified 39 peer-reviewed 
articles published from 2000-2014. Data was identified, extracted and organized into libraries of thematic and descriptive content. The eDelphi method satisfies the consultation and final component of the scoping review (Colquhoun et al., 2014). Using web-survey software, an international panel of experts contributed to the framework through two-rounds of mixed-method questionnaires.

\subsubsection{Scoping Review}

A scoping review is defined as "a form of knowledge synthesis that addresses an exploratory research question aimed at mapping key concepts, types of evidence, and gaps in research related to a defined area or field by systematically searching, selecting, and synthesizing existing knowledge" (Colquhoun et al., 2014, pp. 2-4). Henderson et al. (2014) developed the original conceptual framework through the initial stages of a scoping review: definition of the research question, identification and selection of relevant studies, charting the data, collation, summary, and reporting of results. Scoping review methodology (Colquhoun et al., 2014), recommends inclusion of a final stakeholder consultation stage to obtain insights beyond those offered by the literature (Colquhoun et al., 2014; Levac, Colquhoun, \& O’Brien, 2010).

\subsubsection{Electronic Delphi (eDelphi) Method}

The aim of this study was to guide development of - not validate - the original conceptual framework. The Delphi methodology engages stakeholders to provide personal judgment and opinion about a topic, using methods that promote balanced viewpoint, anonymity, iteration, structured feedback and aggregation of group response to arrive at a consensus (Skulmoski, Hartman, \& Krahn, 2007). Participants in Delphi studies engage in multiple rounds of thoughtfully designed questionnaires (Goluchowicz \& Blind, 2011; Okoli \& Pawlowski, 2004). After each round, the responses from the group are collated and interpreted, and the participants are provided with summarized information to communicate various stakeholder positions (Balasubramanian \& Agarwal, 2012; Okoli \& Pawlowski, 2004). The sequential online questionnaires produce rich data 
because the respondents participate repeatedly and may adjust their responses based on group feedback (Balasubramanian \& Agarwal, 2012).

Several investigators have used this method in family-related studies, such as defining parenting strategies to help parents reduce the risk of their children developing depression and anxiety disorders (Yap, Fowler, Reavley, \& Francis Jorm, 2015), developing an instrument to measure parental child discipline behaviours (Runyan et al., 2009), and reaching consensus on important elements of measuring participation in everyday life for children who need or use power mobility (Field, Miller, Jarus, Ryan, \& Roxborough, 2014). The Delphi method is appropriate for the present study because there is incomplete knowledge about the constructs and components of parent-to-parent support for parents with children who are D/HH. This study used a modified Delphi technique with a structured first round based on our review of the literature.

The Delphi method was modified by engaging experts through a web-based platform $\left(\right.$ SurveyMonkey $\left.{ }^{\mathrm{TM}}\right)$. Referred to as an Electronic Delphi (eDelphi), the process allows for a cost effective approach to allow for participation from around the world (Gill, Leslie, Grech, \& Latour, 2013; Tume, van den Hoogen, Wielenga, \& Latour, 2014).

\subsubsection{Mixed Methods}

The eDelphi methodology used quantitative and qualitative elements in an integrated mixed methods research design (Sandelowski, 2014). Mixed methods occurred during the collection and analysis of data. Qualitative and quantitative methods were used to collect data during Round 1 and 2. During each interpretation phase, the data was blended to compare and confirm results (Caracelli \& Greene, 1993; Sandelowski, 2000). Although consensus is typically conceptualized and represented numerically, consensus can also be assessed by comparing and interpreting qualitative data (Sandelowski, 2000).

\subsubsection{Panel}

Recruitment for Round 1 used a purposive selection strategy in which the investigators identified 100 leaders in provision or research in the area of parent-to-parent support for 
parents of children who are $\mathrm{D} / \mathrm{HH}$ and disabilities from the scoping review. Stakeholders with knowledge about parent-to-parent support in the field of hearing, speech-language pathology or childhood disability were selected from research networks, nongovernmental institutions, national non-profit organizations, individuals who self-identify as Deaf, and parents. The merits of each candidate were debated with an aim toward heterogeneity, as required in Delphi studies (Goluchowicz \& Blind, 2011). Thirty-one potential participants were selected due to their diverse backgrounds in the international community. Experiential knowledge and competency in parent-to-parent support by our participants enhanced reliability of results (Goluchowicz \& Blind, 2011). Participants resided in nine countries: Australia, Austria, Belgium, Canada, Germany, Israel, South Africa, United Kingdom, and United States. Panel diversity was sought in order to balance stakeholder representation, which is beneficial to avoid the issue of self-interest (Ecken, Gnatzy, \& von der Gracht, 2011).

The selection of 30 experts allowed for possible attrition while working to maintain an appropriate heterogeneous sample size and to meet appropriate eDelphi participant size recommendations (Balasubramanian \& Agarwal, 2012; Bardecki, 1984; Okoli \& Pawlowski, 2004). The eDelphi group size does not relate to statistical power, but adequate participation is essential for the establishment of good transferability of results, or for the extent to which the responses can be generalized (Holloway \& Todres, 2003).

Privacy and confidentiality may be precepts of a Delphi study, and the SurveyMonkey web-based platform assured anonymity in each phase. Round 2 included the question, “Did you participate in Round 1?" to help determine purposeful sampling practices.

\subsubsection{Questionnaire Development}

The questionnaire aimed to assess the comprehensiveness, clarity, and applicability of the parent-to-parent support for parents of children who are D/HH conceptual framework (Henderson et al., 2014). Intended to guide researchers, parents and decision-makers in EHDI programs, questions directed participants to evaluate ease of understanding, 
readability and functionality of the model. Using the original design to guide the collection of qualitative and quantitative data, the questionnaire compartmentalized each element of the framework. Participants viewed the image of the original conceptual framework, and then received questions that led participants to methodically consider every component of the model. Participants addressed conceptualization and design, evaluated labels and definitions, assessed wider construct groupings, and reflected on future functionality. See Appendix D for Round 1 and 2 Questionnaires.

During both rounds, the questionnaire used a consistent 11 -point Likert-scale $(0=$ strongly disagree and $10=$ strongly agree) to assess participants' opinions. Likert-scales are a common rating format for surveys to assess judgments of an individual or group (Salkind, 2010). The scale gave the participants the option of a neutral response ( $5=$ neither agree nor disagree), and also allowed us to assess responses on a scale that was analogous to a percentage rating scale. In Round 2, the questionnaire used the explicit closed question technique as an additional qualitative method (Roulston, 2008). Participants were limited in their response choice and asked to choose between " $A$ " or " $\mathrm{B}$ ". The closed questions were intended to confirm consensus on labels. Open-ended questions provided the opportunity to collect qualitative data. After every Likert-scale or closed question, the questionnaire used open-ended questions designed to allow participants to elaborate on their opinions, and provide the panel members with the opportunity to initiate topics (Roulston, 2008).

\subsubsection{Ethical conduct of study}

The study was approved by the Health Sciences Research Ethics Board at the University of Western Ontario (see Appendix A). Respondents agreed to participate by completing the questionnaire.

\subsubsection{Round 1}

The Round 1 questionnaire was distributed and returned between November and December 2014. Thirty-one invited participants were sent a brief introduction to the 
study and informed about the aim and nature of the study in a targeted email message with an invitation to participate and a link to the eDelphi questionnaire. Participants were presented with an overview of the findings from the scoping review of the literature, and the resulting initial informational graphic (Henderson et al., 2014). The graphic depicted the constructs and components of the framework based on evidence resulting from the review of the literature. Twenty-one respondents from seven (or more) countries provided feedback in Round 1, which meets the recommended criteria of a $70 \%$ response rate stated by Keeney et al. (2006) (Keeney, Hasson, \& McKenna, 2006). Four individuals did not identify their country of residence on the questionnaire. It is hypothesized that respondents may have chosen not to indicate their country of residence because it could be an identifier and compromise anonymity. The $70 \%$ response rate supports the purposeful sampling of respondents who may have been motivated by the subject and recognized the need for this conceptual framework to enhance EHDI programs and support parents.

\subsubsection{Round 2}

Two panel members independently identified one additional expert each, and requested permission to share the Round 2 survey. Given the two experts' keen interest, the researchers granted permission. One participant from Round 1 could not participate in Round 2, and informed the researchers. Therefore, 32 experts were invited to participate in Round 2. The questionnaires were distributed and returned between March and May 2015. As per Delphi methodology, participants were provided with summarized diverse opinions and comments, collated judgments, and statistical data from the first round. A revised survey was developed based on participants' quantitative and qualitative feedback.

During Round 2, 17 participants from five (or more) countries completed the full questionnaire. This is consistent with the literature that states that it may be difficult to maintain participation over time in Delphi studies (Keeney, et al., 2006). However, 17 participants meet the criteria of the recommended 10-18 experts on a Delphi panel 
(Balasubramanian \& Agarwal, 2012; Bardecki, 1984; Okoli \& Pawlowski, 2004). Please refer to Table 3 for an overview of the research process.

\section{Table 3: Overview of the Research Process}

\section{Overview of the Research Process}

\begin{tabular}{l|l|l}
\hline Ethics Obtained & September 2014 & \\
\hline $\begin{array}{l}\text { Developed 37 QUAN statements using a } \\
\text { 11-point Likert scale (strongly disagree to } \\
\text { strongly agree), and 14 QUAL open-ended } \\
\text { questions }\end{array}$ & $\begin{array}{l}\text { September - October } \\
2014\end{array}$ & \\
\hline $\begin{array}{l}\text { Collected QUAL and QUAN data } \\
\text { Analyzed QUAL and QUAN data analysis }\end{array}$ & $\begin{array}{l}\text { November - December } \\
\text { January 2015 }\end{array}$ & \\
\hline
\end{tabular}

Developed six QUAN statements using a 11-point Likert scale (strongly disagree to strongly agree), 11 QUAN closed "A" or "B" questions, and 33 QUAL open-ended questions

February 2015

Collected QUAL and QUAN data

March 2014 - May 2015

Analyzed QUAL and QUAN data analysis

May 2014 - June 2015

Phase 2

Decided to close study after two rounds

May 2014

Overall findings and interpretations

June 2015

*QUAN = Quantitative; QUAL = Qualitative 


\subsection{Results}

The conceptual framework of parent-to-parent support for parents of children who are $\mathrm{D} / \mathrm{HH}$ is based on English speaking literature from countries where EHDI programs are established. The goal was to achieve consensus on labels, definitions, constructs, relationships, clarity of the graphic, and potential usability.

High consensus was achieved on many aspects of the initial conceptual framework at the end of Round 1 (mean agreement ranged from $75 \%$ to $95 \%$ ). Yet, as Goluchowicz \& Blind (2011) point out, comments of dissensus in qualitative feedback highlight important issues and provide valuable information (Goluchowicz \& Blind, 2011). Many stakeholders provided opinions with strong rationales in the qualitative data that differed from the quantitative consensus, and these opinions were brought back to the panel in Round 2 (Bolger \& Wright, 2011). Results for the constructs and components of the revised conceptual framework are discussed, and presented as a revised infographic (Figure 3). 
Figure 3: A Revised Conceptual Framework of Parent-to-parent support for parents of children who are deaf or hard of hearing

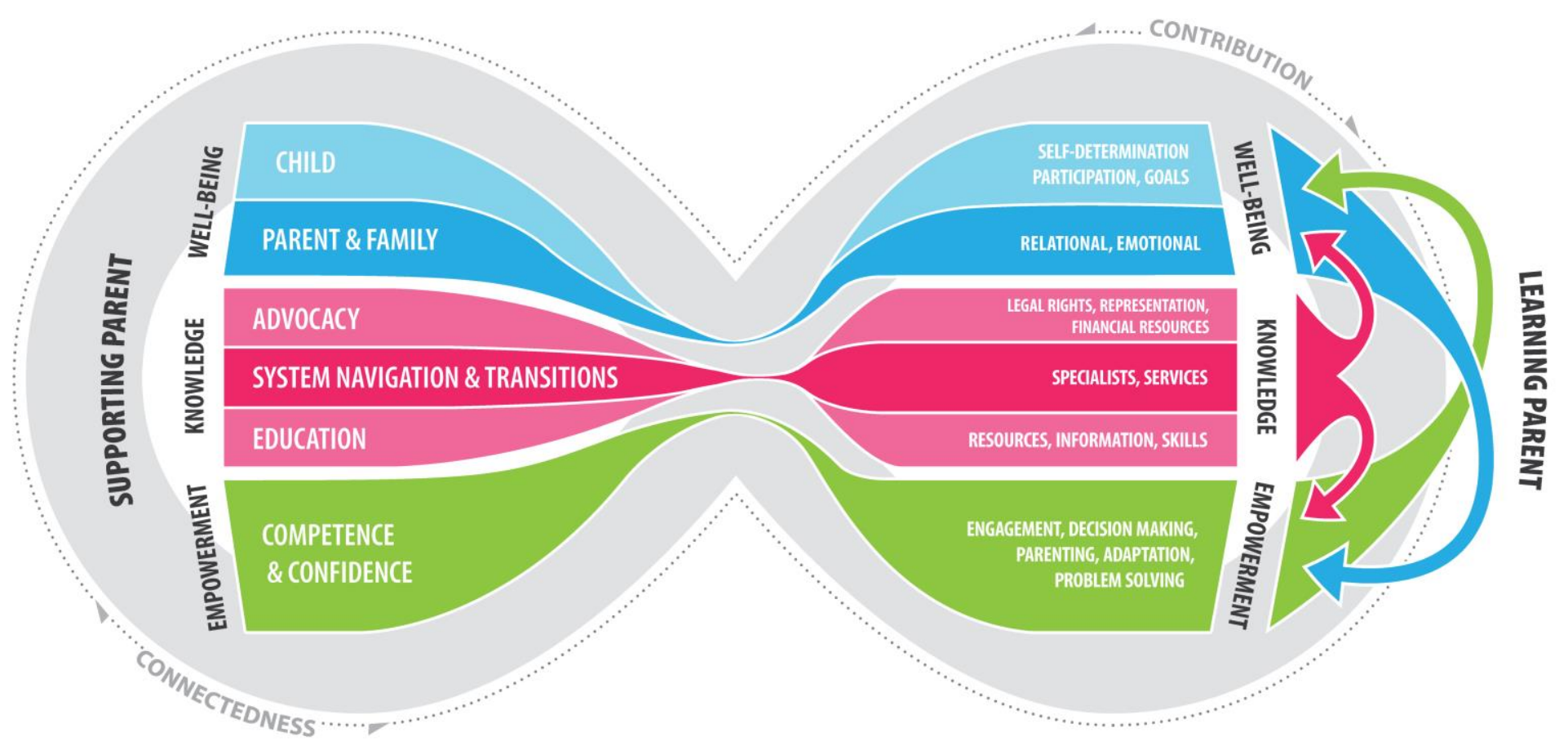




\subsubsection{Parent-to-Parent Support}

Participants gave feedback on the appropriateness of the phrasing of Parent-to-Parent Support. There was strong sentiment (91\%) among respondents (Round 1, $\mathrm{n}=21$ ) that Parent-to-Parent Support is the appropriate descriptor. No respondent disagreed with the descriptor. One participant states, "I think parent-to-parent support actually describes about $90 \%$ of the people involved in $\mathrm{p} 2 \mathrm{p}$ [parent-to-parent] support (others are immediate and extended family members), so it is an accurate term".

As an alternative, participants suggested Family-to-Family Support as a more appropriate descriptor,
Although I think the term works, you may want to consider family-to-family support. Family-centered practice principles emphasize a family systems approach. Thus, the title change might reflect that broader focus on the family. In addition, many children experience parenting beyond the traditional "parent," so the broader term of family-to-family might also capture non-traditional parenting practices.

The authors agree that "family-to-family" support may have been a good alternative had the review of the literature included grandparent, adolescent and sibling data. However, the literature review did not encompass all family member perspectives, and one respondent stated:

I agree entirely with your reasoning and explanation as above, but just have a very slight reservation in that sometimes the primary carers may well be the grandparents or others with parental responsibility. However I think as long as we acknowledge that that can be the case, I think this phrasing is the best.

The scope of the literature review focused on parents with children who are $\mathrm{D} / \mathrm{HH}$ or with other disabilities, and didn't include extended family voices. Given the scope of the literature review, high respondent consensus in Round 1 and thoughtful participant 
responses together with strong quantitative consensus (95\%) in Round 2, Parent-to-Parent Support appears to be the appropriate descriptor for this framework.

\section{Parent-to-Parent Support}

Parent-to-Parent Support is the mutual support of parents who have the lived experience of raising a child who is $\mathrm{D} / \mathrm{HH}$.

Supporting Parent. The majority of respondents (Round 1, n=21) agreed (87\%) with the term Supporting Parent. As an alternative, respondents provided a strong rationale for Mentoring Parent as a better descriptor. With this suggestion, the authors returned to the participants in Round 2 and provided the opportunity to further consider the merits of the descriptors Mentoring Parent or Supporting Parent.

Participants provided varying rationales for Mentoring Parent. One respondent stated, "For being a mentor special teaching, supervision and guidance by professionals is included and not only experience. So the phrasing 'supporting parent' is not appropriate, if more than experience is [required]." One participant expressed, "You are right, that all parents who have a child with a hearing loss have a lived experience. Why I am undecided [is in] regards to the point that a lived experience alone is not enough to become a supporting parent." Another commented, "I would prefer a term including 'mentor' (e.g. parental mentor), because only the experience isn't enough to convey information in an 'unbiased manner' like the JCIH (2013) demands".

Respondents provided strong rationales for Supporting Parent as well. One respondent noted, 'I prefer 'supporting' since 'mentor' is often defined or understood as a hierarchical relationship". Another participant stated, "I prefer supporting parent because in a sense it is broader. The term mentor comes with some level of expectations, possibly implied 
training, etc". Finally, one panel member commented, "I am sensitive to the comment that was made suggesting 'parents are both supporting and learning throughout their ...experience'. Mentor suggests that one parent knows more than the other. Might a term such as 'experienced parent' be more descriptive?"

Respondents expressed beliefs that there may be two types of support in the "experienced parent" dyad, namely a trained parent (mentoring) or an informal parent (supporting). Respondents acknowledged that an experienced parent has the lived experience of a child with hearing loss, and may also be characterized as someone who is teaching, modeling, encouraging, and mentoring.

Learning Parent. The opinion among respondents (Round 1, $\mathrm{n}=21$ ) is that Learning Parent is the most appropriate descriptor for the parent who has a child who is $\mathrm{D} / \mathrm{HH}$, and is seeking support from an experienced parent with a child who is $\mathrm{D} / \mathrm{HH}$. Alternative labels were suggested, with a number of respondents suggesting Novice Parent. Comments provided about the descriptor Novice Parent included, "I think that Learning Parent captures the notion of a parent learning new information and skills, whereas Novice Parent does not seem to include experienced parents who are in a new situation". Other respondents stated, "I like the definition of 'novice parent' more than the term itself", and, "I'm not completely sold on the descriptor Novice although I like the definition. I almost would just leave this as Parent".

One panel member noted:

The word "novice" makes me think of someone that doesn't really have any current skillsets in the given context. I would argue that "new" parents of deaf kids still come to the table with inherent expertise and skillsets that will serve them well: love, understanding their child in the holistic context, etc.

The comments provided about the descriptor Learning Parent included, "I like this term as I think we move between being supporting parents to learning parents constantly through the life of our child", and, "it seems that we are all life-long learners, so the 
supporting parents are also learning. I like the neutrality of 'learning parents', but believe that they are not the only learners in the process. Maybe you could just acknowledge that in the text".

One participant noted:

I think this may imply that the less experienced parent is less capable of effectively parenting their child.....could this be disempowering for them? I very much like the model but have some qualms about this descriptive term.....unless somewhere it can be recognised / acknowledged that this is an evolving role.

Parents learn throughout their child's life. In this context, a learning parent is inexperienced to the situation of raising a child who is $\mathrm{D} / \mathrm{HH}$, or an emerging situation in the child's life. As one respondent stated, "we both come to the table from the very beginning with skills and strengths. New parents may be learners, but they also come from day 1 with parental love for their child, desire to do what's best, and moral and ethical responsibility to be decision makers".

The outside arrows in the conceptual framework indicate the fluidity and movement as parents' roles evolve and change. Parents may move between supporting and learning parent roles. For example, the experienced parent may be in a new situation and also require support. A respondent stated, "While I act as an informal mentor to new families, I receive support myself from parents whose children are older than mine in times of transition".

When encountering a new situation, experienced parents will seek out peer parental advice and move from the supporter to the learner. An experienced parent may become the learning parent and the learning parent may transition to become the experienced and supporting parent. In the continuum of parent-to-parent support, parents may simultaneously exist as both the learning and supporting parent throughout their child's life. 


\section{Supporting and Learning Parent}

The Supporting Parent is a coaching, nurturing and encouraging parent who has the lived experience of a child with hearing loss.

The Learning Parent is a parent new to or inexperienced in a situation of raising a child who is $\mathrm{D} / \mathrm{HH}$. (For example, the parent may have a child recently diagnosed as $\mathrm{D} / \mathrm{HH}$ or may be experiencing a transition in the child or family's life.)

Contribution (previously Mutuality) and Connectedness. The original framework used the descriptor Mutuality to describe the exchange of information, ideas and resources with peer mentors and role models. Respondents (Round 1, n=21) agreed that Mutuality was a fairly appropriate term; however, alternative labels were suggested, including, commonality, collaboration, shared contribution, and connection. Respondents noted, "I would stress the active contribution of both parties aimed at sharing benefits from the relation" and, “don't like either...contributing seems to be a one way direction - send receive; mutuality means almost giving in, giving up. Interactive or exchanging seems more appropriate". Another participant stated, "Contribution seems unidirectional...mentor to learner, when the impact may be bi-directional....that may be an advantage to the term mutuality---however, I am not sure that mutuality is very clear".

Participant contributions indicated both the descriptor label and definition required clarity. Contribution is the active (or external) expression of parent-to-parent support. The contribution comes from a participatory and action-oriented community that shares information, ideas, and resources. Community relationships develop between learning parents, supporting parents, D/HH role models, peers, community members and family members. Developments arising from this community can affect change at the local, regional and national level. 
Connectedness. Participants (Round 1, $\mathrm{n}=21$ ) suggest connectedness is an appropriate descriptor $(87 \%)$ that encompasses social identity, affirmation, validation, comfort, and sense of belonging when raising a child who is $\mathrm{D} / \mathrm{HH}$. Respondents suggested the alternative label of Connection. Respondents commented on the descriptors Connectedness and Connection, "I've always found at least some form of connectedness in parent to parent support groups I've participated in!" and, "Connectedness implies to me more than a connection -- it implies also an emotional interaction between participants".

One participant stated:

In my view, social identity is the overarching concept under which affirmation, sense of belonging and social kinship should be placed. It is the person's affiliation with a social identity that opens up spaces for affirmation, belonging and social kinship. So, I would dismiss the term "connectedness" altogether, because social identity is a more specific concept that covers what you actually explain in the paragraphs in your paper.

The respondents provided strong rationales for the best descriptor to identify the emotional interaction in peer parental support. The authors assert that the conceptual framework as a whole responds to social identity. Social identity is grounded in the idea that the parents in peer-parental support are raising children who are $\mathrm{D} / \mathrm{HH}$. Connectedness describes the emotional connection because a shared social identity may not be the only reason to participate in parent-to-parent support. Therefore, in contrast to Contribution, which is an external representation of parent-to-parent support, Connectedness describes the emotional connection and sharing of anecdotal, life stories and social identify between parents who share the lived experience of raising a child who is $\mathrm{D} / \mathrm{HH}$. 


\section{Contribution and Connectedness}

Contribution is community relationships (D/HH role models, $\mathrm{D} / \mathrm{HH}$ community, peers, social groups, family members), engagement and development through the sharing of ideas, information and resources.

Connectedness is the affirmation, validation, comfort, and sense of belonging found in the emotional connection of sharing of social identity, anecdotal and life stories.

\subsubsection{Well-Being}

Parent-to-parent support contributes to child, and parent and family well-being. The external arrows (Figure 2, beside the descriptor learning parent) indicate knowledge, and confidence and competence improve well-being. Respondents shared insights and information, which ultimately provided alternative labels and descriptors for Child and Parent and Family Well-Being.

Figure 4: Constructs and Components of Well-Being

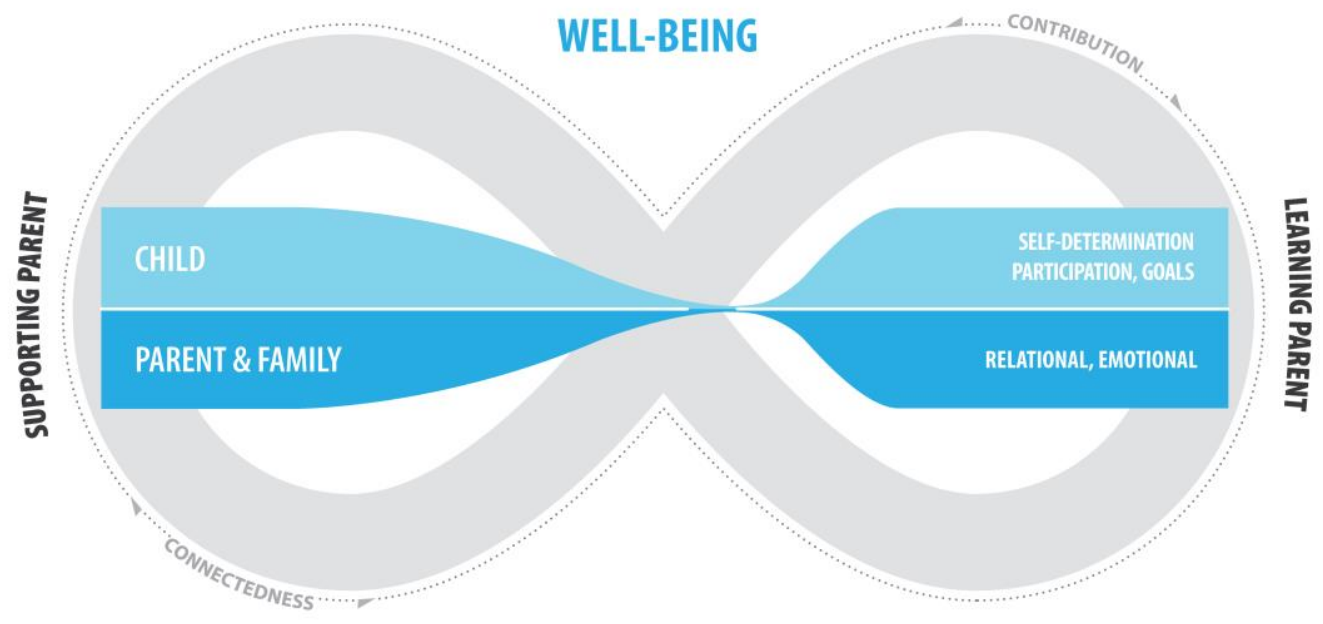




\subsubsection{Child Well-Being}

With input from the consultation process, the learning parent needs support related to child (a) participation, (b) self-determination, and (c) goals.

Participation. Respondents (Round 1, n=21) strongly agreed (94\%) the term Participation described involvement in hearing and Deaf communities, leisure and extracurricular activities, daycare/school, and ventures with family and friends. One respondent reiterated that Participation includes, "leisure times/activities/having fun". Participation is the appropriate descriptor.

Self-determination (formally Autonomy). While respondents (Round 1, n=21) felt the term autonomy (79\%) adequately described decision-making, stress-related coping strategies and persistence, they also suggested alternative labels included selfdetermination, independence, self-advocacy, self-efficacy, and self-reliance.

One respondent stated, "self-determination (to me) encompasses more than autonomy -it includes a sense of understanding of the world around oneself and the willingness and ability to make informed decisions, even in the case of a child".

Based on the self-determination theory (SDT) literature for children who have disabilities, self-determination is comprised of a triad of competence, autonomy and relatedness (Palmer et al., 2012; Poulsen, Rodger, \& Ziviani, 2006). Professionals and parents can use SDT-related strategies to help a child through self- motivated engagement in activities, positive self-perception of feeling competent and confident, and connecting with others for psychological well-being (Poulsen et al., 2006). For example, a child exhibits self-determination when he independently removes his own hearing aids at night and puts them away appropriately. In Round 2, respondents agreed (89\%) SelfDetermination is the appropriate descriptive term.

Goals. Results from Round 1 indicated respondents (n=20) agreed (86\%) Goals describes child well-being as it relates to language achievement, communication outcomes, and 
employment objectives. However, respondents provided alternatives to the descriptor Goals, and suggested, aspirations, planning, goal-setting, positive perspectives, outcomes, planning, and future orienting. In Round 2, the respondents $(\mathrm{n}=18)$ chose between the descriptors Outcomes (44\%) and Goals (56\%).

Respondents stated, "Because this relates to well-being, outcomes seem clearer" and, "Usually parents do not have such structured goals for their children. Often parents talk in terms of desired outcomes" and, "I know what you mean but usually parents do not have such structured goals for their children".

One participant noted:

The two terms are very different in meaning and their appropriateness depends upon the processes which should be emphasized. "Outcomes" implies achievement, regardless of the aspiration, intention, the journey itself. "Goals" is open about whether or not they are achieved but, crucially, for me, emphasises the aspiration, desire and experience more than the thing which is attained. Goals seems to me the better term by far.

The respondents stated a Goal is something that the child is trying to do or achieve; and Outcome is something that happens as a result of an activity. Outcome is used in education health and care plans, and clinical care practice. For children who are D/HH, an intervention, interaction or treatment may be successful or revised based on the clinical outcome. Ultimately, this framework is for parents involved in peer support. An organization may want to measure an outcome in parent-to-parent support, but from a parental perspective, Goals best reflects the child's journey and is a term parents may prefer. 


\section{Well-Being: Child}

Participation is the child's involvement in hearing and Deaf communities, leisure and extracurricular activities, daycare/school, and ventures with family and friends.

Self-determination for the child who is $\mathrm{D} / \mathrm{HH}$ is self-motivation, positive self-perception, and meaningful relationships.

Goals are the language and communication outcomes, social and psychosocial aspirations and educational and employment objectives and achievements.

\subsubsection{Parent and Family Well-being}

For parent and family well-being, the learning parent(s) need Emotional and Relational support. In the first version of the conceptual framework, Adaptational support was believed to be a primary influence on parent and family well-being. While stakeholders (Round 1, n=20) agreed (84\%) adaptation is a vital component for productive family relationships, and an underpinning component of adapting to surfacing and challenging situations, they recommend adaptation is better suited to the construct Competence and Confidence. Therefore the components of Parent and Family Well-Being in the second version of the framework include (a) emotional support, and (b) relational support.

Emotional Support. Respondents (Round 1, n=20) agreed (95\%) the descriptor term Emotional Support describes parent-to-parent support that offers psychological benefit. Suggestions were incorporated into a revised definition.

Relational Support. Respondents (Round 1, n=20) accepted (95\%) the descriptor Relational Support describes bonding with the child, family functioning, family and marital/conjugal cohesiveness, interaction and communication between family members. One respondent "would prefer 'parental cohesiveness' rather than reference to marital or 
conjugal relationships. Even when parents are separated they can still achieve cohesiveness in their parenting". With qualitative input from Rounds 1 and 2, revisions were made to the definition.

\section{Well-Being: Parent and Family}

Emotional Support offers psychological benefit such as coping, acceptance, hopefulness, self-reliance and confidence, readiness to engage in response to potential grief, loneliness, vulnerability and perceived stigma.

Relational Support provides well-being related to family functioning. Family functioning includes bonding with the child, family and parental cohesiveness, and communication between family members. Community interaction is involvement in community and cultural networks, friends and religious institutions.

\subsubsection{Knowledge}

The framework of parent-to-parent support illustrates that empowerment and well-being advances Knowledge. International consultation refined the constructs of Knowledge in the infographic. Knowledge includes (a) advocacy, (b) system navigation and transition, and (c) education. 


\section{Figure 5: Constructs and Components of Knowledge}

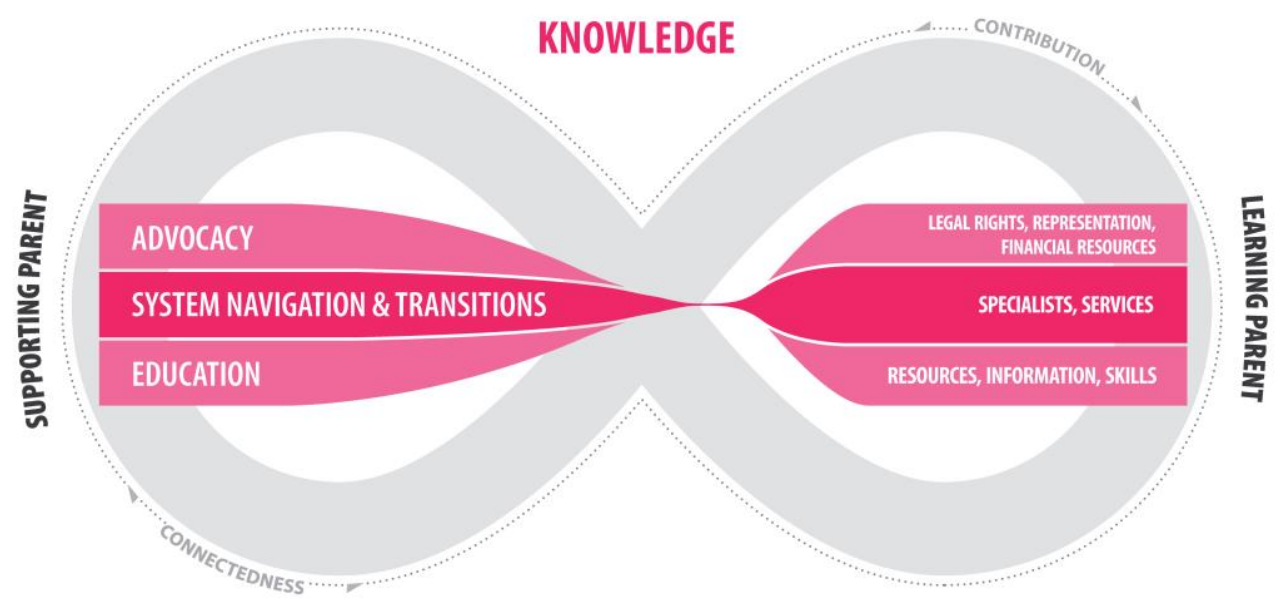

\subsubsection{Advocacy}

Legal Rights. Respondents (Round 1, n=21) reached consensus (91\%) on this descriptive term, and although other descriptors, regulation or legislation, were suggested, the investigators believe that Legal Rights is a better descriptor that parents in most countries may understand. Legal Rights remains the term to describe this component.

Financial Resources (previously Funding). Respondents ( $\mathrm{n}=21)$ in Round 1 demonstrated strong consensus $(87 \%)$ for the descriptor Funding. However, written comments recommended financial services, financial support, funding and resources, provisions, and entitlements as better descriptive terms to Funding. Experts (Round 2, $\mathrm{n}=16)$ agreed (89\%) Financial Resources was the best descriptor.

Representation. Respondents (Round 1, $\mathrm{n}=21$ ) reached consensus $(83 \%)$ that Representation was an appropriate descriptor. However, qualitative data revealed a potential preference for the descriptive term Advocate. Respondents stated, "advocate definition - one stands in the place of or on behalf of...." and, "I think the terms have 
different connotations at different levels and for different purposes. Advocacy has a role, but depending on the end goal, the term representation may be less adversarial and more likely to enhance collaboration to support the child and family".

Respondents emphasized, "representation is too weak" and, "advocate implies a stronger, more focused interaction than representation". Other comments indicated the term Representation as a component of Advocacy may better describe the continuum of advisory engagement of the supporting parent to the learning parent. In addition to written comments related to descriptor terms, one respondent commented, "In the [country] context, 'provincial' and 'federal' are meaningless. Could 'regional' and 'national' be reflected somewhere?" Based on respondent input, there is a revised definition of Representation.

\section{Advocacy Knowledge}

Legal Rights are the laws, regulations, legislation and government policies related to human rights, child's rights, and special education laws.

Financial Resources is financial assistance, insurance, government funding, entitlements and not-for-profit or voluntary sector supplements

Representation refers to peer advocate, parental consultant, and advisor at the community, regional and national levels.

\subsubsection{System Navigation and Transition}

Respondents suggested the magnitude and impact of Transitions on families raising children who are $\mathrm{D} / \mathrm{HH}$ placed this descriptor term at the level of a construct deserving placement as a main topic heading with System Navigation. One respondent remarked, 
"transitional services are a part of the array of services and should be included under services. Special attention may be warranted to transitional stages due to the difficulty parents' encounter as kids move across systems/providers".

The experts emphasized empathetic and action-oriented peer support is crucial during times of System Navigation and Transition.

Specialists (previously Professionals). The panel (Round 1, n=21) agreed (89\%) that Professionals was an appropriate descriptor term; however, respondents also suggested the descriptor Providers. In Round 2, written comments responded negatively to both descriptors Professionals and Providers. Respondents stated, "do not like provider...we are professionals" and, "providers seems appropriately broad" and, "providers does not (in my mind) capture the notion that the individuals are specialists" and, "professionals can be disconnecting".

As an alternative to Professionals and Providers, one respondent stated, "I like 'specialists' as this indicates a high level of knowledge. A professional has earned a degree or certification, but may not be a specialist. With our low-incidence population I prefer 'specialist' which, I think, implies the person is a professional". A specialist is a person who concentrates on a particular subject or activity, and is highly skilled in a specific field. The role of the supporting parent in a parent-to-parent framework is to assist with system navigation and transitions, and provide awareness of specialists and the service-provision of specialists (professional or otherwise).

Services. Participants (Round 1, $\mathrm{n}=21$ ) rated the term Services as appropriate (94\%). Comments suggested the inclusion of services outside the D/HH community:

Other types of (not necessarily professional or deafness-specific) support systems, such as organisations for persons with disabilities, self-help communities, religious organisations, etc. Unless you consider these to be "outside the system". But still, I think "knowledge" about these resources should be included somewhere in the model. 
The supporting parent has the knowledge of services and community resources to assist parents with system navigation and transitions.

\section{System Navigation \& Transition}

Specialists refers to the supporting parent's knowledge during system navigation and transitions to coordinate care with specialists, collaborate with stakeholders, provide a roadmap of care, and facilitate understanding of the role of the specialist(s).

Services refer to community resources, health care, school, legal and regional services.

\subsubsection{Education}

Information. Participants $(\mathrm{n}=21)$ noted that insight, context and experience are just as important as Information. The authors agree that life experience is invaluable and the contribution that represents life experience is included in the outside arrows of the infographic labelled Contribution and Connectedness. Information received high agreement (Round 1, 91\%).

Skills. Skills was considered an appropriate descriptor (86\%) by participants (Round 1, $\mathrm{n}=21$ ). Respondent comments provided on descriptors Training and Skills included, "training does not convey partnership in my mind" and, "I like the term 'skills' as acquisition of skills is the outcome for the novice parent. Conversely, training seems to me to be the role of the mentor" and, "I don't see mentor parents as important providers of skills or training; I see their value in provisions of other support. I am not comfortable, actually, with the inclusion of either term in the model". Participants further stated, "I think the term skills is broad enough to cover the intent yet specific enough to communicate the parent is gaining new skills. Training does not necessarily communicate 
this", and, "a skilled parent may transition into the role of mentor parent with appropriate training/supports".

One respondent expressed:

I think for me, you need to clearly keep separate what parent to parent support provides vs. what a professional with a skillset provides. i.e. I don't think most parent to parent models TEACH these skills as much as provide WHERE a family can get access to expertise in these things for example: sign language acquisition (sign language instructors) and hearing aid use (audiologist) would be in the purview of the professional service provision, NOT parent-to-parent support. Though parents might talk about WHERE they can get these services [...] I think there is an imperative line that needs to be drawn about what parent to parent support IS and what it is not!!!

In the peer-reviewed literature, parents with children who have hearing loss are looking for training to develop their skills in important communication areas, and seek out best practice training from clinical care specialists (Hardonk et al., 2011; Jamieson et al., 2011). However, parents indicate that the reality of their situation is that their child may be ineligible or on a waitlist to receive specific instruction, or specialized service may be unavailable (Jamieson et al., 2011). Therefore, parents may not have access to specialists to receive training or practice skills, and this highlights a gap in service delivery. When there is a gap or barrier in service delivery, such as a family placed on a waitlist to learn sign language, the family has an unmet need that requires attention. Parents want the service, and if they cannot receive it from specialists, they will seek direct guidance from a peer to practice skills and promote their child's communication as an interim solution when specialists and specialized services are unavailable. Supporting parents may have the knowledge of skills to offer a learning parent when there is an unmet need in service delivery. 


\section{Education Knowledge}

Information refers to providing accurate, well-balanced and comprehensive information regarding technological and research advancements, and educational, communication and assistive device options.

Skills refer to skill-based instruction and support, such as sign language and deviceappropriate technological skills, as a supplement to specialized services and support.

\subsubsection{Empowerment}

Experts in the consultation process agreed parent-to-parent support positively influences parental Empowerment. Empowerment is a construct and influenced by knowledge and well-being. The original conceptual framework was revised through the consultation process. In addition to the peer-reviewed literature, expert judgment agrees parent-toparent support provides confidence and competence in (1) decision-making, (2) problemsolving, (3) parenting, and (4) adaptation, and (5) engagement.

\section{Figure 6: Constructs and Components of Empowerment}

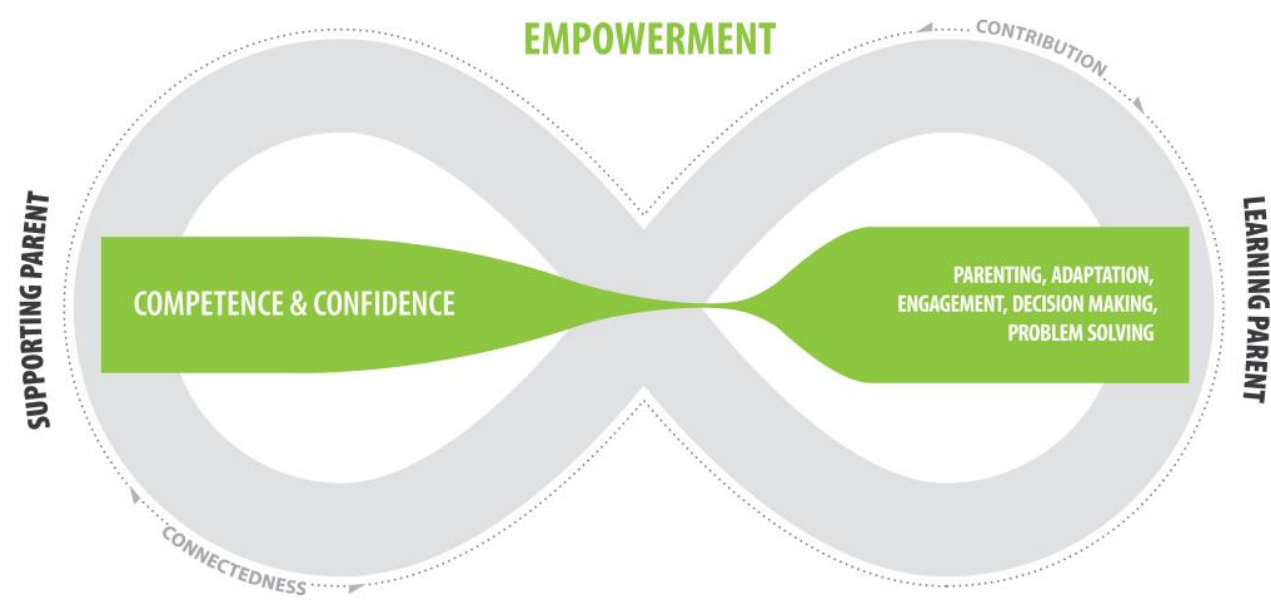




\subsubsection{Confidence and Competence}

Adaptation (includes previous label Self-Awareness). The term Adaptational described a component of parent-to-parent support that helped with adjustment, acceptance, motivation, hopefulness, resilience, learning and optimism. Many participants suggested that although Adaptation fit well within the construct Well-Being, it was more appropriate to include it as a component of Competence \& Confidence. In Round 1, a respondent noted that self-awareness "is a necessary condition in the process of developing and/or having competence $\&$ confidence". The change to combine selfawareness and adaptation as one component of Empowerment received consensus. Participants (Round 2, n=16) chose between Adaptation and Self-awareness, and preferred the descriptor Adaptation (75\%).

Engagement, Decision-making and Parenting. Based on expert (Round 1, n=21) feedback, the highly-rated descriptors Engagement (95\%), Decision-making (92\%) and Parenting (91\%) each received revised definitions in the conceptual framework.

Problem-solving. Respondents (Round 1, n=21) agreed strongly (94\%) that the descriptor Problem-Solving was appropriate. One respondent suggested coping skills as an alternative that reflects a more positive approach. Due to the high consensus for the term problem-solving, the term remained unchanged. 


\section{Empowerment: Confidence and Competence}

Adaptation describes the component of parent-to-parent support that helps with adjustment, acceptance, motivation, hopefulness, resilience, learning and optimism.

Engagement refers to the component of parent-to-parent support that helps with a parent's ability and readiness to optimize their parental role and engage in their child's habilitation process.

Decision-making refers to the component of parent-to-parent support that provides access to knowledge and resources, and the opportunity to cultivate ideas for informed choice and decision-making.

Parenting refers to the component of parent-to-parent support that provides practical parenting skills (e.g. teaching their child to safely cross the street), offers parenting advice to improve parent-child interactions and encourages responsive parenting to support the child's communication development in daily life.

Problem-solving refers to the component of parent-to-parent support that empowers parents to trust their coping abilities and acquire problem-solving skills specific to a child who is deaf or hard of hearing.

The terms from the scoping review and eDelphi studies are presented in Table 4. 
Table 4: Original and revised descriptor terms

\begin{tabular}{|c|c|c|}
\hline & $\begin{array}{l}\text { Stage 1: Results from the } \\
\text { Scoping Review of the } \\
\text { literature }\end{array}$ & $\begin{array}{c}\text { Stage 2: Results from the Delphi } \\
\text { Study }\end{array}$ \\
\hline & Original Descriptor Term & Revised Descriptor Term \\
\hline Title: & $\begin{array}{l}\text { Parent-to-parent support for } \\
\text { parents of children who are } \\
\text { deaf or hard of hearing }\end{array}$ & $\begin{array}{l}\text { Parent-to-parent support for parents of } \\
\text { children who are deaf or hard of } \\
\text { hearing }\end{array}$ \\
\hline Name: & Supporting Parent & Supporting Parent \\
\hline & Learning Parent & Learning Parent \\
\hline $\begin{array}{l}\text { Construct: } \\
\text { Well-Being }\end{array}$ & $\begin{array}{cl}\text { Child } & \\
\text { - Participation } \\
\text { - Autonomy } \\
\text { - Goals }\end{array}$ & $\begin{array}{c}\text { Child } \\
\text { - Participation } \\
\text { - Self-determination } \\
\text { - Goals }\end{array}$ \\
\hline & $\begin{array}{l}\text { Parent and Family } \\
\text { - Emotional } \\
\text { - Relational } \\
\text { - Adaptational }\end{array}$ & $\begin{array}{r}\text { Parent and Family } \\
\text { - Emotional } \\
\text { - Relational }\end{array}$ \\
\hline $\begin{array}{l}\text { Construct: } \\
\text { Knowledge }\end{array}$ & $\begin{array}{l}\text { Advocacy } \\
\text { - Legal Rights } \\
\text { - Funding } \\
\text { - Representation }\end{array}$ & $\begin{array}{l}\text { Advocacy } \\
\text { - Legal Rights } \\
\text { - Financial Resources } \\
\text { - } \text { Representation }\end{array}$ \\
\hline & $\begin{array}{l}\text { System Navigation } \\
\text { - Professionals } \\
\text { - Services } \\
\text { - Transitions }\end{array}$ & $\begin{array}{l}\text { System Navigation \& Transitions } \\
\text { - Specialists } \\
\text { - Services }\end{array}$ \\
\hline & $\begin{array}{l}\text { Education } \\
\text { - Information } \\
\text { - Skills } \\
\text { - Resources }\end{array}$ & $\begin{array}{l}\text { Education } \\
\text { - Information } \\
\text { - Skills }\end{array}$ \\
\hline $\begin{array}{l}\text { Construct: } \\
\text { Empowerment }\end{array}$ & $\begin{array}{l}\text { Competence \& Confidence } \\
\text { - Engagement } \\
\text { - Decision-making }\end{array}$ & $\begin{array}{l}\text { Competence \& Confidence } \\
\text { - Engagement } \\
\text { - Decision-making }\end{array}$ \\
\hline
\end{tabular}




\begin{tabular}{|lll|}
\hline & $\bullet$ Parenting & $\bullet$ Parenting \\
& $\bullet$ Self-awareness & $\bullet$ Adaptation \\
& $\bullet$ Problem-solving & $\bullet$ Problem-solving \\
\hline Relationship: & Mutuality & Contribution \\
& Connectedness & Connectedness \\
\hline
\end{tabular}

\subsection{The conceptual framework as a model}

One way to understand the conceptual framework of parent-to-parent support is through a model that can promote common understanding. This model may help guide change to improve parent-to-parent support for parents of children who are $\mathrm{D} / \mathrm{HH}$. A model can help decision-makers understand context and content better, and facilitate interventions (Exworthy, 2008). Using the model as a problem solving-approach, participants were asked, "how certain are you that this revised conceptual framework has the ability to serve as a model for parent-to-parent support for parents of children who are deaf or hard of hearing?" Twenty of the 21 respondents agreed with significant certainty (Round 1 , $85 \%$ ) that the conceptual framework has the ability to serve as a model for parent-toparent support for parents of children who are D/HH.

Additionally, respondents were certain (Round 1, 89\%; 13/21 $\geq 90$ ) of the applicability of the framework for their or their colleagues' work. Many respondents reported similar comments to this, "it gives the user a sound overview on the most important variables that have to be considered when working in the context of parent-to-parent support". Comments of uncertainty generally focused on environmental factors of parent-to-parent support. One respondent stated, "parents shape meaning-making with regard to Deafness and hearing loss within a discursive context and this is not well-illustrated or documented". The authors agree that the contextual piece of the conceptual framework requires additional investigation. These insightful comments indicate the appropriateness of the experts participating in the study. 
Models must be appropriately organized and designed, in order to be effective. Respondents agreed (Round 1, 16/20 $\geq 80$ ) the conceptual framework was appropriately organized and designed. Some respondents noted that it was "clear and comprehensive" and a "promising model". Respondents offered suggestions to revise the model to better reflect the relationship between the supporting and learning parents. The need for further clarification concerned the representation of the arrows outside of the helix. The outside arrows illustrate three fluid movements and concepts: (1) the parents are grounded in a relationship of Connectedness and Contribution, (2) the learning parent may assume the role of the supporting parent, and (3) the parents may alternative between roles of supporting and learning parents during periods of transition throughout their child's life. The conceptual framework was updated to reflect these suggestions.

Ultimately, the research aimed to establish and demonstrate a foundation for parent-toparent support. The respondents stated with certainty (Round 2, 15/16 $\geq 90 \%$ ) that the conceptual framework was comprehensive and identified the components and constructs of parent-to-parent support for parents who are D/HH. One respondent's comment illustrates an example of hesitation, "generally really logical enhancements....only reservations are those commented on in previous sections in respect of terminology". The integrated mixed method analysis strived to be accountable to both quantitative and qualitative data, and address suggestions for revision. The research aimed to carefully address recommendations, criticism and approval.

Visual presentation of the framework in an informational graphic provided an opportunity for parents, experts, researchers and others to be open and reflective on the components of parent-to-parent support for parents of children who are $\mathrm{D} / \mathrm{HH}$. After completing the questionnaire, one respondent noted:

This exercise has me thinking so much about moments in my life of being supported and supporting other families.... So at the end of the day, there is a component of parent-to-parent support that I believe cannot be written about, researched, labeled, frameworked, or defined. It just is. Maybe it's the listening 
part, the laughter, the tears, the humor and the wine that just got me through to the next thing, the next day, etc. in this thing we are calling a 'framework' it just is.

The knowledge gained through listening to experts express themselves in response to this study may frame possible discussion points for continued research about the intangible spirit outside of a tangible framework when engaging in parent-to-parent support.

\subsection{Other important and relevant information provided by experts}

\subsubsection{Environmental Context}

The challenges of the role of the supporting parents, existing professional and community systems, and the social determinants of health are all too real, and continue to impact the provision of parent-to-parent support. Simply put, the model cannot "stand alone" because the context in which parent-to-parent support is provided is impactful. One respondent stated, "parent-to-parent support is embedded within a large context of various support and provision of care mechanisms such as families, professionals, institutional, D/HH role models, existing community, etc. This could be made more apparent". This comment suggests that the influence of environmental factors impacts how support is given and received. Participants expressed the importance of engaging with the framework in a parent-to-parent support environment. They argued how support is given is necessary to understand what support is provided.

Role of Supporting Parents. Supporting parents assume evolving and non-static roles in a spectrum of parent-to-parent support. Many respondents recommended full or partial training of the supporting parent:

I might add the word 'trained' - Supporting Trained parent. In order for Parent to parent support to be successful, I believe that there is some training involved in one's ability to be able to share one's story without bias, support in context to the supported family's needs, and skills in listening, knowledge of available resources etc. 
Parents can assume many roles in the environment of parent-to-parent support. Emerging from this consultation process is the understanding that there is a continuum of trained and informal parents who provide support to learning parents. Respondents indicated supporting parents require training to know when to refer families to various professional systems (audiology, psychiatry, or care coordinators) to ensure families obtain comprehensive and evidence-based care. The limits and boundaries of the supporting parent was another concern. Respondents' comments suggested the supporting parent operate in a non-judgmental, unbiased, trusting, respectful, honest, confident, holistic, credible and unconditional way. Inclusive parent-to-parent support would consider cultural, spiritual and religious contexts, and help parents find support within selfidentified communities. A theme of equality also emerged. Some participants commented that there is a hierarchy to this relationship; others responded that a hierarchy is disempowering and parents participate in mutual mentoring. Future research would examine viewpoints on the roles, responsibilities and relationships of the supporting and learning parents, including the ethical and legal considerations of the supporting parent as a key factor in Child and Family Centred Care (Shaul, 2014).

Professional Systems. Respondents commented that successful parent-to-parent support requires professional and organizational oversight and support, namely in the government or voluntary sector. In some cases, however, challenges may exist that impede sustainability of parent-to-parent support. The issues relate to not only ensuring access to supporting parents across all degrees of impairment (mild to deaf), but also to language and cultural diversity, including Deaf culture, and geographic (rural, remote and northern) locations. Organization-based parent-to-parent support may not have the appropriate processes, logistical or financial support to offer all families. Parent-to-parent support refers parents to specialists, partners with specialists and professionals, and provides adjunct care to parents. Participants commented there is disconnection between parent-to-parent support and professional systems: 
P2P does not supplant what professionals bring to parents, and professionals should not look at P2P support as a threat and/or somehow taking over 'their' job. when a clear framework of what parents DO provide each other, maybe then more professionals will not be gatekeepers and keep families from one another. i.e. 'the family is not ready to meet other families'.....

One respondent pointedly acknowledged that the model is not supportive to parents if parents are unaware of parent-to-parent support systems:

I think somehow it needs to address/acknowledge how to facilitate this / how parents get connected with one another. What system needs to exist to make this possible? Many parents do not know how to find/access other parents. Many audiologists do not help connect parents with one another.

Additional research may address concerns regarding educating professionals regarding the benefits of parent-to-parent support. The literature and experts refer to an outdated contextual atmosphere of service-provision that provides medically-focused care, rather than a holistic child and family-centred philosophy that recognizes and supports (financial and otherwise) formal and informal parent support as central to child and family well-being.

Community systems: Parent-to-parent support should recognize/continue to recognize and emphasize the importance of community systems, including cultural, kinship and religious ties. However, not all parents may want or need parent-to-parent support, or may prefer support outside of the social identity of raising a child who is $\mathrm{D} / \mathrm{HH}$.

Social Determinants of Health: The conceptual framework does not account for parental income, employment and job security, education levels, early childhood development, food (in)security, social exclusion and social safety networks, gender, race, disabilities, housing and social status, among other important factors that affect parental and child well-being. Parent-to-parent support exists in a wider national and cultural system, and the social determinants of health may impact how parent-to-parent support is provided. 
More work is required to understand the environment of support, and how the interrelated environmental constructs interact with this model of parent-to-parent support for parents of children who are D/HH. Defining an environmental conceptual framework, and the relationship with this model, can help parents, health professionals and organizations target what is needed before developing and organizing intervention programs of parentto-parent support for parents of children who are $\mathrm{D} / \mathrm{HH}$.

\subsection{Discussion}

As parent-to-parent support is increasingly integrated in EHDI programs, best practice suggests that providers "ensure that all families have access to parent-to-parent support from other families of children who are $\mathrm{D} / \mathrm{HH}$ [and] recognize the key role of parent-toparent support in promoting social and emotional well-being for families" (Moeller et al., 2013, p. 430). Academic and non-governmental institutions have identified the need to develop guidelines of parent-to-parent support (Joint Committee on Infant Hearing, 2013; Moeller et al., 2013; Poon \& Zaidman-Zait, 2014). The conceptual framework is an evidence-based model that identifies the constructs, components, and complexities of exchange in parent-to-parent support. For decision-makers in EHDI programs, this conceptual framework has the potential to inform policy-development, and programs.

The framework demonstrates the centrality of parent-to-parent support in EHDI programs, and identifies parent-to-parent support as a tenet of C\&FCC principles. In part, the functionality of the framework may inform C\&FCC evidence-based decisions and provisions for appropriate, efficient and effective resource allocation and program improvements. Participants stated, "we are constantly having to defend parent to parent support as an 'add on' to the journey as opposed to [an] 'essential element' so I think this model will give us the teeth to move parent to parent support into [a] systemic requirement" and, "an advantage of the framework is that providers can better recognize what parents have to offer one another and the value of helping connect parents to other parents. I wonder if providers don't necessarily recognize how important this is" and, "a 
parent-to-parent support conceptual framework has the potential for real-world organizational application in EHDI programs".

There is an ongoing dialogue regarding the value of parent-to-parent support and this framework acknowledges and reinforces the importance of this type of support in EHDI services. It serves as a tool, and provides a problem-solving approach to develop, improve or evaluate existing parent-to-parent support programs.

\subsection{Strengths and Limitations}

There are emerging possibilities and hope for parent-to-parent support in EHDI programs. The participants in this study are particularly invested in the quality of parentto-parent support, and their tacit knowledge provided judgment and opinion, not otherwise reported in the peer-reviewed literature. The eDelphi methodology provided an opportunity to engage in knowledge transfer and arrive at a deeper understanding of the constructs and components of this model. Revisions to the framework's structure, constructs, terms, and definitions led to developing a comprehensive model.

Strengths of the Delphi methodology included knowledgeable participants, international representation and heterogeneity of participants. Many participants are involved in EHDI programs, and may have had daily interactions with parents. They recognized the historic and evolving nature of parent-to-parent support in C\&FCC philosophy and its role in organizations across countries. The integration of peer-reviewed literature and expert representation addressed academic, tacit and experiential knowledge to co-create this conceptual framework.

The study had strong participation rates (Round 1=21; Round 2=17). However, equal participation for both rounds may have been obtained by securing assurance to participation before the study commenced (Balasubramanian \& Agarwal, 2012; Okoli \& Pawlowski, 2004). The researchers decided to protect the voluntary nature of the study and participant anonymity in lieu of required participant commitment. 
Given the realities of the participants' diverse leadership roles, regional and national differences, and, for some participants who acknowledged English was a second language, terms did not always reach quantitative consensus. For many "A" or "B" closed questions, the respondents did not achieve consensus on the labels. To illustrate, when asked to choose between Supporting Parent or Mentoring Parent, respondents indicated a split in preference for Supporting Parent (44\%) and Mentoring Parent (56\%). There was a similar response when asked to choose between Learning Parent (50\%) or Novice Parent (50\%). This reoccurred with Connectedness (50\%) and Connection (50\%); and Goals (56\%) and Outcomes (44\%). Therefore, the researchers relied on qualitative data to determine whether a term was an individual's preference, a neutral response or the most appropriate descriptor based on the peer-reviewed research and common language usage. The researchers understand parents and EHDI programs may prefer to use a different label according to regional preference. Crucially, however, the label definitions had very good agreement. The participants approved the design, and agreed with the comprehensiveness of the framework. The central focus of this research was to provide a solution-seeking framework and tool; therefore, decision-makers are encouraged to modify terms, if desired, to better meet the needs of parents in their region.

\subsection{Conclusion}

This study provides revisions to the conceptual framework of parent-to-parent support developed through the scoping literature review. The conceptual framework of parent-toparent support for parents of children who are $\mathrm{D} / \mathrm{HH}$ is now grounded in the explicit and tacit knowledge of stakeholders, and provides a better understanding of the role of parentto-parent support in EHDI programs. This may have important policy-development and program implications, and enhance evidence-based C\&FCC provisions. The complementary eDelphi and scoping review methodologies provided the best approach to this complex and important topic of parent-to-parent support. 


\subsection{Future Directions}

The revised conceptual framework of parent-to-parent support must exist in the complexities of existing health care and environmental systems. Parent-to-parent support will interact and adapt to current EHDI programs, medical and community systems, government initiatives, cultural, kinship and religious contexts, and other environmental factors. Partnering with the Deaf community is crucial.

The context of how support is provided may be as important as what support is given. Research and design of an evidence-based environmental framework of parent-to-parent support would provide insight into best-practice implementation of the current framework. Environmental context may draw attention to providing parent-to-parent support in a C\&FCC philosophy and consider the legal, moral, and ethical elements of parents, organizations, stakeholders and decision-makers. Further, it may better help researchers understand parent-to-parent support in relation to the social determinants of health in promoting health for parents and families who are raising a child who is $\mathrm{D} / \mathrm{HH}$. Reflecting on parent-to-parent support strategies, this model is a vital research component in understanding the overall complex system of parent-to-parent support for parents of children who are $\mathrm{D} / \mathrm{HH}$.

\subsection{Acknowledgements}

Funding for this work was provided by the Ontario Ministry of Children and Youth Services. We are indebted to the panel of experts for their participation and contributions. 


\subsection{Bibliography}

Åsberg, K. K., Vogel, J. J., \& Bowers, C. A. (2007). Exploring Correlates and Predictors of Stress in Parents of Children Who are Deaf: Implications of Perceived Social Support and Mode of Communication. Journal of Child and Family Studies, 17(4), 486-499. doi:10.1007/s10826-007-9169-7

Bagatto, M., Scollie, S. D., Hyde, M., \& Seewald, R. (2010). Protocol for the provision of amplification within the Ontario infant hearing program. International Journal of Audiology, 49 Suppl 1, S70-9. doi:10.3109/14992020903080751

Balasubramanian, R., \& Agarwal, D. (2012). Delphi Technique- A Review. International Journal of Public Health Dentistry, 3(2), 16-25.

Banach, M., \& Couse, L. J. (2012). Interdisciplinary Co-Facilitation of Support Groups for Parents of Children with Autism: An Opportunity for Professional Preparation. Social Work With Groups, 35(4), 313-329. doi:10.1080/01609513.2012.671103

Banach, M., Iudice, J., Conway, L., \& Couse, L. J. (2010). Family Support and Empowerment: Post Autism Diagnosis Support Group for Parents. Social Work With Groups, 33(1), 69-83. doi:10.1080/01609510903437383

Bardecki, M. J. (1984). Participants' response to the Delphi method: An attitudinal perspective. Technological Forecasting and Social Change, 25, 281-292. doi:10.1016/0040-1625(84)90006-4

Barlow, J. H., \& Ellard, D. R. (2006). The psychosocial well-being of children with chronic disease, their parents and siblings: an overview of the research evidence base. Child: Care, Health and Development, 32(1), 19-31. doi:10.1111/j.13652214.2006.00591.x 
Baum, L. S. (2004). Internet parent support groups for primary caregivers of a child with special health care needs. Pediatric Nursing, 30(5), 381-8, 401. Retrieved from http://www.ncbi.nlm.nih.gov/pubmed/15587531

Bolger, F., \& Wright, G. (2011). Improving the Delphi process: Lessons from social psychological research. Technological Forecasting and Social Change, 78(9), 1500-1513. doi:10.1016/j.techfore.2011.07.007

Bradham, T. S., Houston, K. T., Guignard, G. H., \& Hoffman, J. (2011). Strategic Analysis of Family Support in EHDI Systems. The Volta Review, 111(2), 181-194.

Brown, P.M., Abu Bakar, Z., Rickards, F.W., \& Griffin, P. (2006). Family Functioning, Early Intervention Support, and Spoken Language and Placement Outcomes for Children with Profound Hearing Loss. Deafness and Education International, 8(4), 207-226. doi:10.1002/dei

Caracelli, V. J., \& Greene, J. C. (1993). Data Analysis Strategies for Mixed-Method Evaluation Designs. Educational Evaluation and Policy Analysis, 15(2), 195-207. doi:10.3102/01623737015002195

Colquhoun, H. L., Levac, D., O’Brien, K. K., Straus, S., Tricco, A. C., Perrier, L., ... Moher, D. (2014). Scoping reviews: Time for clarity in definition, methods, and reporting. Journal of Clinical Epidemiology, 67(12), 1291-1294.

doi:10.1016/j.jclinepi.2014.03.013

Dalzell, J., Nelson, H., Haigh, C., Williams, A., \& Monti, P. (2007). Involving families who have deaf children using a Family Needs Survey: A multi-agency perspective. Child Care Health and Development, 33(5), 576-585. doi:10.1111/j.13652214.2007.00761.x

Ecken, P., Gnatzy, T., \& von der Gracht, H. A. (2011). Desirability bias in foresight: Consequences for decision quality based on Delphi results. Technological 
Forecasting and Social Change, 78(9), 1654-1670.

doi:10.1016/j.techfore.2011.05.006

Eleweke, C. J., Gilbert, S., \& Bays, D. (2008). Information about Support Services for Families of Young Children with Hearing Loss : A Review of Some Useful Outcomes and

Exworthy, M. (2008). Policy to tackle the social determinants of health: using conceptual models to understand the policy process. Health Policy and Planning, 23(5), 318 27. doi:10.1093/heapol/czn022

Field, D. a, Miller, W. C., Jarus, T., Ryan, S. E., \& Roxborough, L. (2014). Important elements of measuring participation for children who need or use power mobility: a modified Delphi survey. Developmental Medicine \& Child Neurology, 57, 556-563. doi:10.1111/dmcn.12645

Fitzpatrick, E. (2010). A Framework for Research and Practice in Infant Hearing. Canadian Journal of Speech-Language Pathology and Audiology, 34(1), 25-32.

Fitzpatrick, E., Graham, I. D., Durieux-Smith, A., Angus, D., \& Coyle, D. (2007).

Parents' perspectives on the impact of the early diagnosis of childhood hearing loss. International Journal of Audiology, 46(2), 97-106.

doi:10.1080/14992020600977770

Gill, F. J., Leslie, G. D., Grech, C., \& Latour, J. M. (2013). Using a web-based survey tool to undertake a Delphi study: Application for nurse education research. Nurse Education Today, 33(11), 1322-1328. doi:10.1016/j.nedt.2013.02.016

Goluchowicz, K., \& Blind, K. (2011). Identification of future fields of standardisation: An explorative application of the Delphi methodology. Technological Forecasting and Social Change, 78(9), 1526-1541. doi:10.1016/j.techfore.2011.04.014 
Hardonk, S., Desnerck, G., Loots, G., Van Hove, G., Van Kerschaver, E., Sigurjónsdóttir, H. B., ... Louckx, F. (2011). Congenitally deaf children's care trajectories in the context of universal neonatal hearing screening: a qualitative study of the parental experiences. Journal of Deaf Studies and Deaf Education, 16(3), 305-24. doi:10.1093/deafed/enq055

Hardonk, S., Desnerck, G., Matthijs, L., Loots, G., Hove, G. Van, Kerschaver, E. Van, ... Louckx, F. (2013). Analysing care-related decisions in parents of congenitally deaf children: introduction of an explanatory model. Scandinavian Journal of Disability Research, 15(3), 264-281. doi:10.1080/15017419.2012.703966

Hardonk, S., Matthijs, L., Van Kerschaver, E., \& Vanroelen, C. (2011). From Screening to Care : A Qualitative Analysis of the Parental Experiences Related to Screening and (Re)habilitation Care of Children with Congenital Deafness in Flanders, Belgium. The Volta Review, 111(3), 299-324.

Henderson, R. J., Johnson, A., \& Moodie, S. T. (2014). Parent-to-Parent Support for Parents With Children Who Are Deaf or Hard of Hearing: A Conceptual Framework. American Journal of Audiology, 23(4), 437-48. doi:10.1044/2014_AJA-14-0029

Hoagwood, K. E., Cavaleri, M., Olin, S., Burns, B., Slaton, E., Gruttadaro, D., \& Hughes, R. (2010). Family support in children's mental health: a review and synthesis. Clinical Child and Family Psychology Review, 13(1), 1-45. doi:10.1007/s10567009-0060-5

Holloway, I., \& Todres, L. (2003). The status of method: flexibility, consistency and coherence. Qualitative Research. Thousand Oaks, CA: Sage Publications.

Ireys, H., Chernoff, R., Stein, R., DeVet, K., \& Silver, E. (2001). Outcomes of Community-Based Family-to-Family Support: Lessons Learned From a Decade of 
Randomized Trials. Children's Services, 4(4), 203-216.

doi:10.1207/S15326918CS0404_04

Jackson, C. W. (2011). Family Supports and Resources for Parents of Children Who are Deaf or Hard of Hearing. American Annals of the Deaf, 156(4), 343-362. doi:10.1353/aad.2011.0038

Jackson, C. W., Wegner, J. R., \& Turnbull, A. P. (2010). Family Quality of Life Following Early Identification of Deafness. Language, Speech and Hearing Services in Schools, 41(April), 194-206.

Jamieson, J. R., Zaidman-Zait, A., \& Poon, B. (2011). Family Support Needs as Perceived by Parents of Preadolescents and Adolescents Who are Deaf or Hard of Hearing. Deafness \& Education International, 13(3), 110-130. doi:10.1179/1557069X11Y.0000000005

Joint Committee on Infant Hearing. (2007). Year 2007 position statement: Principles and guidelines for early hearing detection and intervention programs. Pediatrics, 120(4), 898-921. doi:10.1542/peds.2007-2333

Joint Committee on Infant Hearing. (2013). Supplement to the JCIH 2007 position statement: principles and guidelines for early intervention after confirmation that a child is deaf or hard of hearing. Pediatrics, 131(4), e1324-49. doi:10.1542/peds.2013-0008

Keeney, S., Hasson, F., \& McKenna, H. (2006). Consulting the oracle: Ten lessons from using the Delphi technique in nursing research. Journal of Advanced Nursing, 53(2), 205-212. doi:10.1111/j.1365-2648.2006.03716.x

Kerr, S. M., \& McIntosh, J. B. (2000). Coping when a child has a disability: exploring the impact of parent-to-parent support. Child: Care, Health and Development, 26(4), 309-22. Retrieved from http://www.ncbi.nlm.nih.gov/pubmed/10931070 
Larson, R., Munoz, K., DesGeorges, J., Nelson, L., \& Kennedy, S. (2012). Early Hearing Detection and Intervetion: Parent Experiences With the Diagnostic Hearing Assessment. American Journal of Audiology, 21, 91-99

Law, M., King, S., Stewart, D., \& King, G. (2001). The perceived effects of parent-led support groups for parents of children with disabilities. Physical \& Occupational Therapy in Pediatrics, 21(2-3), 29-48. Retrieved from http://www.ncbi.nlm.nih.gov/pubmed/12029852

Lederberg, A. R., \& Golbach, T. (2002). Parenting stress and social support in hearing mothers of deaf and hearing children: a longitudinal study. Journal of Deaf Studies and Deaf Education, 7(4), 330-45. doi:10.1093/deafed/7.4.330

Levac, D., Colquhoun, H., \& O’Brien, K. K. (2010). Scoping studies: advancing the methodology. Implementation Science, 5, 69. doi:10.1186/1748-5908-5-69

Mathiesen, A. M., Frost, C. J., Dent, K. M., \& Feldkamp, M. L. (2012). Parental needs among children with birth defects: defining a parent-to-parent support network. Journal of Genetic Counseling, 21(6), 862-72. doi:10.1007/s10897-012-9518-6

Mitchell, R. E., \& Karchmer, M. A. (2004). Chasing the Mythical Ten Percent: Parental Hearing Status of Deaf and Hard of Hearing Students in the United States. Sign Language Studies, 4(2), 138-163. doi:10.1353/sls.2004.0005

Moeller, M. P., Carr, G., Seaver, L., Stredler-Brown, A., \& Holzinger, D. (2013). Best practices in family-centered early intervention for children who are deaf or hard of hearing: an international consensus statement. Journal of Deaf Studies and Deaf Education, 18(4), 429-45. doi:10.1093/deafed/ent034

Muñoz, K., Blaiser, K., \& Barwick, K. (2013). Parent hearing aid experiences in the United States. Journal of the American Academy of Audiology, 24(1), 5-16. doi:10.3766/jaaa.24.1.2 
Okoli, C., \& Pawlowski, S. D. (2004). The Delphi method as a research tool: an example, design considerations and applications. Information \& Management, 42(1), 15-29. doi:10.1016/j.im.2003.11.002

Olin, S. S., Williams, N., Pollock, M., Armusewicz, K., Kutash, K., Glisson, C., \& Hoagwood, K. E. (2014). Quality Indicators for Family Support Services and Their Relationship to Organizational Social Context. Administration and Policy in Mental Health, 4(1), 43-54. doi:10.1007/s10488-013-0499-z

Palmer, S. B., Summers, J. A., Brotherson, M. J., Erwin, E. J., Maude, S. P., StroupRentier, V., ... Haines, S. J. (2012). Foundations for Self-Determination in Early Childhood: An Inclusive Model for Children With Disabilities. Topics in Early Childhood Special Education, 33(1), 38-47. doi:10.1177/0271121412445288

Poon, B. T., \& Zaidman-Zait, A. (2014). Social Support for Parents of Deaf Children: Moving Toward Contextualized Understanding. Journal of Deaf Studies and Deaf Education, 19(2), 176-88. doi:10.1093/deafed/ent041

Poulsen, A. A., Rodger, S., \& Ziviani, J. M. (2006). Understanding children's motivation from a self-determination theoretical perspective: Implications for practice. Australian Occupational Therapy Journal, 53, 78-86. doi:10.1111/j.14401630.2006.00569.x

Resch, J. A., Mireles, G., Benz, M. R., Grenwelge, C., Peterson, R., \& Zhang, D. (2010). Giving parents a voice: A qualitative study of the challenges experienced by parents of children with disabilities. Rehabilitation Psychology, 55(2), 139-50. doi:10.1037/a0019473

Roulston, K. (2008a). Closed question. In L. Given (Ed.), The SAGE encyclopedia of qualitative research methods. (p. 85). Thousand Oaks, CA: SAGE Publications, Inc. doi: http://dx.doi.org.proxy1.lib.uwo.ca/10.4135/9781412963909.n46 
Roulston, K. (2008b). Open-ended question. In L. Given (Ed.), The SAGE encyclopedia of qualitative research methods. (pp. 583-584). Thousand Oaks, CA: SAGE Publications, Inc. doi: http://dx.doi.org.proxy1.lib.uwo.ca/10.4135/9781412963909.n300

Runyan, D. K., Dunne, M. P., Zolotor, A. J., Madrid, B., Jain, D., Gerbaka, B., ... Youssef, R. M. (2009). The development and piloting of the ISPCAN Child Abuse Screening Tool-Parent version (ICAST-P). Child Abuse and Neglect, 33(11), 826832. doi:10.1016/j.chiabu.2009.09.006

Salkind, N.J. (Ed.). (2010) Encyclopedia of research design. Thousand Oaks, CA: SAGE Publications, Inc. doi: http://dx Salkind, N. J. (Ed.). (2010). Encyclopedia of research design. Thousand Oaks, CA: SAGE Publications, Inc. doi: http://dx.doi.org.proxy1.lib.uwo.ca/10.4135/9781412961288

Sandelowski, M. (2000). Combining qualitative and quantitative sampling, data collection, and analysis techniques in mixed-method studies. Research in Nursing \& Health, 23(3), 246-255. doi:10.1002/1098-240x(200006)23:3<246::aidnur9>3.0.co;2-h

Sandelowski, M. (2014). Unmixing mixed-methods research. Research in Nursing and Health, 37(1), 3-8. doi:10.1002/nur.21570

Shaul, R. (2014). Paediatric Patient and Family-Centred Care: Ethical and Legal Issues. International Library of Ethics, Law, and the New Medicine, 57, 1-358. doi:10.1007/978-1-4939-0323-8

Sipal, R. F., \& Sayin, U. (2012). Impact of Perceived Social Support and Depression on the Parental Attitudes of Mothers of Children Who are Deaf. Journal of Child and Family Studies, 22(8), 1103-1111. doi:10.1007/s10826-012-9672-3

Skulmoski, G. J., Hartman, F. T., \& Krahn, J. (2006) The Delphi method for graduate. Journal of Information Technology Education, 6, 1-21. 
Tume, L. N., van den Hoogen, A., Wielenga, J. M., \& Latour, J. M. (2014). An Electronic Delphi Study to Establish Pediatric Intensive Care Nursing Research Priorities in 20 European Countries. Pediatric Critical Care Medicine, 15(5), 1. doi:10.1097/PCC.0000000000000109

Yap, M. B. H., Fowler, M., Reavley, N., \& Francis Jorm, A. (2015). Parenting Strategies for Reducing the Risk of Childhood Depression and Anxiety Disorders: a Delphi Consensus Study. Journal of Affective Disorders, 183, 330-338. doi:10.1016/j.jad.2015.05.031 


\section{Chapter 4}

\section{Conclusion of integrated thesis}

\subsection{Introduction}

Early Hearing Detection and Intervention (EHDI) programs that successfully support parents are comprehensive; they reach out to parents, and provide parent-to-parent support as a practical strategy to support children with hearing loss. Parent-to-parent support networks provide authentic peer parental partnerships, and help to build positive relationships with professionals and clinicians who are engaged and concerned for the well-being of their child who is D/HH (Moeller et al, 2013). The results from this research produced an initial conceptual framework of parent-to-parent support for parents of children who are D/HH (Henderson, Johnson, \& Moodie, 2014) as well as a revised version after receiving expert feedback acquired through an eDelphi study. The foundational characteristics differentiate parent-to-parent support from professionalparent support, and the research stresses the importance of both support systems to work in tandem.

This research project used a dual-stage scoping review to define the contribution of parent-to-parent support for parents who have a child who is $\mathrm{D} / \mathrm{HH}$. Parents indicated there is a quality of support when learning from a parent who is also raising a child with hearing loss that cannot be duplicated by professionals. International consensus statements confirm parent-to-parent support is essential for families and children to thrive, and recommend access to and provision of parent-to-parent as an element of a comprehensive EHDI program (Joint Committee on Infant Hearing, 2013; Moeller, Carr, , Seaver, Stredler-Brown, \& Holzinger, 2013). These position statements may be momentous for altering the perception of parent-to-parent support in EHDI programs. Historically considered voluntary or secondary, parent-to-parent support is now seen as an essential component of a comprehensive EHDI program. 
There was a gap in the peer-reviewed literature: what is parent-to-parent support for parents of children who are $\mathrm{D} / \mathrm{HH}$ ?

Parent support takes many forms, and numerous not-for-profits offer differing types of parent-to-parent support. However, a guiding and evidence-based model of parent-toparent support was absent in the literature. The research had to start at the foundation of support. Instead of focusing on "how support was given", the research asked, "what support is needed"? This would have a significant impact on the literature in parent-toparent support. Therefore, the conceptual framework was developed and defined by the research question, What are the Constructs and Components of a Conceptual Framework of Parent-to-Parent Support for Parents of Children who are Deaf or Hard of Hearing $(\mathrm{D} / \mathrm{HH})$ ?

The main findings are chapter specific and detailed in two consecutive articles. Chapter 2: Parent-to-Parent Support for Parents of Children who are Deaf or Hard of Hearing: A Conceptual Framework is a peer-reviewed publication and presents the findings from a scoping review of the $\mathrm{D} / \mathrm{HH}$ and childhood disability literature. Chapter 3: A Revised Conceptual Framework of Parent-to-Parent Support for Parents of Children who are Deaf or Hard of Hearing: A modified Delphi Study completed the consultation component, and the second stage of the scoping review. The second study sharpened the original model, and identified areas of improvement in constructs, components, labels, definitions, relationships, and design of the conceptual framework. The culmination of these research studies are presented in a revised infographic model

\section{Findings from the Dual-stage Scoping Review:}

The framework and infographic may be strengthened with a consultative document: Labels and Definitions: A Guide to Understanding the Conceptual Framework of Parentto-Parent Support for Parents of Children who are Deaf or Hard of Hearing. 
Table 5. Labels and Definitions: A Guide to Understanding the Conceptual

Framework for Parent-to-Parent Support for Parents of Children who are Deaf or Hard of Hearing

\begin{tabular}{|c|c|}
\hline LABELS & DEFINITIONS \\
\hline $\begin{array}{l}\text { Parent-to-Parent } \\
\text { Support }\end{array}$ & $\begin{array}{l}\text { Parent-to-Parent Support is the mutual support of parents who have } \\
\text { the lived experience of raising a child who is D/HH. }\end{array}$ \\
\hline \multicolumn{2}{|c|}{ Supporting and Learning Parents } \\
\hline Supporting Parent & $\begin{array}{l}\text { The Supporting Parent is a coaching, nurturing and encouraging parent } \\
\text { who has the lived experience of a child with hearing loss. }\end{array}$ \\
\hline Learning Parent & $\begin{array}{l}\text { The Learning Parent is a parent new to or inexperienced in a situation } \\
\text { of raising a child who is } \mathrm{D} / \mathrm{HH} \text {. (For example, the parent may have a } \\
\text { child recently diagnosed as D/HH or may be experiencing a transition } \\
\text { in the child or family's life.) }\end{array}$ \\
\hline \multicolumn{2}{|c|}{ Contribution and Connectedness } \\
\hline Contribution & $\begin{array}{l}\text { Contribution is community relationships (D/HH role models, D/HH } \\
\text { community, peers, social groups, and family members), engagement } \\
\text { and development through the sharing of ideas, information and } \\
\text { resources. }\end{array}$ \\
\hline Connectedness & $\begin{array}{l}\text { Connectedness is the affirmation, validation, comfort, and sense of } \\
\text { belonging found in the emotional connection of sharing a social } \\
\text { identity, anecdotal and life stories. }\end{array}$ \\
\hline
\end{tabular}




\begin{tabular}{|c|c|}
\hline \multicolumn{2}{|l|}{ WELL-BEING } \\
\hline \multicolumn{2}{|l|}{ Child Well-Being } \\
\hline Participation & $\begin{array}{l}\text { Participation is the child's involvement in hearing and Deaf } \\
\text { communities, leisure and extracurricular activities, daycare/school, } \\
\text { and ventures with family and friends. }\end{array}$ \\
\hline Self-determination & $\begin{array}{l}\text { Self-determination for the child who is } \mathrm{D} / \mathrm{HH} \text { is self-motivation, } \\
\text { positive self-perception, and meaningful relationships. }\end{array}$ \\
\hline Goals & $\begin{array}{l}\text { Goals are the language and communication outcomes, social and } \\
\text { psychosocial aspirations and educational and employment } \\
\text { objectives and achievements. }\end{array}$ \\
\hline \multicolumn{2}{|c|}{ Parent and Family Well-being } \\
\hline Emotional Support & $\begin{array}{l}\text { Emotional Support offers psychological benefit such as coping, } \\
\text { acceptance, hopefulness, self-reliance and confidence, readiness to } \\
\text { engage in response to potential grief, loneliness, vulnerability and } \\
\text { perceived stigma. }\end{array}$ \\
\hline Relational Support & $\begin{array}{l}\text { Relational Support provides well-being related to family } \\
\text { functioning. Family functioning includes bonding with the child, } \\
\text { family and parental cohesiveness, and communication between } \\
\text { family members. Community interaction is involvement in } \\
\text { community and cultural networks, friends and religious } \\
\text { institutions. }\end{array}$ \\
\hline
\end{tabular}




\section{KNOWLEDGE}

\begin{tabular}{|c|c|}
\hline Legal Rights & $\begin{array}{l}\text { Legal Rights are the laws, regulations, legislation and government } \\
\text { policies related to human rights, child's rights, and special } \\
\text { education laws. }\end{array}$ \\
\hline Financial Resources & $\begin{array}{l}\text { Financial Resources is financial assistance, insurance, government } \\
\text { funding, entitlements and not-for-profit or voluntary sector } \\
\text { supplements }\end{array}$ \\
\hline Representation & $\begin{array}{l}\text { Representation refers to peer-advocate, parental consultant, and } \\
\text { advisor at the regional and national levels. }\end{array}$ \\
\hline
\end{tabular}

System Navigation \& Transition

\begin{tabular}{|l|l} 
Specialists & $\begin{array}{l}\text { Specialists refers to the supporting parent's knowledge during } \\
\text { system navigation and transitions to coordinate care with } \\
\text { specialists, collaborate with stakeholders, provide a roadmap of } \\
\text { care, and facilitate understanding of the role of the specialist(s). }\end{array}$ \\
\hline Services & $\begin{array}{l}\text { Services refer to community resources, health care, school, legal } \\
\text { and regional services. }\end{array}$
\end{tabular}

Education Knowledge

Information

Information refers to providing accurate, well-balanced and comprehensive information regarding technological and research advancements, and educational, communication and assistive device options.

Skills

Skills refer to skill-based instruction and support, such as sign 


\section{EMPOWERMENT}

\section{Confidence \& Competence}

\begin{tabular}{|c|c|}
\hline Adaptation & $\begin{array}{l}\text { Adaptation describes the component of parent-to-parent support } \\
\text { that helps with adjustment, acceptance, motivation, hopefulness, } \\
\text { resilience, learning and optimism. }\end{array}$ \\
\hline Engagement & $\begin{array}{l}\text { Engagement refers to the component of parent-to-parent support } \\
\text { that helps with a parent's ability and readiness to optimize their } \\
\text { parental role and engage in their child's habilitation process. }\end{array}$ \\
\hline Decision-making & $\begin{array}{l}\text { Decision-making refers to the component of parent-to-parent } \\
\text { support that provides access to knowledge and resources, and the } \\
\text { opportunity to cultivate ideas for informed choice and decision- } \\
\text { making. }\end{array}$ \\
\hline Parenting & $\begin{array}{l}\text { Parenting refers to the component of parent-to-parent support that } \\
\text { provides practical parenting skills (e.g. teaching their child to } \\
\text { safely cross the street), offers parenting advice to improve parent- } \\
\text { child interactions and encourages responsive parenting to support } \\
\text { the child's communication development in daily life. }\end{array}$ \\
\hline Problem-solving & $\begin{array}{l}\text { Problem-solving refers to the component of parent-to-parent } \\
\text { support that empowers parents to trust their coping abilities and } \\
\text { acquire problem-solving skills specific to a child who is deaf or } \\
\text { hard of hearing. }\end{array}$ \\
\hline
\end{tabular}




\subsection{Summary}

International consensus documents urged decision-makers to become attuned to the value of parent-to-parent support, and find ways to incorporate this support in EHDI programs. Yet, how can a decision-maker consider parent-to-parent support without a common understanding of the role of parent-to-parent support? The conceptual framework developed during this thesis period contributes to developing concepts of parent-to-parent support for parents of children who are D/HH to be explored, debated and discussed. The model may be useful during the various practical stages of planning, implementing and evaluating a parent-to-parent support program or intervention in a comprehensive EHDI programs.

There are many opportunities for the conceptual framework to have meaningful impact in theory, research and practice. The conceptual framework provides definitions and the relationships, constructs and components of parent-to-parent support. As academic literature, the research addresses a gap in the peer-reviewed literature, and provides a previously absent evidence-based model in response to the gap. The conceptual framework responds to a high-priority subject matter, which was identified in the international arena. It fosters an international common understanding, and clarifies the foundational characteristics of parent-to-parent support. The research contributes to the literature and overall understanding of the role of parent-to-parent support in family and child centred care philosophy.

For EHDI programs, a conceptual framework may assist decision-makers in policy and decision-making. The research paves a way to accepting parent-to-parent support as a necessary component of EHDI programs, and confirms the relevance and importance of parent-to-parent support. This research positions parent-to-parent support as an asset to an organization, worthy of funding and recognition. The framework can also be used as a tool, providing guidance that can be used to develop, improve, and/or monitor/evaluate parent-to-parent support programs. 
For parents and professionals, the framework is presented in a clear and concise informational graphic together with a supplement manual of labels and definitions. The aim is that any parent can use this framework to interact and co-learn with families within, or outside of, EHDI program or voluntary organizations.

\subsection{Future implications}

One of the benefits of this conceptual framework is that it may build awareness of biases and assumptions about parent-to-parent support, which may impact access to and provision of support. The hope is that it provides a path for care and informs policy and programming decisions regarding best practice parent-to-parent support. This framework may provide a foundation to further explore how research can be used to contribute to families and communities who are raising children with hearing loss.

A worthwhile and necessary exploration for future research consideration would be an exploration of the context in which parent-to-parent support is delivered. What are the moral, ethical, legal considerations when providing parent-to-parent support? What are the roles of the supporting and learning parents? What are the influences of the social determinants of health? The environment or context of support may be as important as the content of support. Therefore, an important subsequent research study would respond to the question, What are the constructs and components of the environment of parent-toparent support?

The two-year research project focused on the conceptualization of parent-to-parent support. It provides a good foundation, but it also emphasizes researchers and decisionmakers must continue to listen to parents beyond this framework, and allow the model to organically improve and evolve. Conversations with families may lead to new ideas about parent-to-parent support, and continue to propel forward this research. 


\subsection{Bibliography}

Moeller, M. P., Carr, G., Seaver, L., Stredler-Brown, A., \& Holzinger, D. (2013). Best practices in family-centered early intervention for children who are deaf or hard of hearing: an international consensus statement. Journal of Deaf Studies and Deaf Education, 18(4), 429-45. doi:10.1093/deafed/ent034

Joint Committee on Infant Hearing. (2013). Supplement to the JCIH 2007 position statement: principles and guidelines for early intervention after confirmation that a child is deaf or hard of hearing. Pediatrics, 131(4), e1324-49.

doi:10.1542/peds.2013-0008 


\section{Appendices}

\section{Appendix A: Western Research Ethics Approval}

Festern

Research
Research Ethics

Western University Health Science Research Ethics Board

HSREB Delegated Initial Approval Notice

Principal Investigator: Dr. Sheila Moodie

Department \& Institution: Health SciencesiCommunication Sciences \& Disorders, Western University

HSREB File Number: 105812

Study Title: Evaluation of a conceptual framework of parent-to-parent support for parents of children who are deaf or hard of hearing

Sponsor:

HSREB Initial Approval Date: October 16, 2014

HSREB Expiry Date: December 31, 2015

Documents Approved and/or Received for Information:

Docin

or Received for Information:
\begin{tabular}{|l|l|}
\hline Comments & Version Date \\
\hline Survey Link - https://www.surveymonkey.com/s/Evaluation_Conceptual_Framework & $2014 / 09 / 22$ \\
\hline recruitment (email) & $2014 / 09 / 16$ \\
\hline Contains Letter of Information and Survey & $2014 / 09 / 16$ \\
\hline
\end{tabular}

Instruments

Recruitment Items

recruitment (email)

Contains Letter of Information and Surve

2014/09/16

The Western University Health Science Research Ethics Board (HSREB) has reviewed and approved the above named study, as of the HSREB Initial Approval Datenoted above.

HSREB approval for this study remains valid until the HSREB Expiry Date noted above, conditional to timely submission and acceptance of HSREB ContinuingEthics Review. If an Updated Approval Notice is required prior to the HSREB Expiry Date, the Principal Investigator is responsible for completing andsubritting an HSREB Updated Approval Form in a timely fashion.

The Westem University HSREB operates in compliance with the Tri-Council Policy Statement Ethical Conduct for Research Involving Humans (TCPS2), theInternational Conference on Harmonization of Technical Requirements for Registration of Pharmaceuticals for Human Use Guideline for Good Climical Pacilich

Members of the HSREB who are named as Investigators in research studies do not participate in discussions related to, nor vote on such studies when theyare presented to the REB.

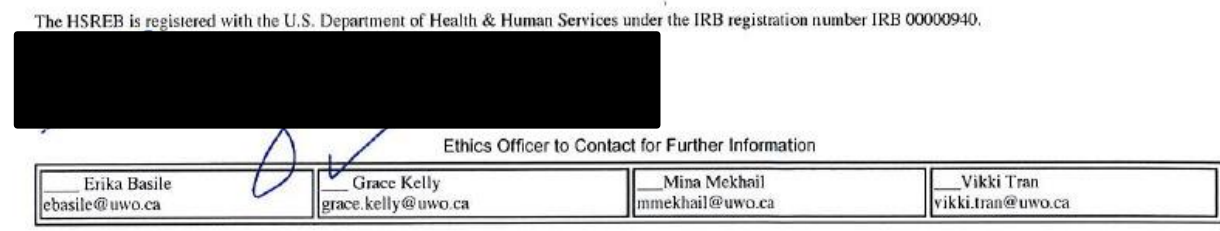

This is an official document. Please retain the original in your files. 


\section{Appendix B: Supplemental Material for Scoping Review Study (Chapter 2)}

This material is intended as supplementary. This table lists the 39 articles included in this scoping review, and identifies the constructs and components extracted from the articles.

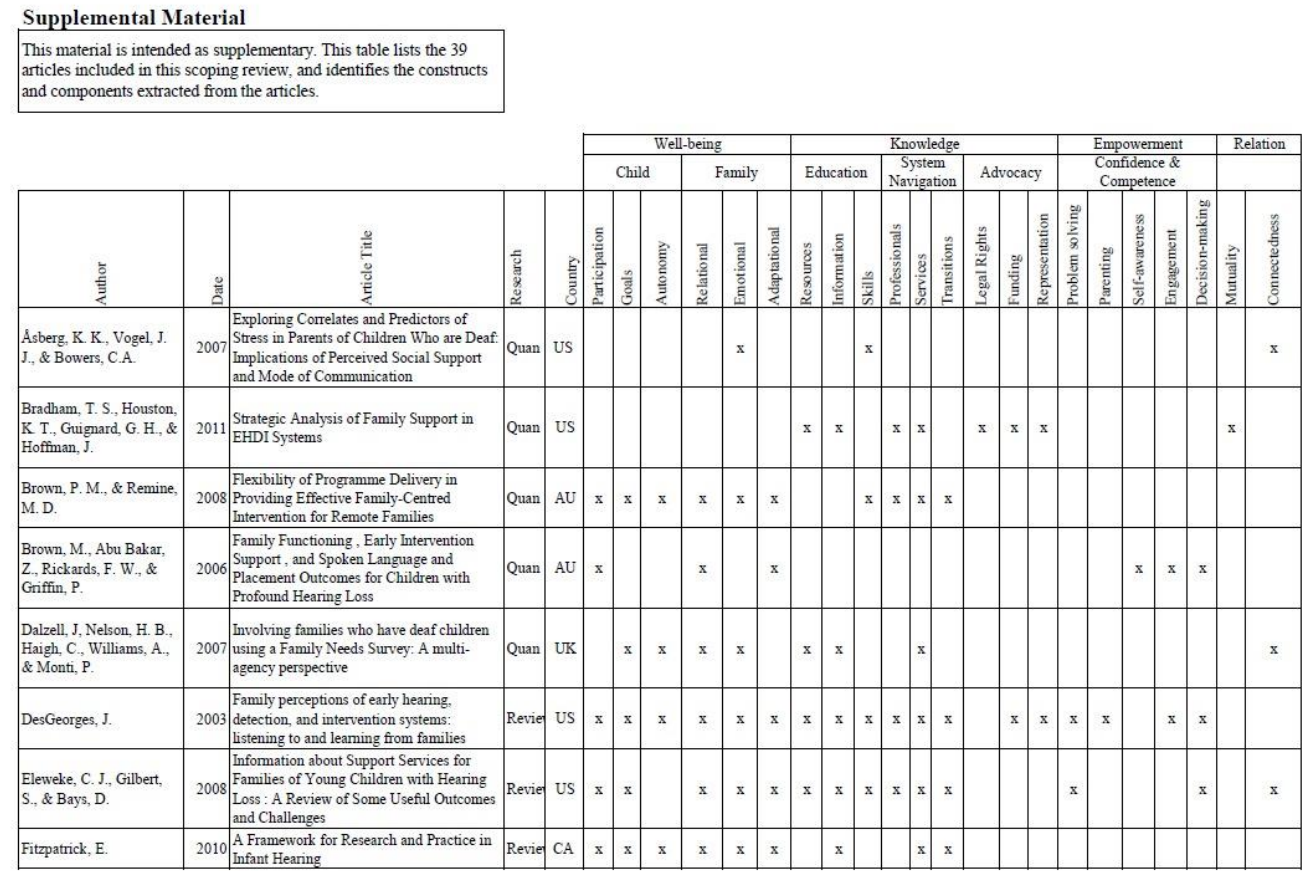




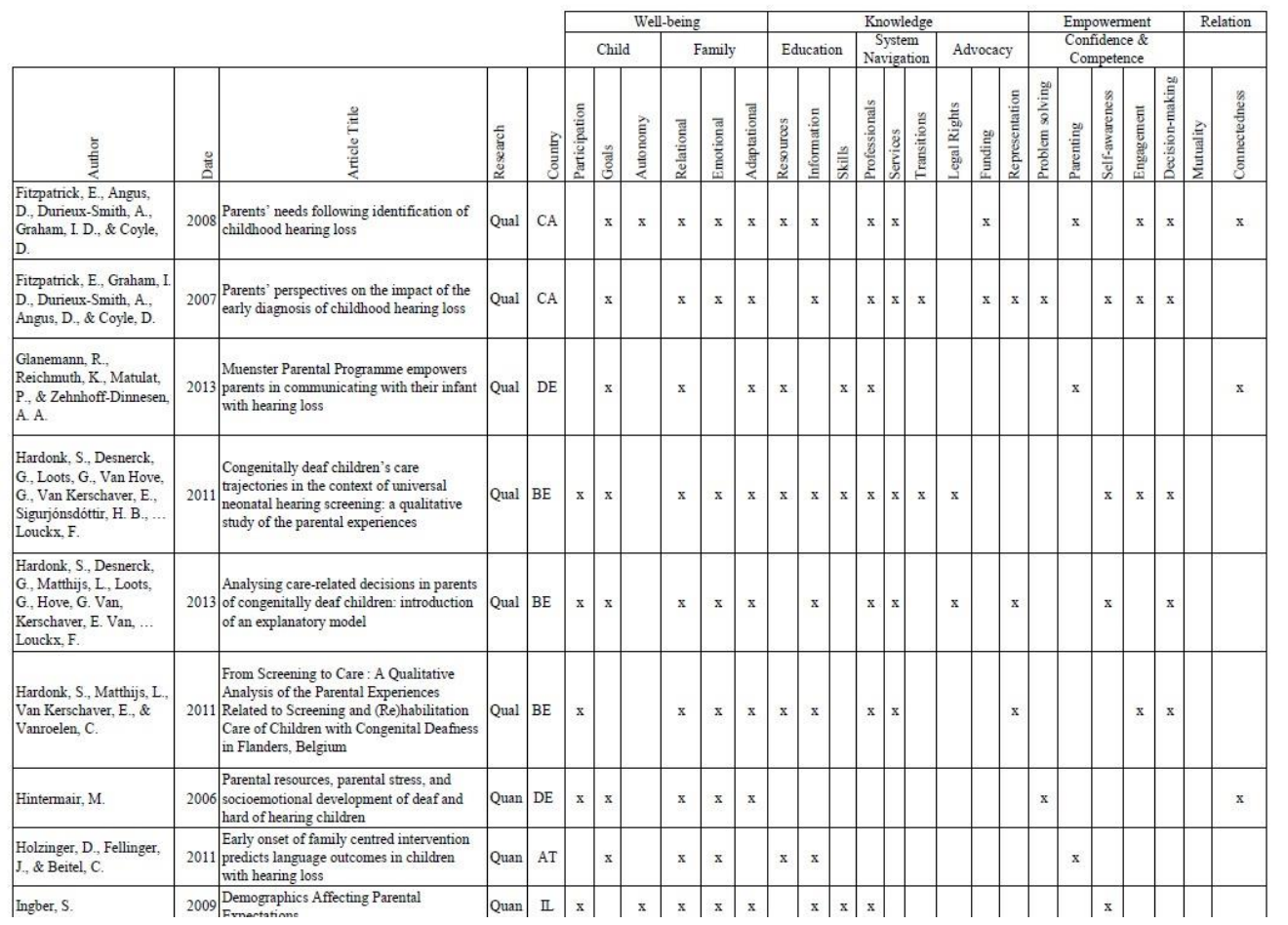

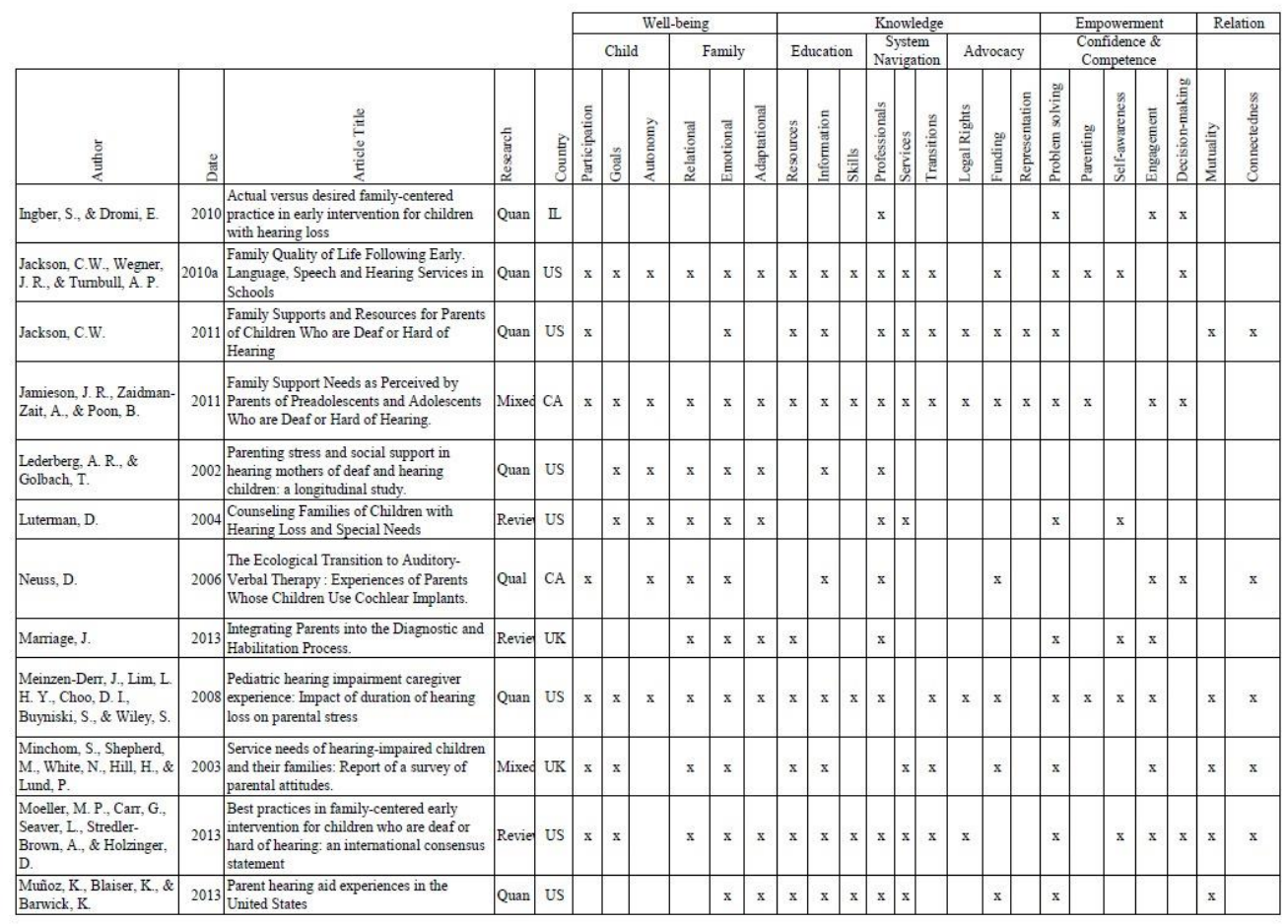



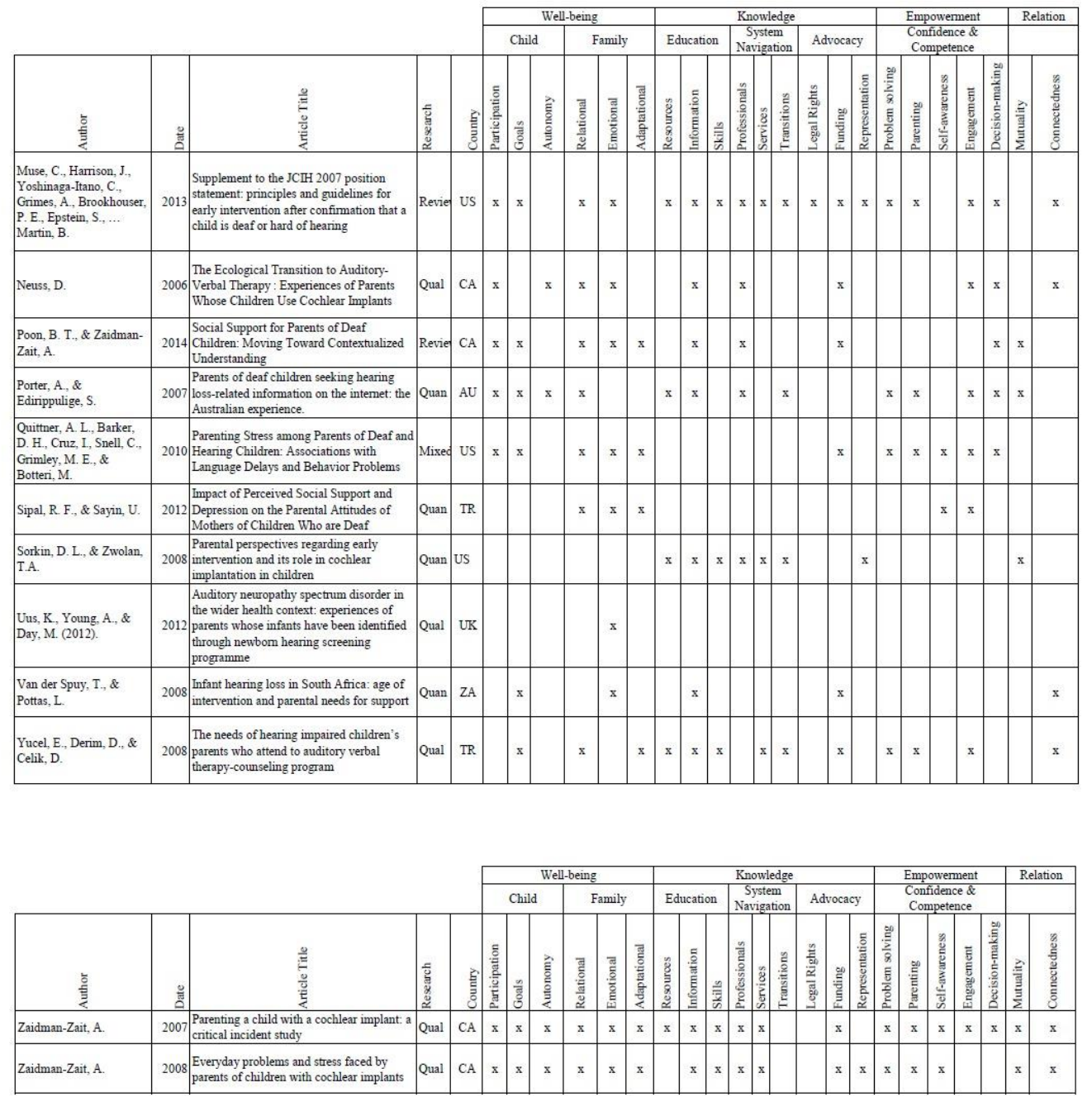


\section{Appendix C: Permission for use of Chapter 2 manuscript}

- Permissions Asha Permissions@asha.org via uwo.ı

Jul 10

to Sheila, Rebecca -

Dear Dr. Moodie:

Thank you for contacting ASHA. It is ASHA's policy that

Authors may post on their personal web sites, on department or university intranets, or in university repositories, the final, accepted manuscript along with the abstract from the final, published article when available, provided that the publication information (including the Web address of the journal site) is provided as applicable.

If Ms. Henderson would like to include the accepted manuscript in her thesis, she may do so, but we cannot grant permission for the final accepted article to be placed in open access repositories as a part of the thesis.

Best regards,

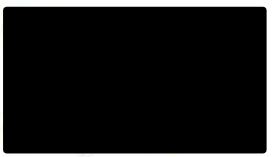

Subscription \& Permissions Manager

American Speech-Language-Hearing Association 


\section{Appendix D: Round 1 and 2 electronic Delphi study questionnaire}

\begin{tabular}{|c|c|}
\hline & $\begin{array}{l}\text { Round } 1 \text { Closed-Ended Questions } \\
\text { 11-point Likert Scale } 1 \text { (strongly disagree), } 6 \text { (neither agree nor disagree), } 11 \text { (strongly agree) }\end{array}$ \\
\hline 1 & Parent-to-parent support is the appropriate phrasing to describe this conceptual framework. \\
\hline 2 & Supporting parent(s) have the lived experience of a child with hearing loss. \\
\hline 3 & $\begin{array}{l}\text { The learning parent(s) have a child with hearing loss who are seeking support from an experienced } \\
\text { parent. }\end{array}$ \\
\hline 4 & $\begin{array}{l}\text { Mutuality is the exchange of information, ideas and resources with peer mentors and role models. } \\
\text { Mutuality is the appropriate word. }\end{array}$ \\
\hline 5 & $\begin{array}{l}\text { Connectedness refers to social identity, affirmation, a sense of belonging, social } \\
\text { kinship.Connectedness is the appropriate word. }\end{array}$ \\
\hline 6 & $\begin{array}{l}\text { Connectedness and mutuality are components to describe the relationship between the supporting } \\
\text { parent and the learning parent.Are there additional components of the parent-to-parent relationship } \\
\text { that should be included in this category? }\end{array}$ \\
\hline 7 & $\begin{array}{l}\text { For child well-being, the learning parent(s) need support related to child-autonomy, participation and } \\
\text { goals.Autonomy: decision-making, stress-related coping strategies, persistence.Autonomy is the } \\
\text { appropriate word. }\end{array}$ \\
\hline 8 & $\begin{array}{l}\text { Participation: participation in hearing and Deaf communities, leisure and extracurricular activities, } \\
\text { daycare/school, and ventures with family and friends.Participation is the appropriate word. }\end{array}$ \\
\hline 9 & $\begin{array}{l}\text { Goals: language achievement, communication outcomes, employment objectives. Goals is the } \\
\text { appropriate word. }\end{array}$ \\
\hline 10 & $\begin{array}{l}\text { Autonomy, Goals and Participation are components of child well-being.Are there additional } \\
\text { components of child well-being that should be included in this category? }\end{array}$ \\
\hline 11 & $\begin{array}{l}\text { In terms of parent and family well-being the learning parent(s) indicate that they need relational, } \\
\text { emotional and adaptational support from the supporting parent for their well-being and the well- } \\
\text { being of other family members.Relational: bonding with the child, family functioning, family and } \\
\text { marital cohesiveness, interaction and communication between family members. Relational is the } \\
\text { appropriate word. }\end{array}$ \\
\hline 12 & $\begin{array}{l}\text { Emotional: parent-to-parent support offers psychological benefit such as coping, self-reliance, } \\
\text { confidence, readiness to engage and bravery in response to grief, loneliness, vulnerability and } \\
\text { perceived stigma. Emotional is the appropriate word. }\end{array}$ \\
\hline 13 & $\begin{array}{l}\text { Adaptational: parent-to-parent support helps with adjustment, acceptance, motivation, hopefulness, } \\
\text { resilience, learning and optimism.Adaptational is the appropriate word. }\end{array}$ \\
\hline 14 & $\begin{array}{l}\text { Relational, Emotional and Adaptational are components of parent(s) and family well-being.Are there } \\
\text { additional components of parent(s) and family well-being that should be included in this category? }\end{array}$ \\
\hline
\end{tabular}


In terms of advocacy, the learning parent(s) indicate that they need to know about legal rights,

15

16

17

18

19

20

21

22

23

24

25

26

27

28

29

30 funding and representation from the supporting parent for an accurate knowledge base. Legal rights: laws, human rights, child's rights and special education laws. Legal rights are the appropriate words.

Funding: financial assistance, insurance, government funding, not-for-profit supplements. Funding is the appropriate word.

Representation: peer advocate, parental consultant, advocate at local, provincial, and federal levels. Representation is the appropriate word.

Legal rights, Funding and Representation are components of advocacy knowledgeAre there additional components of advocacy knowledge that should be included in this category?

In terms of system navigation, the learning parent(s) indicate that they need to know about professionals, services and transitions from the supporting parent.Professionals: provide a roadmap of care, coordinate efforts with specialists, facilitate understanding of the role of specialists.Professionals is the appropriate word.

Services: maneuvering through health care, school, legal and community services.Services is the appropriate word.

Transitions: entering daycare, school, becoming an adolescent, career exploration.Transitions is the appropriate word.

Professionals, Services and Transitions are important components of system navigation knowledgeAre there additional components of system navigation knowledge that should be included in this category?

In terms of resources, parent-to-parent support provides referrals to recognized affiliations, community partners and support programs. Resources is the appropriate word.

In terms of information, parent-to-parent support provides accurate, well-balanced and comprehensive information regarding technological and research advancements, communication and assistive device options. Information is the appropriate word.

In terms of skills, parent-to-parent support provides skill-based instruction, such as sign language and device-appropriate / technological skills, as a supplement to professional support.Skills is the appropriate word.

Resources, Information and Skills are important components of education knowledge.Are there additional components of education knowledge that should be included in this category?

Engagement: Parent-to-parent support helps learning parent(s) with their ability and readiness to assume their parental role and engage in their child's habilitation process. Engagement is the appropriate word.

Decision-making: Parent-to-parent support provides access to knowledge and resources, and the opportunity to cultivate ideas for informed decision-making.Decision-making is the appropriate word.

Parenting: Parent-to-parent support provides practical parenting skills (e.g. teaching their child to safely cross the street) and offers parenting advice to improve parent-child interactions.Parenting is the appropriate word.

Self-awareness Parent-to-parent support may provide a sense of self-awareness. Self-awareness is a process; parents build on areas of strength, acknowledge areas to learn and become confident to act in-line with family values. Self-awareness is the appropriate word. 


\begin{tabular}{|c|c|}
\hline 31 & $\begin{array}{l}\text { Problem-solving: Parent-to-parent support empowers parents to trust their coping abilities and } \\
\text { acquire problem-solving skills specific to a child who is deaf or hard of hearing. Problem-solving is the } \\
\text { appropriate word. }\end{array}$ \\
\hline \multirow{2}{*}{$\begin{array}{l}32 \\
33\end{array}$} & $\begin{array}{l}\text { Engagement, Decision-making, Parenting, Self-awareness, and Problem-solving are components of } \\
\text { confidence } \& \text { competence. Are there additional components of confidence \& competence that should } \\
\text { be included in this category? }\end{array}$ \\
\hline & $\begin{array}{l}\text { In the flexure of the learning parent, arrows indicate relationships exist between the defining } \\
\text { constructs, namely that knowledge and well-being promote empowerment and empowerment and } \\
\text { knowledge increase well-being. These relationships are appropriately indicated with the arrows. }\end{array}$ \\
\hline \multicolumn{2}{|r|}{$\begin{array}{l}\text { Round } 1 \text { Closed-ended Question } \\
\text { 11-point Likert Scale } 1 \text { (very uncertain), } 6 \text { (neither uncertain or certain), } 11 \text { (very certain) }\end{array}$} \\
\hline 34 & How certain are you that the conceptual framework is appropriately organized and designed? \\
\hline 35 & $\begin{array}{l}\text { How certain are you that the conceptual framework identifies the components and constructs of } \\
\text { parent-to-parent support for parents who are deaf or hard of hearing? }\end{array}$ \\
\hline 36 & $\begin{array}{l}\text { How certain are you that this conceptual framework has the ability to serve as a model for parent-to- } \\
\text { parent support for parents of children who are deaf or hard of hearing? }\end{array}$ \\
\hline 37 & $\begin{array}{l}\text { Overall, how certain are you that this conceptual framework is applicable to your work and/or your } \\
\text { colleagues work? }\end{array}$ \\
\hline 38 & $\begin{array}{l}\text { How certain are you that this conceptual framework addresses the gap in the literature calling for a } \\
\text { conceptual framework of parent-to-parent support? }\end{array}$ \\
\hline
\end{tabular}

\begin{tabular}{|c|c|}
\hline & $\begin{array}{c}\text { Round } 2 \text { Closed-Ended Questions } \\
\text { Closed answer A or B }\end{array}$ \\
\hline 1 & $\begin{array}{l}\text { The average rating of } 87 \% \text { (scale } 0-100 \text { ) indicates that the average sentiment among respondents is } \\
\text { that Supporting Parent is an appropriate descriptor to describe the parent with the lived experience } \\
\text { of raising a child who is D/HH. Alternative labels were suggested, with a number of respondents } \\
\text { suggesting Mentor Parent. Mentor Parent defined as: a teaching, supporting and encouraging parent } \\
\text { who has the lived experience of a child with hearing loss. Click on the button beside the descriptor } \\
\text { term(s) that you MOST PREFER. }\end{array}$ \\
\hline 2 & $\begin{array}{l}\text { The average rating of } 75 \% \text { (scale } 0-100 \text { ) indicates that the average sentiment among respondents is } \\
\text { that Learning Parent is a mostly appropriate descriptor to describe the parent(s) who has/have a child } \\
\text { who is } \mathrm{D} / \mathrm{HH} \text { and are seeking support from an experienced parent with a child who is } \mathrm{D} / \mathrm{HH} \text {. } \\
\text { Alternative labels were suggested, with a number of respondents suggesting Novice Parent. Novice } \\
\text { Parent defined as: a parent new to or inexperienced in a situation. For example, the parent may have } \\
\text { a child recently diagnosed as } \mathrm{D} / \mathrm{HH} \text { or may be experiencing a transition in the child or family's life. } \\
\text { Click on the button beside the descriptor term(s) that you MOST PREFER. }\end{array}$ \\
\hline
\end{tabular}


The average rating of 78 (scale $0-100$ ) indicates that the average sentiment among respondents is that Mutuality is a fairly appropriate descriptor to describe the the exchange of information, ideas and resources with peer mentors and role models. Alternative labels were suggested, so with your input: Contribution is defined as: active interaction by mentors, peers and $\mathrm{D} / \mathrm{HH}$ role models. It is the sharing of information, ideas and resources, including anecdotal and life stories. Click on the button beside the descriptor term(s) that you MOST PREFER.

The average rating of $87 \%$ (scale $0-100$ ) indicates that the average sentiment among respondents is that Connectedness is an appropriate descriptor to refer to social identity, affirmation, a sense of belonging, social kinship. Alternative labels were suggested, with a number of respondents suggesting Connection. Connection refers to social identity, affirmation, validation, comfort, a sense of belonging, social and family kinship, and inclusion in a group. Click on the button beside the descriptor term(s) that you MOST PREFER.

The term autonomy received an average rating of 79 , indicating respondents felt it more than adequately described decision-making, stress-related coping strategies and persistence. Respondents indicated self-determination was a better term and commented that the child's health and emotional well-being could be better represented by this descriptor. Self-determination is defined as autonomy, competence (self-efficacy) and relatedness. Click on the button beside the descriptor term(s) that you MOST PREFER.

The term goals received an average rating of 86 , indicating respondents felt it more than adequately described child well-being as related to language achievement, communication outcomes, and employment objectives.As alternatives to the descriptor 'goals', respondents suggested: 'aspirations', 'planning', 'goal-setting', 'positive perspectives' and 'outcomes'. Therefore based on these suggestions we are proposing outcomes as the descriptor for the conceptual framework. Outcomes: language and communication achievements, social and psychosocial aspirations and educational and employment objectives. Click on the button beside the descriptor term(s) that you MOST PREFER.

The term representation received an average rating of 83 , indicating respondents agreed that it was an appropriate descriptor. Written comments revealed a potential preference for the descriptive term 'Advocate'. With your input: Advocate or Representation peer advocate, parental consultant, representative at local, provincial, and federal levels. Click on the button beside the descriptor term(s) that you MOST PREFER.

The term professionals received an average rating of 89 , indicating respondents agreed that it was an appropriate descriptor. Written comments revealed a potential preference for the descriptive term 'Providers'. With your input: Providers: coordinate care with specialists, collaborate with stakeholders, provide a roadmap of care, and facilitate understanding of the role of the specialist(s). Click on the button beside the descriptor term(s) that you MOST PREFER.

The term skills received an average rating of 86 , indicating respondents agreed that it was an 9 appropriate descriptor. Written comments revealed a potential preference for the descriptive term 'Training'. With your input: Training: parent-to-parent support provides skill-based instruction, such as sign language and device-appropriate technological skills, as a supplement to provider/professional support. Click on the button beside the descriptor term(s) that you MOST PREFER. 
The term self-awareness received an average rating of 85 , indicating respondents agreed the descriptor 'self-awareness' was appropriate. Written comments indicated that self-awareness "is a

10 necessary condition in the process of developing and/or having competence \& confidence." It was suggested that adaptation (taken from parent $\&$ family well-being) was a more appropriate descriptor. Adaptation: parent-to-parent support helps with adjustment and acceptance. Click on the button beside the descriptor term(s) that you MOST PREFER.

\begin{tabular}{|c|c|}
\hline & Round 2 Open-ended Questions \\
\hline 1 & $\begin{array}{l}\text { Mentor Parent or Supporting Parent defined as: a teaching, supporting and encouraging parent who } \\
\text { has the lived experience of a child with hearing loss. Please provide any written additions / edits that } \\
\text { you would like to see made to the definition of this definition. }\end{array}$ \\
\hline 2 & $\begin{array}{l}\text { Novice Parent or Learning Parent defined as: a parent new to or inexperienced in a situation. For } \\
\text { example, the parent may have a child recently diagnosed as } \mathrm{D} / \mathrm{HH} \text { or may be experiencing a transition } \\
\text { in the child or family's life. Please provide any written additions / edits that you would like to see } \\
\text { made to this definition. }\end{array}$ \\
\hline 3 & $\begin{array}{l}\text { Contribution or Mutuality is defined as: active interaction by mentors, peers and D/HH role models. It } \\
\text { is the sharing of information, ideas and resources, including anecdotal and life stories. Please provide } \\
\text { any written additions / edits that you would like to see made to this definition. }\end{array}$ \\
\hline 4 & $\begin{array}{l}\text { Connection or Connectedness refers to social identity, affirmation, validation, comfort, a sense of } \\
\text { belonging, social and family kinship, and inclusion in a group. Please provide any written additions / } \\
\text { edits that you would like to see made to this definition. }\end{array}$ \\
\hline 5 & $\begin{array}{l}\text { The term participation received an average rating of } 94 \% \text {, indicating respondents agreed strongly the } \\
\text { word "participation" described involvement in hearing and Deaf communities, leisure and } \\
\text { extracurricular activities, daycare/school, and ventures with family and friends. It is agreed that } \\
\text { Participation is the appropriate descriptor. Please add comments if you wish. }\end{array}$ \\
\hline 6 & $\begin{array}{l}\text { Self-determination or Autonomy is defined as autonomy, competence (self-efficacy) and relatedness. } \\
\text { Please provide any written additions / edits that you would like to see made to this definition. }\end{array}$ \\
\hline 7 & $\begin{array}{l}\text { Outcomes or Goals: language and communication achievements, social and psychosocial aspirations } \\
\text { and educational and employment objectives. Please provide any written additions / edits that you } \\
\text { would like to see made to this definition. }\end{array}$ \\
\hline 8 & $\begin{array}{l}\text { The term relational received an average rating of } 89 \text {, indicating respondents agreed that it described } \\
\text { bonding with the child, family functioning, family and marital cohesiveness, interaction and } \\
\text { communication between family members. Some revisions have been made to the definition. } \\
\text { Therefore, with your input: Relational: family functioning and community interaction. Family } \\
\text { functioning refers to bonding with the child, family and marital/conjugal cohesiveness, } \\
\text { communication between family members. Community interaction is involvement in community and } \\
\text { cultural networks, friends and religious institutions. It is agreed that Relational is the appropriate } \\
\text { descriptor. Please provide any written additions / edits that you would like to see made to the } \\
\text { definition of Relational. }\end{array}$ \\
\hline
\end{tabular}


The term emotional received an average rating of 95 , indicating respondents agreed strongly the word "emotional" described parent-to-parent support that offers psychological benefit such as coping, acceptance, hopefulness, self-reliance and confidence, readiness to engage in response to grief, loneliness, vulnerability and perceived stigma. It is agreed that Emotional is the appropriate descriptor. Please provide any written additions / edits that you would like to see made to the definition of Emotional.

The term adaptational received an average rating of 83 , indicating respondents agreed that it was an appropriate word to describe parent-to-parent support that helped with adjustment, acceptance, motivation, hopefulness, resilience, learning and optimism. Respondents indicated that adaptation is a component of competence \& confidence and not well-being. We have moved the qualities of adaptation, such as acceptance and adjustment to the framework components of Competence and Confidence. Including adaptational within the components of Competence and Confidence is appropriate

The term legal rights received an average rating of 91 , indicating respondents strongly agreed that it was an appropriate descriptor. Some respondents preferred the descriptors 'regulation(s)' or 'legislation' over 'legal rights'. Although 'regulatory rights' may be more accurate, we believe that parents may better understand the descriptor 'legal rights'. Legal Rights: laws, regulations and legislation related to human rights, child's rights, and special education laws. Given the high consensus on this term, we have decided to keep the descriptor 'legal rights'.It is agreed that Legal Rights is the appropriate descriptor. Please provide any written additions / edits that you would like to see made to the definition of Legal Rights.

Financial Resources or Funding: financial assistance, insurance, government funding, not-for-profit supplements. Please provide any written additions / edits that you would like to see made to this definition.

Advocate or Representation: peer advocate, parental consultant, representative at local, provincial, and federal levels. Please provide any written additions / edits that you would like to see made to this definition.

Providers or Professionals: coordinate care with specialists, collaborate with stakeholders, provide a roadmap of care, and facilitate understanding of the role of the specialist(s). Please provide any written additions / edits that you would like to see made to this definition.

The term transitions received an average rating of 95, indicating respondents agreed strongly the word services was an appropriate descriptive term. Respondents noted that Transitions was a very important component for the parent-to-parent framework and belonged as a main topic heading along with System Navigation. It is agreed that Transitions is a very important component to the framework and belongs with the heading System Navigation. Revising the label to read System Navigation and Transitions is appropriate

The term services received an average rating of 94, indicating respondents agreed strongly the word services was an appropriate descriptive term. Services: maneuvering through health care, school, legal and community services. It is agreed that Services is the appropriate descriptor. Please provide any written additions / edits that you would like to see made to the definition of Services. 
The term information received an average rating of 91 , indicating respondents strongly agreed the word information was an appropriate descriptive term. Respondents noted that insight, context and experience are just as important as information. We agree that life experience is invaluable and believe that this is included in Contribution and Connection Information: parent-to-parent support provides accurate, well-balanced and comprehensive information regarding technological and research advancements, communication and assistive device options. It is agreed that Information is the appropriate descriptor. Please provide any written additions / edits that you would like to see made to the definition of Information.

The term resources received an average rating of 89 , indicating respondents agreed the word resources was an appropriate descriptive term. To provide clarification and to differentiate it from other resources included in the framework (such as financial resources), we have changed the descriptor to Community Resources. Community Resources: provides referrals to recognized affiliations, community partners and support programs. It is agreed that Community Resources is the appropriate descriptor. Please provide any written additions / edits that you would like to see made to the definition of Community Resources.

Training or Skills: parent-to-parent support provides skill-based instruction, such as sign language and device-appropriate technological skills, as a supplement to provider/professional support. Please provide any written additions / edits that you would like to see made to this definition.

The term engagement received an average rating of 95, indicating respondents agreed strongly the word engagement was an appropriate descriptive term. Engagement: parent-to-parent support helps learning parent(s) with their ability and readiness to assume their parental role and engage in their child's habilitation process. It is agreed that engagement is the appropriate descriptor. Please provide any written additions / edits that you would like to see made to the definition of Engagement.

The term decision-making received an average rating of 92 , indicating respondents agreed strongly the descriptor 'decision-making' was appropriate. Decision-making: parent-to-parent support provides access to knowledge and resources, and the opportunity to cultivate ideas for informed decision-making. It is agreed that decision-making is the appropriate descriptor. Please provide any written additions / edits that you would like to see made to the definition of decision-making.

The term parenting received an average rating of 91, indicating respondents agreed strongly the descriptor 'parenting' was appropriate. Based on your feedback, the definition associated with the descriptor 'parenting' has been revised. Parenting: parent-to-parent support provides practical parenting skills (e.g. teaching their child to safely cross the street), offers parenting advice to improve parent-child interactions and encourages responsive parenting to support the child's communication development in daily life. It is agreed that parenting is the appropriate descriptor. Please provide any written additions / edits that you would like to see made to the definition of parenting.

The term problem-solving received an average rating of 94 , indicating respondents agreed strongly the descriptor 'problem-solving' was appropriate. Problem-solving: parent-to-parent support empowers parents to trust their coping abilities and acquire problem-solving skills specific to a child who is deaf or hard of hearing. It is agreed that problem-solving is the appropriate descriptor. Please provide any written additions / edits that you would like to see made to the definition of problemsolving. 
24

25

26

27

28

Adaptation or Self-awareness: parent-to-parent support helps with adjustment and acceptance. Please provide any written additions / edits that you would like to see made to this definition.

Considering the revisions made to the framework: How certain are you now that the REVISED conceptual framework identifies the components and constructs of parent-to-parent support for parents with children who are Deaf or Hard of Hearing?

Considering the revisions made to the framework: How certain are you that this REVISED conceptual framework has the ability to serve as a model for parent-to-parent support for parents of children who are deaf or hard of hearing?

27 Considering the revisions made to the framework: Overall, how certain are you that this REVISED conceptual framework is applicable to your work and/or your colleagues work?

We welcome additional comments related to version 2 of the framework below. 


\title{
Curriculum Vitae
}

\author{
Name: Rebecca Henderson \\ Post-secondary Laurentian University \\ Education and Sudbury, Ontario, Canada \\ Degrees: 1998-2003 \\ Seneca College, \\ Toronto, ON \\ 2003-2004 \\ The University of Western Ontario \\ London, Ontario, Canada \\ 2013-2015 M.Sc.
}

Honours and Province of Ontario Graduate Scholarship

Awards: 2013-2015

$\begin{array}{ll}\text { Related Work } & \text { Teaching Assistant } \\ \text { Experience } & \text { The University of Western Ontario } \\ & 2013-2015\end{array}$

\section{Publications:}

Henderson, R. J., Johnson, A., \& Moodie, S. T. (2014). Parent-to-Parent Support for Parents With Children Who Are Deaf or Hard of Hearing: A Conceptual Framework. American Journal of Audiology, 23(4), 437-48.

doi:10.1044/2014_AJA-14-0029

Vergunst, R. (2006). Reforms in the Central Intelligence Agency, Academic Credit. 895 Days that Changed the World (pp. 138-151). Mount, G.. Montreal: Black Books, 2006. *This chapter is an edited version of the undergraduate Honours Essay (thesis) of Rebecca Vergunst accepted by Laurentian University’s History Department in 2003. 